Author manuscript

Environ Sci Technol. Author manuscript; available in PMC 2020 July 29.

About author manuscripts

Submit a manuscript

Published in final edited form as:

Environ Sci Technol. 2019 July 02; 53(13): 7265-7287. doi:10.1021/acs.est.9b01453.

\title{
Next-Generation Multifunctional Carbon-Metal Nanohybrids for Energy and Environmental Applications
}

\author{
Dengjun Wang ${ }^{\mathrm{a}}$, Navid B. Saleh ${ }^{\mathrm{b}}$, Wenjie Sun ${ }^{\mathrm{c}}$, Chang Min Park ${ }^{\mathrm{d}}$, Chongyang Shen ${ }^{\mathrm{e}}$, \\ Nirupam Aich ${ }^{f}$, Willie J. G. M. Peijnenburg ${ }^{g}$, Wei Zhang ${ }^{h}$, Yan Jin', Chunming Suj
}

aNational Research Council Resident Research Associate at the United States Environmental Protection Agency, Ada, Oklahoma 74820, United States ${ }^{\text {b}}$ Department of Civil, Architectural and Environmental Engineering, University of Texas at Austin, Austin, Texas 78712, United States 'Department of Civil and Environmental Engineering, Southern Methodist University, Dallas, Texas 75275, United States dDepartment of Environmental Engineering, Kyungpook National University, Buk-gu, Daegu 41566, South Korea eDepartment of Soil and Water Sciences, China Agricultural University, Beijing 100193, China 'Department of Civil, Structural and Environmental Engineering, University at Buffalo, The State University of New York, Buffalo, New York 14260, United States IInstitute of Environmental Sciences (CML), Leiden University, P.O. Box 9518, 2300 RA Leiden, The Netherlands. Center for Safety of Substances and Products, National Institute for Public Health and the Environment, P.O. Box 1, 3720 BA Bilthoven, The Netherlands hepartment of Plant, Soil and Microbial Sciences, and Environmental Science and Policy Program, Michigan State University, East Lansing, Michigan 48824, United States 'Department of Plant and Soil Sciences, University of Delaware, Newark, Delaware 19716, United States jGroundwater, Watershed, and Ecosystem Restoration Division, National Risk Management Research Laboratory, Office of Research and Development, United States Environmental Protection Agency, Ada, Oklahoma 74820, United States

\section{Abstract}

\begin{abstract}
Nanotechnology has unprecedentedly revolutionized human societies over the past decades and will continue to advance our broad societal goals in the coming decades. The research, development, and particularly the application of engineered nanomaterials have shifted the focus from "less efficient" single-component nanomaterials toward "superior-performance", nextgeneration multifunctional nanohybrids. Carbon nanomaterials (e.g., carbon nanotubes, graphene family nanomaterials, carbon dots, and graphitic carbon nitride) and metal/metal oxide nanoparticles (e.g., $\mathrm{Ag}, \mathrm{Au}, \mathrm{CdS}, \mathrm{Cu} 2 \mathrm{O}, \mathrm{MoS} 2, \mathrm{TiO} 2$, and $\mathrm{ZnO}$ ) combinations are the most commonly pursued nanohybrids (carbon-metal nanohybrids; CMNHs), which exhibit appealing properties and promising multifunctionalities for addressing multiple complex challenges faced by humanity at the critical energy-water-environment (EWE) nexus. In this frontier review, we first highlight the altered and newly emerging properties (e.g., electronic and optical attributes, particle size, shape, morphology, crystallinity, dimensionality, carbon/metal ratio, and hybridization mode) of CMNHs that are distinct from those of their parent component materials. We then illustrate how these important newly emerging properties and functions of CMNHs direct their performances at the EWE nexus including energy harvesting (e.g., $\mathrm{H} 2 \mathrm{O}$ splitting and $\mathrm{CO} 2$ conversion), water treatment (e.g., contaminant removal and membrane technology), and environmental sensing and
\end{abstract}


in situ nanoremediation. This review concludes with identifications of critical knowledge gaps and future research directions for maximizing the benefits of next-generation multifunctional CMNHs at the EWE nexus and beyond.

\section{Graphical Abstract}

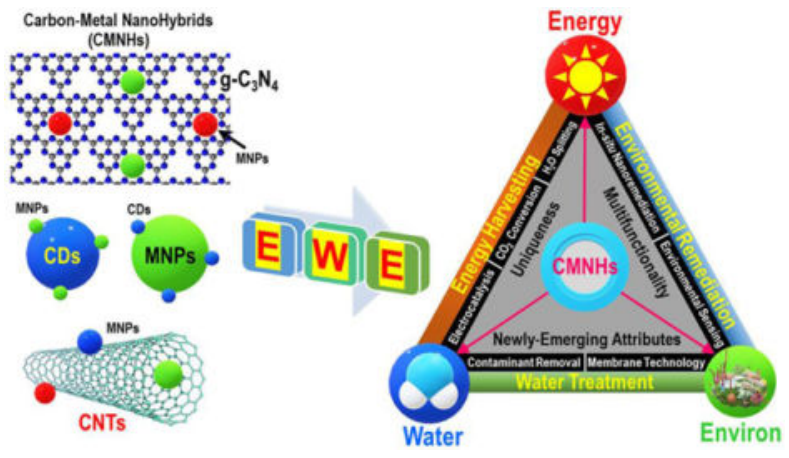

\section{Introduction}

To meet growing energy demand, mitigate water scarcity, and address global environmental pollution at the important energy-water-environment (EWE) nexus, $(1,2)$ there is an everincreasing need to engineer next-generation "superfunctional materials" that possess enhanced and/or fundamentally new properties and exhibit multifunctionalities.(3,4) For example, the inherent optical and electronic properties of conventional single-component materials (e.g., $\mathrm{TiO}_{2}$ ) may be insufficient to achieve or sustain adequate catalytic efficiency for energy harvesting (e.g., photocatalytic $\mathrm{H}_{2} \mathrm{O}$ splitting for $\mathrm{H}_{2}$ and $\mathrm{O}_{2}$ evolution) and contaminant (e.g., recalcitrant perfluorochemicals) removal due to very limited use of solar energy and rapid recombination of photogenerated electron-hole pairs during catalytic processes.(5) Hence, there is a strong need to retain or enhance the catalytic capability, and in the meantime invoke new (e.g., sunlight harvesting, contaminant adsorption and redox, biocidal, and antifouling) properties through assemblage of guest material(s) to parent matrices, fabricating multicomponent nanohybrids.(5,6) To deliver such advantages sustainably, the multifunctional nanohybrids need to maintain environmentally benign attributes.(7)

Carbon-based nanomaterials (CNMs) have always been in the frontier of materials science including carbon nanotubes (CNTs), (8) graphene family nanomaterials (GFNs: graphene, graphene oxide; GO, and reduced graphene oxide; RGO),(9) and most-recently, emerging materials namely carbon dots (CDs)(10) and graphitic carbon nitride $\left(g-\mathrm{C}_{3} \mathrm{~N}_{4}\right)$. (5) CNMs are chemically stable and structurally diverse with prominent light-absorptive and electron transport properties, and have appealing catalytic, redox, fluorescence, and luminescence attributes. Despite these advantages, CNMs are not as efficient in delivering some of the key functions as compared to those delivered by metal/metal oxide nanoparticles (MNPs like $\mathrm{TiO}_{2}$ and $\mathrm{ZnO}$ semiconductors) such as wide bandgap, ability to maintain high electron-hole pairs separation and transfer efficiency, exceptional heat transfer and electron transport properties, and capability to donate metal ions (e.g., $\mathrm{Ag}^{+}$) for biocidal applications.(11,12) 
Hence, rationally designing nanohybrids with at least two dissimilar NMs (such as CNMs and MNPs) with diverse properties and complementary functionalities holds a great promise for addressing issues and challenges faced by humanity at the EWE nexus.(2-6,13)

Multiple benefits for EWE applications can be harnessed through hierarchical assemblage of CNMs and MNPs. First, during synthesis of carbon-metal nanohybrids (CMNHs), CNMs can be used to precisely engineer the properties (e.g., size, shape, morphology, crystallinity, and dimensionality) of MNPs that are relevant to the light-absorptive and contaminantadsorptive/(photo)catalytic functions by controlling particle nucleation and growth.(14-18) Particularly, CNMs (1D CNTs and 2D g- $\mathrm{C}_{3} \mathrm{~N}_{4}$ or GFNs nanosheets) can distribute and effectively stabilize the anchored MNPs, and thus can result in reduced aggregation, photocorrosion, leaching, and/or surface passivation of the composite material (Figure 1a,b). These advantages are attributed to the uniqueness of CNMs featuring thermal and chemical stability, large specific surface area (SSA), abundant surface-active sites and defects, and rich oxygen-containing functional groups.(19-22) The hybridized MNPs, in turn, also facilitate achieving a high degree of dispersion for the CNMs (2D layered $\mathrm{g}-\mathrm{C}_{3} \mathrm{~N}_{4}$ and GFNs) through enhanced physical segregation, constructing few-layered CNMs with large SSA and abundant surface-reactive sites.(23) Furthermore, CNMs can preconcentrate contaminants $(24,25)$ or lower contaminant reaction potentials,(26) and thus facilitate the subsequent catalytic/redox reactions at the hybridized carbon-metal interfaces (CMIs; Figure 1a). Also, the range of light and electromagnetic absorption of MNPs can be extended due to the inherent ultraviolet-visible-near-infrared (UV-vis-NIR) light responses of CNMs ( $\mathrm{g}-\mathrm{C}_{3} \mathrm{~N}_{4}$ and $\mathrm{CDs}$ ).(5,27-30) Most strikingly, the charge, electron, heat, and mass transfer and separation within the precisely assembled nanoheterostructures are optimized due to enlarged interfacial contact areas, intimate interfacial interactions, altered electronic properties (bandgap), formation of new local charge centers, and creation of internal electric fields (Figure 1a; detailed mechanisms are illustrated in Section 2.1 below), all of which can enhance the catalytic/redox performances of CMNHs toward more efficient energy harvesting, water treatment, and environmental sensing and remediation (Figure 1c).(5,6) For certain CNMs ( $\left(\mathrm{g}_{-} \mathrm{C}_{3} \mathrm{~N}_{4}\right.$ and $\left.\mathrm{CDs}\right)$ and MNPs $\left(\mathrm{ZnO}(31)\right.$ and $\left.\mathrm{Ag}_{2} \mathrm{SO}_{4}(32)\right)$, their redox potentials are magnified after hybridization, further facilitating the degradation of recalcitrant contaminants (e.g., perfluorochemicals). Additionally, some MNPs (e.g., Ag, $\mathrm{Au}, \mathrm{Bi}$, and $\mathrm{Cu}$ ) demonstrate localized surface plasmon resonance (LSPR), which can be improved when hybridized with CNMs ( $\left(\mathrm{g}_{3} \mathrm{~N}_{4}\right.$ and $\mathrm{CDs}$ ), and such attributes may further facilitate simultaneous and rapid catalytic degradation of multiple contaminants. $(5,6)$

This frontier review presents a comprehensive summary of research efforts on CMNHs (particularly for the most appealing $\mathrm{g}_{-} \mathrm{C}_{3} \mathrm{~N}_{4}$ - and CDs-based CMNHs) that can be positioned for addressing multiple challenges at the EWE nexus. The altered and newly emerging attributes of CMNHs introduced through material hybridization are highlighted first. It is followed by a detailed discussion on opportunities for applications relevant to energy, water, and the environment. Example applications include $\mathrm{H}_{2} \mathrm{O}$ splitting and $\mathrm{CO}_{2}$ conversion, contaminant removal and membrane technology, and environmental sensing and in situ nanoremediation. Critical knowledge gaps and challenges in these fields are also systematically elucidated to identify future research strategies for this exceptional class of nanohybrids at the EWE nexus and beyond. 


\section{Altered and Newly-Emerging Attributes of CMNHs}

\subsection{Electronic, Optical, Band, and Interfacial Charge Transfer Properties}

Hybridizing CNMs and MNPs tailors the electronic and optical properties of CMNHs including electronic energy levels (bandgap structure), charge-carrier density and lifetime, UV-vis-NIR-light absorption, and nonradiative paths, $(33,34)$ all of which are strongly related to the intimately contacted carbon-metal interfaces (CMIs; Figure 1a). $(5,6,17)$ Taking g- $\mathrm{C}_{3} \mathrm{~N}_{4}$ as an example: assembling g- $\mathrm{C}_{3} \mathrm{~N}_{4}$ and MNPs with well-matched band and electronic structures(35) produces new electronic structures; that is, band bending is generated at the CMIs and creates a new built-in electric field within a charge region for accelerated spatial separation and migration of photogenerated electron-hole pairs (Figure 1a).(5) Through first-principles calculations with charge density difference and Mulliken population identifications, Ma et al.(36) demonstrated the formation of new built-in electric field at the type-II band alignment $\mathrm{g}_{-} \mathrm{C}_{3} \mathrm{~N}_{4}-\mathrm{BiPO}_{4}$ interface. This new built-in electric field also frequently appears in other $\mathrm{g}-\mathrm{C}_{3} \mathrm{~N}_{4}$ nanohybrids decorated with noble metals $(\mathrm{Ag}, \mathrm{Au}$, $\mathrm{Bi}, \mathrm{Pd}$, and $\mathrm{Pt}$ ), transition metals $(\mathrm{Ce}, \mathrm{Cu}, \mathrm{Fe}$, and $\mathrm{Ni}$ ), and transition metal compounds (metal hydroxides and sulfides), $(5,6,37,38)$ as validated with density functional theory (DFT) and total density of states calculations.(39) Also, the light absorption efficiency at the UV-vis-NIR range is enhanced particularly for $\mathrm{g}_{-} \mathrm{C}_{3} \mathrm{~N}_{4}$ - and CDs-CMNHs that include $\mathrm{Ag}$, $\mathrm{Au}, \mathrm{Cu}$, and $\mathrm{Bi}$ in their nanoheterostructures, because these MNPs act as electron reservoirs and plasmonic cocatalysts mediated by LSPR. $(5,40)$ As evidenced by finite integration simulation technique,(37) the local electromagnetic field (Figure 1a) produced by LSPR is another newly emerging attribute of CMNHs. More importantly, the new built-in electric field and the local electromagnetic field are closely intertwined, since the former modifies the latter by tuning the spin-polarized band structure and the Fermi level of CMNHss.(41) Furthermore, when the LSPR absorption of MNPs is partially overlapped with the optical absorption of CNMs $\left(\mathrm{g}-\mathrm{C}_{3} \mathrm{~N}_{4}\right)$, the LSPR triggers plasmon resonance energy transfer (PRET; Figure 2) and excites charge-carriers at the CMIs (Figure 1a).(42,43) Both LSRP and PRET effects play positive roles in boosting electron and charge separation, decreasing charge-carriers density, and prolonging lifetime of charge separation for enhanced catalytic performance.(5) Finally, two or more of the new built-in electric field domains and chargecarriers are created for ternary g- $\mathrm{C}_{3} \mathrm{~N}_{4}$-bimetallic systems (e.g., g- $\mathrm{C}_{3} \mathrm{~N}_{4}-\mathrm{Ag}-\mathrm{Ag}_{3} \mathrm{PO}_{4}$; Figure 3); and as such, the catalytic efficiency, stability, selectivity, and durability of the ternary systems are maximized.(5) The above alterations also frequently emerge for CDs-, GFNs-, and CNTs-CMNHs.

CDs exhibit strong UV-vis-NIR-light absorption due to $\pi \rightarrow \pi^{*}$ transition of $\mathrm{C}=\mathrm{C}$ bonds and $n \rightarrow \pi^{*}$ transition of $\mathrm{C}=\mathrm{O}$ bonds. $(28,44)$ One of the intriguing features of $\mathrm{CDs}$, that is, photoluminescence can be efficiently quenched either by electron acceptor or donor, evidencing that CDs are both UV-vis-NIR-light- and redox-responsive photocatalysts. $(28,44)$ Integrating CDs with MNPs creates unique up- and down-converted photoluminescence properties, rendering CDs-CMNHs exciting photocatalysts. Especially, the up-converting photoluminescence attribute of CDs, that is, the ability to emit shorter wavelength (higher intensity) of lights (300-530 nm) compared to the excitation wavelengths (700-1000 nm), can be utilized to excite lower energy photons (sunlight) into a 
higher energy level. Hence, the UV-vis-NIR-light absorption range of CD-metal nanohybrids is broadened in photocatalytic applications.(45-48) Additionally, for CDs and g- $\mathrm{C}_{3} \mathrm{~N}_{4}$ that process energy transfer properties, overlapping between the emission spectra of $\mathrm{CDs} / \mathrm{g}-\mathrm{C}_{3} \mathrm{~N}_{4}$ and the absorption spectra of MNPs causes excitation of plasmon resonance and creates strong local electric fields around MNPs. The newly created local electric fields perturb the inherent exciton states of $\mathrm{CDs} / \mathrm{g}-\mathrm{C}_{3} \mathrm{~N}_{4}$, and thus induce fluorescence resonance energy transfer (Figures 1a and 2).(49-51) The fluorescence resonance energy transfer and other energy transfer-related (luminescence and photoelectrochemical) attributes make CMNHs promising sensors for environmental sensing.

While the CMIs can prolong the charge-carriers lifetime and thus enhance catalytic performance of CMNHs (Figure 1a), there is a maximum number of charges (saturation point) that the CMIs can store until the band bending terminates the current flow.(20) This indicates the presence of an optimized metal loading capacity (MLC), below and above which the catalytic performance of CMNHs can deteriorate. MNPs displaying a higher work function provide an enlarged Schottky barrier and elevate the charge separation efficiency; both of which are ultimately reflected by the enhanced catalytic performance of CMNHs. $(20,52)$

\subsection{Particle Size, Shape, Morphology, Crystallinity, and Dimensionality}

During in situ synthesis of CMNHs, the size of MNPs is often tuned because CNMs control the nucleation and growth of MNPs.(14-17) Due to high thermal conductivity, CNMs can stabilize small MNPs by suppressing their growth during crystallization and phase transformation via heat sink effect.(53) The heat sink effect enables formation of small ( $\sim 5$ $\mathrm{nm}$ ) CdS quantum dots onto g- $\mathrm{C}_{3} \mathrm{~N}_{4}$ nanosheets; whereas, CdS can grow into $\sim 100 \mathrm{~nm}$ particles without g- $\mathrm{C}_{3} \mathrm{~N}_{4}$. (54) Roughly 10.5, 7.4, and $7.1 \mathrm{~nm} \mathrm{TiO}_{2} \mathrm{NPs}$ are formed when 0 , 1 , and $2 \mathrm{wt} \%$, respectively, of $\mathrm{GO}$ nanosheets are added during $\mathrm{GO}-\mathrm{TiO}_{2}$ synthesis, validating the inhibiting effect of CNMs in MNP growth.(55) Varying carbon/metal ratio also produces nanohybrids with different sizes; for example, upon addition of $10 \% \mathrm{Ag}$, the particle size of CDs- $\mathrm{Au}_{1.0}$ decreases from $\sim 30.0$ to $\sim 4.1 \mathrm{~nm}\left(\mathrm{CDs}-\mathrm{Au}_{0.9} \mathrm{Ag}_{0.1}\right)$.(56)

MNPs' shape and morphology are also tailored due to the strong influence of CNMs.(1417) $\mathrm{g}-\mathrm{C}_{3} \mathrm{~N}_{4}$ nanosheets can anchor differently shaped $\mathrm{TiO}_{2}$ (0D NPs, $1 \mathrm{D}$ nanowires, $2 \mathrm{D}$ nanosheets, and 3D mesoporous nanocrystals)(57) and $\mathrm{CeO}_{2}$ (rods, cubes, and octahedrons). (38) CDs drive the morphology change of $\mathrm{Cu}_{2} \mathrm{O}$, evolving from cubes to spheres through modulation of the Ostwald ripening step during nucleation and surface reconstruction processes.(58) MNPs' crystallinity can also be tuned; for example, $\mathrm{KBr} / \mathrm{KI}$ and $\mathrm{HCHO} /$ $\mathrm{Na}_{2} \mathrm{C}_{2} \mathrm{O}_{4}$ are common crystal phase-controlling agents for stabilizing (100) and (111) facets of Pd NPs.(59) High-resolution transmission electron microscope (HRTEM) images show that the Pd nanocrystals display cubic and tetrahedral profiles enclosed by (100) and (111) facets onto g- $\mathrm{C}_{3} \mathrm{~N}_{4}$ nanosheets.(59) The higher energy (001) facet of anatase $\mathrm{TiO}_{2} \mathrm{NPs}$ can also be decorated onto g- $\mathrm{C}_{3} \mathrm{~N}_{4}$ nanosheets using a solvent evaporation process to boost photocatalytic performance.(60) The (110), (100), and (111) facets of $\mathrm{CeO}_{2} \mathrm{NPs}$ are anchored onto g- $\mathrm{C}_{3} \mathrm{~N}_{4}$ nanosheets based upon HRTEM observations. And the g- $\mathrm{C}_{3} \mathrm{~N}_{4}-\mathrm{CeO}_{2}$ 
(110) nanohybrids exhibit the highest photocatalytic activity as demonstrated by $\mathrm{H}_{2} \mathrm{O}$ splitting.(38)

Acting as supporting templates (Figure 1b), the larger-sized g- $\mathrm{C}_{3} \mathrm{~N}_{4}$, GFNs, and CNTs can control nucleation and growth of smaller MNPs (Supporting Information (SI) Figure S1a$\mathrm{d}, \mathrm{g}, \mathrm{h})$. Small CDs $(1-10 \mathrm{~nm})$ can also act as templates, but in most cases, are attached onto MNPs surfaces, constructing a "dot-on-particle" (CDs-on-MNPs) heterodimer structure (SI Figure S1e,f).(61) Using physical mixing and hydro/solvothermal techniques (SI Tables S5S7), small CDs are intimately deposited onto $\mathrm{Cu}_{2} \mathrm{O}$ with lattice spacings of 0.32 and 0.25 $\mathrm{nm}$ for CDs (002) and $\mathrm{Cu}_{2} \mathrm{O}$ (111) planes (SI Figure S1f).(62) The surface-coarsened $\mathrm{TiO}_{2}$ nanobelts have large SSA and abundant nucleation sites for CDs growth (SI Figure S1e).(63) Using a solvothermal method, a lattice-spacing of $0.211 \mathrm{~nm}$ CDs is also achieved and the CDs are decorated onto $\mathrm{Na}_{2} \mathrm{~W}_{4} \mathrm{O}_{13}$ flakes.(64) Conversely, under a chemical reduction approach, MNPs prefer to grow onto CDs surfaces, forming a core-shell (CDs-MNPs) structure because CDs' oxygen-containing groups facilitate the formation of MNPs via chemical reduction pathways.(65) A shell of $\mathrm{Pd}(66)$ and $\mathrm{Ag}(65)$ NPs are formed onto CDs surfaces, as confirmed by HRTEM and selected-area electron diffraction analyses.

Dimensionality is a fundamental parameter that defines the atomic structure of material, and thus determines material properties and functions.(67) Assembling CNMs and MNPs creates equivalent or higher dimensional nanohybrids.(68) $\mathrm{TiO}_{2}$ nanobelts retain their original 1D nature after surface-loading of small CDs (SI Figure S1e). This holds true for $2 \mathrm{D} \mathrm{g}-\mathrm{C}_{3} \mathrm{~N}_{4} /$ GFNs and 1D CNTs when surface-loaded with spherical MNPs (SI Figure S1a-d,g,h); because the nanoheterojunctions mask the 0D nature of MNPs.(68) However, the dimensionality is increased when vertically stacking $2 \mathrm{D} \mathrm{g}-\mathrm{C}_{3} \mathrm{~N}_{4}$ or GFNs with $2 \mathrm{D}$ MNPs like $\mathrm{WS}_{2}$ and $\mathrm{MoS}_{2}$, constructing new 3D graphene- $\mathrm{WS}_{2}(69)$ and graphene- $\mathrm{MoS}_{2} \cdot(70,71)$ Coupling 1D CNTs and 2D GFNs with MNPs $\left(\mathrm{Co}, \mathrm{Fe}_{3} \mathrm{O}_{4}\right.$, and $\left.\mathrm{FeCo}\right)$ also yields 3D CNTsGFNs-metal nanohybrids (SI Table S1). Increased dimensionality of CMNHs makes them more accessible to contaminants and can guide their applications at the EWE nexus and beyond.(72)

\subsection{Carbon/Metal Ratio and Hybridization Mode}

Carbon/metal ratio or metal loading capacity (MLC) is another key attribute (SI Figure $\mathrm{S} 1 \mathrm{~g}, \mathrm{~h})$ of CMNHs, because MLC determines particle dispersion state in aqueous solutions, sunlight utilization, and catalytic performance. The absorption edge of $\mathrm{g}-\mathrm{C}_{3} \mathrm{~N}_{4}-\mathrm{CdS}$ nanohybrids can be tailored by varying the mass ratio of $\mathrm{g}-\mathrm{C}_{3} \mathrm{~N}_{4} / \mathrm{CdS}$, yielding a shift in the optical absorption toward higher wavelengths in the visible-light region.(73) The optimum activity of $\mathrm{g}_{-} \mathrm{C}_{3} \mathrm{~N}_{4}-\mathrm{CdS}$ (7:3) is $\sim 21$ - and $\sim 42$-times higher than that of bare $\mathrm{g}-\mathrm{C}_{3} \mathrm{~N}_{4}$, as shown via degradation of methyl blue and 4-aminobenzonic acid, respectively.(73) The photocurrent density of $\mathrm{CDs}-\mathrm{TiO}_{2}$ nanohybrids is enhanced and reaches a maximum with increasing content of CDs $(0-0.4 \mathrm{mg} / \mathrm{mL})$, but a further increase in CDs content decreases the photocurrent due to CDs aggregation (which compromises electron and charge transfer). (74) The optimal MLC also exists for CNTs- and GFNs-CMNHs $\left(\mathrm{CNT}-\mathrm{TiO}_{2},(75) \mathrm{GO}-\right.$ $\mathrm{Ag}-\mathrm{Ti},(76)$ and RGO-MoS $2-\mathrm{ZnS}(77)$ ). Besides MLC, the distribution of MNPs onto CNMs can be tuned by controlling synthesis conditions; that is, by controlling electrochemical 
deposition potential and time, or by varying the amount of nucleation in the dispersion of metal precursors $\left(\mathrm{g}-\mathrm{C}_{3} \mathrm{~N}_{4}-\mathrm{TiO}_{2}\right) \cdot(57)$

Depending upon the hybridization mode, ex-situ and in situ strategies can be used to hybridize CNMs and MNPs.(78) The ex-situ approach utilizes covalent, noncovalent, $\pi-\pi$ stacking, and electrostatic interactions to combine parent NMs via interlinkers.(78) $\mathrm{The}^{\mathrm{SiO}_{2}}$ interlinker is used to covalently bind silane-functionalized CDs and AuNPs, forming a coreshell unit.(79) For comparison, the in situ approach involves direct nucleation, growth, and deposition of MNPs onto CNMs using electrochemical, sol-gel process, hydrothermal/ solvothermal, and gas-phase deposition techniques (SI Tables S5-S10).(78) The advantages of the in situ approach mainly include (1) CNMs can stabilize uncommon or novel crystal phases of MNPs; and (2) continuous amorphous or single-crystalline films with controlled thickness or discrete units of NPs, nanorods, nanobelts, and nanobeads can be fabricated with the presence of CNMs.(78) Compared to the ex-situ methods, the in situ method produces well-contacted CMIs, which is the key in catalytic and redox reactions of CMNHs (see Section 3 below).(5,6)

\section{Energy, Water, and Environmental Applications of CMNHs}

While some reviews exist for CMNHs since 2015 including those for CNTs-,(80-82) GFNs-, $(80,82-84)$ CDs-, $(28,45,46)$ and g- $_{3} \mathrm{~N}_{4}$-based CMNHs, $(5,6,52,85,86)$ the altered and newly emerging attributes of CMNHs have not been highlighted, particularly with respect to how these can be harnessed for EWE applications (Figure 1). In this section, unique properties of the hierarchical nanoheterojunctions are identified for their use in energy harvesting, water treatment, and environmental remediation.

\subsection{Energy Harvesting}

3.1.1. Overall $\mathrm{H}_{2} \mathrm{O}$ Splitting for $\mathrm{H}_{2}$ and $\mathrm{O}_{2}$ Production-The appealing attributes of CMNHs (Section 2) bring in exceptional advantages, which can be harnessed for transformational applications in energy harvesting, such as for $\mathrm{H}_{2} \mathrm{O}$ splitting $\left(\mathrm{H}_{2}\right.$ and $\mathrm{O}_{2}$ evolution) and $\mathrm{CO}_{2}$ conversion using solar radiation. $(5,6) \mathrm{H}_{2}$ is a clean and renewable fuel with the highest energy density (140 MJ/kg).(87) Functioning as an economically feasible photocatalyst, the g- $\mathrm{C}_{3} \mathrm{~N}_{4}$-based CMNHs can effectively split $\mathrm{H}_{2} \mathrm{O}$ to produce $\mathrm{H}_{2}$ and $\mathrm{O}_{2}$ under solar irradiation. $(5,6)$ In the pioneering work of Wang et al.,(88) the photocatalytic $\mathrm{H}_{2}$-evolution rate under visible-light illumination is elevated by $1-2$ orders of magnitude (from $0.1-4$ to $10.7 \mu \mathrm{mol} / \mathrm{h}$ ), when $3 \mathrm{wt} \% \mathrm{Pt}$ is decorated onto $2 \mathrm{D} \mathrm{g}-\mathrm{C}_{3} \mathrm{~N}_{4}$ nanosheets. Such advantages could be imparted on the nanohybrids by the introduction of CMI (with new built-in electric field and local electromagnetic field; Figure 1a) that prolongs charge-carriers lifetime and accelerates the separation and transfer of photogenerated electron-hole pairs. (88) The pivotal role of new built-in electric field in speeding charge separation and transfer during photocatalytic $\mathrm{H}_{2}$-evolution is also demonstrated for $\mathrm{g}_{-} \mathrm{C}_{3} \mathrm{~N}_{4}-\mathrm{SrTiO}_{3}$ with XPS and DFT analyses.(89) To minimize cost and make practical applications possible, research directions have later been directed toward Pt-free inexpensive MNPs-incorporated $\mathrm{g}_{-} \mathrm{C}_{3} \mathrm{~N}_{4}-$ CMNHs (including $\mathrm{TiO}_{2}, \mathrm{ZnO}, \mathrm{MoS}_{2}, \mathrm{Fe}_{2} \mathrm{O}_{3}, \mathrm{CdS}$, and $\left.\mathrm{BiVO}_{4}\right) \cdot(5,6,90)$ One of the highest photocatalytic $\mathrm{H}_{2}$-evolution rates upon visible-light irradiation is reported at $31400 \mu \mathrm{mol} / \mathrm{h} / \mathrm{g}$ 
for ultrathin $\mathrm{g}-\mathrm{C}_{3} \mathrm{~N}_{4}-\mathrm{a}-\mathrm{Fe}_{2} \mathrm{O}_{3}$ due to the large SSA, optimized light absorption, and accelerated transfer of photogenerated electron-hole pairs at the well-contacted g- $\mathrm{C}_{3} \mathrm{~N}_{4}$-a$\mathrm{Fe}_{2} \mathrm{O}_{3} \mathrm{CMI}$, whose quantum efficiency also reaches up to $\sim 4.4 \%$ at $420 \mathrm{~nm}$.(91)

Benefiting from the wide-ranged light response, high light-absorption efficiency, and low charge-carriers recombination rate, the LSPR-responsive MNPs ( $\mathrm{Ag}, \mathrm{Au}, \mathrm{Cu}$, and $\mathrm{Bi}$ ) profoundly broaden the application scope of $\mathrm{CMNHs}$ in plasmonic photocatalysis $\left(\mathrm{H}_{2} \mathrm{O}\right.$ splitting), surface-enhanced Raman scattering, and plasmon-enhanced fluorescence.(6) In photocatalytic $\mathrm{H}_{2} \mathrm{O}$ splitting, the visible-light-responsive photocurrent density is 1000 -folds higher for $1 \mathrm{wt} \%$ Au-decorated g- $\mathrm{C}_{3} \mathrm{~N}_{4}$ compared to the bare g- $\mathrm{C}_{3} \mathrm{~N}_{4}$ due to LSPR, yielding

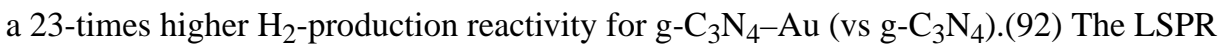
frequency and contribution in photocatalytic applications vary, depending on the size, shape, crystallinity, and dimensionality of MNPs, as well as MLC and hybridization mode between MNPs and CNMs (Section 2); because these factors affect light absorption, CMI, and the plasmon resonance energy transfer (PRET; Section 2.1) of CMNHs.(6,93) Evidence shows that there is an optimal physical distance between MNPs (e.g., AgNPs) and photocatalysts (e.g., $\mathrm{g}_{-} \mathrm{C}_{3} \mathrm{~N}_{4}$ ) when the LSPR absorption of MNPs partially overlaps with the optical absorption of photocatalyst. $(5,6,94)$ This is because LSPR-induced PRET effect shortens the charge-carriers transfer distance and inhibits the charge-carriers recombination. However, nonradiative energy transfer-Förster resonance energy transfer (FRET) occurs when the distance between MNPs and photocatalyst is too close, which adversely quenches the photogenerated charge-carriers. Using an engineered-nanogap strategy, that is, by loading plasmonic $\mathrm{Ag} @ \mathrm{SiO}_{2}$ (core@ shell) nanostructures (nanogap = 8-21 nm) onto g- $\mathrm{C}_{3} \mathrm{~N}_{4}$, Chen et al.(94) demonstrated that the optimized nanogap of $12 \mathrm{~nm}$ can balance the positive PRET and negative FRET effects based upon finite difference time domain (FDTD) simulations, (93) which yields the maximum $\mathrm{H}_{2}$-production activity $(11.4 \mu \mathrm{mol} / \mathrm{h})$ under solar irradiation. These findings open-up doors for nanoengineering of efficient CMNHs by precisely tuning architectures (distance between CNMs and MNPs) of CMNHs for $\mathrm{H}_{2} \mathrm{O}$ splitting.

Recently, the Z-scheme photocatalytic system (two different photocatalysts are coupled by an appropriate shuttle redox mediator to form Z-shape catalytic system; for example, Figure 3) has attracted tremendous attention since it speeds up electron-hole pairs separation/ transfer spatiotemporally (Section 2), and concurrently retains or enhances redox capability of CMNHs. $(5,6,86,95)$ Compared to g- $\mathrm{C}_{3} \mathrm{~N}_{4}$ and $\mathrm{g}_{-} \mathrm{C}_{3} \mathrm{~N}_{4}-\mathrm{CdS}$, the Z-scheme g- $\mathrm{C}_{3} \mathrm{~N}_{4}-\mathrm{Au}-$ $\mathrm{CdS}$ is $>34$-times ( $3.1 \mathrm{vs} 106 \mu \mathrm{mol} / \mathrm{h}$ ) more active in photocatalytic $\mathrm{H}_{2}$-evolution. Such an enhancement occurs primarily due to AuNPs' role as "electron-bridges"(95) that promote electron transfer between g- $_{3} \mathrm{~N}_{4}$ and CdS.(96) Notably, the Au@CdS (core@ shell)assembled g- $\mathrm{C}_{3} \mathrm{~N}_{4}$ nanosheet shows $\sim 126$-folds $(0.15 \mathrm{vs} 19 \mu \mathrm{mol} / \mathrm{h} / \mathrm{g})$ higher $\mathrm{H}_{2}$-production rate than bare $\mathrm{g}-\mathrm{C}_{3} \mathrm{~N}_{4}$ due to enhanced light absorption and Z-scheme separation of chargecarriers.(97) Other Z-scheme systems showing excellent photocatalytic $\mathrm{H}_{2} \mathrm{O}$ splitting efficiency and high stability and selectivity include $\mathrm{g}_{-} \mathrm{C}_{3} \mathrm{~N}_{4}-\mathrm{Ag}_{3} \mathrm{PO}_{4}-\mathrm{Ag}_{2} \mathrm{MoO}_{4},(98) \mathrm{g}$ $\mathrm{C}_{3} \mathrm{~N}_{4}-\mathrm{Au}-\mathrm{TiO}_{2},(95) \mathrm{g}_{-} \mathrm{C}_{3} \mathrm{~N}_{4}-\mathrm{TiO}_{2},(99)$ and $\mathrm{g}-\mathrm{C}_{3} \mathrm{~N}_{4}-\mathrm{NiTiO}_{3}(100)$ (SI Table S4).

Attributed to the highly porous nanostructures, large SSA, wide-spectrum light absorption, fast electron-hole separation at CMIs, and favorable $\pi-\pi$ interactions (enhanced chargecarriers generation and transfer) between metal organic frameworks (MOFs) and triazine 
rings of $\mathrm{g}-\mathrm{C}_{3} \mathrm{~N}_{4}$, the hierarchically arranged $\mathrm{g}-\mathrm{C}_{3} \mathrm{~N}_{4}$-MOFs (ZIF-8, UiO-66, and MIL-53) (101) demonstrate remarkable $\mathrm{H}_{2} \mathrm{O}$ splitting performance. The g- $\mathrm{C}_{3} \mathrm{~N}_{4}$-ZIF- 8 composites present a high $\mathrm{H}_{2}$-production rate of $309.5 \mu \mathrm{mol} / \mathrm{h} / \mathrm{g}$ due to the synergy among photoluminescence, electron-hole separation and charge transportation, and redox capabilities.(102) Using time-resolved transient fluorescent spectroscopy measurements, Wang et al.(103) found that the photoluminescence lifetime of charge-carriers is shorter in g$\mathrm{C}_{3} \mathrm{~N}_{4}$-UiO-66 vs g- $\mathrm{C}_{3} \mathrm{~N}_{4}$ (2.26 vs $2.88 \mathrm{~ns}$ ), yielding a 17-times increase in $\mathrm{H}_{2}$-evolution rate, since the shorter photoluminescence lifetime reveals a more rapid transfer of photogenerated electrons. The $\mathrm{H}_{2}$-production rate of $905.4 \mu \mathrm{mol} / \mathrm{h} / \mathrm{g}$ is achieved for $\mathrm{g}_{-} \mathrm{C}_{3} \mathrm{~N}_{4}-$ MIL-53(Fe), which is 335- and 47-folds higher than that of MIL-53(Fe) and g- $\mathrm{C}_{3} \mathrm{~N}_{4}$, respectively. The greater catalytically active sites and expedited electron-hole migration at g- $\mathrm{C}_{3} \mathrm{~N}_{4}-\mathrm{MIL}-53(\mathrm{Fe}) \mathrm{CMIs}$ are responsible for such enhancement.(104)

Besides photocatalytic activity, the stability and selectivity of CMNHs in $\mathrm{H}_{2} \mathrm{O}$ splitting are optimized when bimetallic NPs are decorated onto CNMs.(6) The 1.0 wt \% PtCo-loaded g$\mathrm{C}_{3} \mathrm{~N}_{4}$ nanohybrids show greater $\mathrm{H}_{2}$-evolution rate $(960 \mu \mathrm{mol} / \mathrm{h} / \mathrm{g})$ and stability $(\sim 28 \mathrm{~h})$ compared to monometallic g- $\mathrm{C}_{3} \mathrm{~N}_{4}-\mathrm{Pt}(330 \mu \mathrm{mol} / \mathrm{h} / \mathrm{g})$, because bimetallic PtCo NPs increase surface defect density and alter the Fermi level of CMNHs (both of which promote photoinduced electron-hole pairs separation).(105) A 3.5- $\left(\mathrm{g}-\mathrm{C}_{3} \mathrm{~N}_{4}-\mathrm{Au}\right)$ and 1.6-folds (g$\mathrm{C}_{3} \mathrm{~N}_{4}-\mathrm{Pd}$ ) increase in $\mathrm{H}_{2}$-evolution rate is reported for $0.5 \mathrm{wt} \%$ AuPd-decorated g- $\mathrm{C}_{3} \mathrm{~N}_{4}$ $(326 \mu \mathrm{mol} / \mathrm{h} / \mathrm{g}$ ), which can maintain high photocatalytic activity after four cycles by sustaining visible-light absorption and transfer of electron-hole pairs from the AuPd alloy. (106) It is also remarkable to note that the $\mathrm{g}-\mathrm{C}_{3} \mathrm{~N}_{4}-\mathrm{PtCo}$ nanohybrids possess a long-term stability after $510 \mathrm{~h}$ of reaction with no noticeable deactivation in photocatalytic $\mathrm{H}_{2} \mathrm{O}$ splitting.(107)

Both $\mathrm{g}_{-} \mathrm{C}_{3} \mathrm{~N}_{4}$ and $\mathrm{CDs}$ can convert NIR-light to visible-light, making them useful as universal energy-transfer materials for photocatalytic energy conversion. Particularly, the ternary g- $\mathrm{C}_{3} \mathrm{~N}_{4}$-MNPs-CDs nanoheterojunctions excel in $\mathrm{H}_{2} \mathrm{O}$ splitting. A 53-times higher $\mathrm{H}_{2}$-evolution rate $(212.4 \mu \mathrm{mol} / \mathrm{h} / \mathrm{g})$ is reported for the $\mathrm{Z}$-scheme $\mathrm{g}-\mathrm{C}_{3} \mathrm{~N}_{4}-\mathrm{MoS}_{2}-\mathrm{CDs}$ with excellent photostability than that of $\mathrm{g}_{-} \mathrm{C}_{3} \mathrm{~N}_{4}-\mathrm{MoS}_{2}$. Enhanced light absorption, accelerated charge transfer at two CMIs $\left(\mathrm{g}-\mathrm{C}_{3} \mathrm{~N}_{4}-\mathrm{MoS}_{2}\right.$ and $\left.\mathrm{CDs}-\mathrm{MoS}_{2}\right)$, and more catalytically active sites rendered by $\mathrm{MoS}_{2}$ are responsible for the observed results.(108) The ultrastable g$\mathrm{C}_{3} \mathrm{~N}_{4}$-UiO-66-CDs photocatalyst achieves a $\mathrm{H}_{2}$-production rate of $2930 \mu \mathrm{mol} / \mathrm{h} / \mathrm{g}$ upon visible-light illumination, which is 32.4-, 38.6-, and 17.5-folds higher than that of $\mathrm{g}_{-} \mathrm{C}_{3} \mathrm{~N}_{4}$, UiO-66, and g- $\mathrm{C}_{3} \mathrm{~N}_{4}-\mathrm{UiO}-66$, respectively.(109) Other types of CMNHs also perform well in photocatalytic $\mathrm{H}_{2} \mathrm{O}$ splitting. The commonly used CDs-CMNHs, for example, CDs$\mathrm{BiVO}_{4}$ and $\mathrm{CDs}-\mathrm{NiP}$ photocatalysts show the optimal $\mathrm{H}_{2}$-evolution rates of 4.02 and 398 $\mu \mathrm{mol} / \mathrm{h} / \mathrm{g}$, respectively, under visible-light illumination, which are much higher than the $\mathrm{H}_{2}$ evolution rate of parent component materials. $(45,48,110)$ Recent findings on photocatalytic $\mathrm{H}_{2} \mathrm{O}$ splitting by CNTs-, GFNs-, CDs-, and g- $\mathrm{C}_{3} \mathrm{~N}_{4}-\mathrm{CMNHs}$ are detailed in SI Tables S1S4.

3.1.2. $\mathrm{CO}_{2}$ Conversion for Energy Storage-Converting the major greenhouse gas $\mathrm{CO}_{2}$ into energy-bearing products $\left(\mathrm{CO}, \mathrm{CH}_{4}, \mathrm{HCOOH}, \mathrm{HCHO}\right.$, and $\left.\mathrm{CH}_{3} \mathrm{OH}\right)$ offers a feasible means not only in combatting climate change but also in alleviating energy crisis. 
$(111,112)$ Again, the appealing electronic/optical/catalytic/redox attributes of $\mathrm{g}-\mathrm{C}_{3} \mathrm{~N}_{4}-$ $\mathrm{CMNHs}$ make them the next-generation of robust photocatalysts, which facilitate $\mathrm{CO}_{2}$ conversion for energy storage. $(5,6) \mathrm{High}$ yield $(107 \mu \mathrm{mol} / \mathrm{h} / \mathrm{g})$ and selectivity $(94 \%)$ are reported for $43 \mathrm{wt} \% \mathrm{Co}_{4}$-decorated g- $\mathrm{C}_{3} \mathrm{~N}_{4}$ nanohybrids in $\mathrm{CO}_{2}$ photoreduction under visible-light irradiation (425-700 nm), which occurs due to facilitated charge transfer at the CMIs and excellent surface oxidative capability of $\mathrm{Co}_{4}$.(113) Using the Z-scheme $\mathrm{g}_{-} \mathrm{C}_{3} \mathrm{~N}_{4}-$ $\mathrm{SnO}_{2-X}$ photocatalyst at $\mathrm{MLC}=42.2 \mathrm{wt} \% \mathrm{SnO}_{2-X}$, the $\mathrm{CO}_{2}$ photoreduction rate reaches $22.7 \mu \mathrm{mol} / \mathrm{h} / \mathrm{g}$, which is 4.3 - and 5-folds higher than that of $\mathrm{g}-\mathrm{C}_{3} \mathrm{~N}_{4}$ and P25 $\left(\mathrm{TiO}_{2}\right)$, respectively (Figure 3a).(114) This occurs because under the direct $\mathrm{Z}$-scheme system, electrons at the $\mathrm{CB}$ of $\mathrm{SnO}_{2-x}$ interact with photoexcited holes at the $\mathrm{g}_{-} \mathrm{C}_{3} \mathrm{~N}_{4} \mathrm{VB}$, creating a strong reducing capability for the excited electrons in $\mathrm{g}-\mathrm{C}_{3} \mathrm{~N}_{4}$, which can reduce $\mathrm{CO}_{2}$ to $\mathrm{CO}$, $\mathrm{CH}_{4}$, and $\mathrm{CH}_{3} \mathrm{OH}$ (Figure 3b). A higher $\mathrm{CO}_{2}$ conversion rate $(57.5 \mu \mathrm{mol} / \mathrm{h} / \mathrm{g})$ is later reported by the same group for the Z-scheme $\mathrm{g}-\mathrm{C}_{3} \mathrm{~N}_{4}-\mathrm{Ag}-\mathrm{Ag}_{3} \mathrm{PO}_{4}$ nanoheterostructures, in which AgNPs function as electron mediator and charge transmission bridge to construct the $\mathrm{Z}$-scheme system (electrons flow through $\mathrm{Ag}_{3} \mathrm{PO}_{4} \mathrm{CB}$ to g- $\mathrm{C}_{3} \mathrm{~N}_{4} \mathrm{VB}$; Figure $3 \mathrm{c}-3 \mathrm{~d}$ ).(115) Not only that, the synergy between Z-scheme electron/charge transfer and LSRP effect of AgNPs (energize more electrons) causes 12.7-, 7.9-, and 2-times enhancement in electron consumption rate $(87.3 \mu \mathrm{mol} / \mathrm{h} / \mathrm{g})$ for the $\mathrm{g}-\mathrm{C}_{3} \mathrm{~N}_{4}-\mathrm{Ag}-\mathrm{TiO}_{2}$ than $\mathrm{TiO}_{2}, \mathrm{~g}_{-} \mathrm{C}_{3} \mathrm{~N}_{4}$, and $\mathrm{Ag}-$ $\mathrm{TiO}_{2}$, respectively.(116) These findings provide a head start for nanoscale engineering of highly efficient $\mathrm{Z}$-scheme photocatalyst to convert $\mathrm{CO}_{2}$ into energy-bearing chemical products.

The altered attributes including particle size, shape, and morphology of MNPs in CMNHs (Section 2) can significantly impact the efficiency and product selectivity in $\mathrm{CO}_{2}$ conversion. Larger AuNPs (100-150 nm in size) function as electron/charge bridges in the Z-scheme g$\mathrm{C}_{3} \mathrm{~N}_{4}-\mathrm{Au}-\mathrm{BiOBr}$ composite and enhance $\mathrm{CO}_{2}$ reduction ( $\mathrm{CO}$ production rate $=6.67$ vs 2.63 $\mu \mathrm{mol} / \mathrm{h} / \mathrm{g}$ for g- $\mathrm{C}_{3} \mathrm{~N}_{4}-\mathrm{Au}-\mathrm{BiOBr}$ vs g- $\mathrm{C}_{3} \mathrm{~N}_{4}-\mathrm{BiOBr}$ ). Whereas smaller 10-20 nm AuNPs promote $\mathrm{CO}_{2}$ reduction largely due to LSRP.(117) The uniformly decorated PdNPs with different preferentially exposed facets (cubic (100) and tetrahedral (111)) onto g- $\mathrm{C}_{3} \mathrm{~N}_{4}$ nanosheets exhibit varying degrees of $\mathrm{CO}_{2}$ reduction. For these catalysts, the $\mathrm{Pd}(111)-g$ $\mathrm{C}_{3} \mathrm{~N}_{4}$ performs better due to higher adsorption energy $\left(E_{\mathrm{A}}=0.230 \mathrm{vs} 0.064 \mathrm{eV}\right)$ of $\mathrm{CO}_{2}$ by $\operatorname{Pd}(111)$ compared to $\mathrm{Pd}(100)$, determined via first-principles calculations.(59) After $\mathrm{CO}_{2}$ adsorption, the activation barrier $\left(E_{\mathrm{B}}\right)$ is lowered from 7.15 to $3.98 \mathrm{eV}$ and from 6.79 to 4.15 $\mathrm{eV}$, respectively, for $\operatorname{Pd}(111)$ and $\operatorname{Pd}(100)$ facets, again validating that $\operatorname{Pd}(111)$ is more active for $\mathrm{CO}_{2}$ reduction $(3.98 \mathrm{eV}<4.15 \mathrm{eV}$ ).(59) Using DFT calculations, Cao et al.(118) also showed that the tetrahedral $\mathrm{Pd}(111)$ facet is more active than cubic $\mathrm{Pd}(100)$ in $\mathrm{CO}_{2}$ photoreduction by $\mathrm{g}-\mathrm{C}_{3} \mathrm{~N}_{4}-\mathrm{Pd}$. The underlying cause is identified as the electron sink effect, $\mathrm{CO}_{2}$ adsorption, and $\mathrm{CH}_{3} \mathrm{OH}$ desorption capability of $\mathrm{Pd}(111)$. These findings bring forward exciting new opportunities for tailoring MNPs' size and structure in CMNHs to achieve better $\mathrm{CO}_{2}$ reduction.

Besides g- $\mathrm{C}_{3} \mathrm{~N}_{4}-\mathrm{CMNHs}$, other $\mathrm{CMNHs}$ with various catalytically active sites and defects (Stone-Wales defects and vacancies) and oxygen-containing groups, along with stable particles in suspension (nonaggregating due to surface coating of negatively charged CDs; Section 2.2) and inhibited surface passivation of MNPs (Figure 1b) also exhibit efficient $\mathrm{CO}_{2}$ reduction. Examples include: $\mathrm{CDs}-\mathrm{Cu}_{2} \mathrm{O}$ nanohybrids which show efficient production 
of $\mathrm{CH}_{3} \mathrm{OH}\left(56 \mu \mathrm{mol} / \mathrm{h} / \mathrm{g}\right.$ ) compared to that of $\mathrm{Cu}_{2} \mathrm{O}$ only ( $\_38 \mu \mathrm{mol} / \mathrm{h} / \mathrm{g}$ ). In these systems, CDs function as photosensitizers and electron donors/acceptors, which prevent chargecarriers recombination.(119) The diffuse reflectance spectroscopic measurements further indicate that the $\mathrm{CDs}-\mathrm{Cu}_{2} \mathrm{O}$ can adsorb higher amount of light in the $640-2500 \mathrm{~nm}$ wavelength region compared to $\mathrm{Cu}_{2} \mathrm{O}$, demonstrating that the $\mathrm{CDs}-\mathrm{Cu}_{2} \mathrm{O}$ is more NIRsensitive and can better utilize a wider portion of the electromagnetic spectrum for $\mathrm{CO}_{2}$ photoreduction.(119) The NIR-light-driven $\mathrm{CO}_{2}$ reduction is also observed for $1 \mathrm{wt} \% \mathrm{CD}$-$\mathrm{Bi}_{2} \mathrm{WO}_{6}$, which shows 9.5- and 3.1-folds increment in $\mathrm{CH}_{4}$ production over $\mathrm{Bi}_{2} \mathrm{WO}_{6}$ nanoplatelets and nanosheets, respectively.(120) The full-spectrum UV-vis-NIR-driven $\mathrm{CO}_{2}$ photoreduction also frequently occurs for other CDs-CMNHs $\left(\mathrm{CDs}-\mathrm{TiO}_{2},(121) \mathrm{CDs}-\mathrm{CdS}\right.$, (122) and CDs- $\mathrm{ZnO}(123))$. These findings present a potentially new platform for developing highly efficient and inexpensive $\mathrm{CDs}-\mathrm{CMNHs}$ for $\mathrm{CO}_{2}$ conversion using the full-spectrum of inexhaustible sunlight.

Regardless of CNMs type, an optimal MLC always exists for CMNHs (Section 2.3), which renders catalytic performance (for $\mathrm{H}_{2} \mathrm{O}$ splitting, $\mathrm{CO}_{2}$ conversion, and contaminant removal). Compared to other MLCs, the $1 \mathrm{wt} \% \mathrm{MgO}^{-1} \mathrm{wt} \% \mathrm{CuNi}$-loaded CNTs present the highest catalytic efficacy. This is due to the promoted dispersion of Ni (larger SSA and more catalytically active sites), restrained reduction of $\mathrm{NiO}$, and lowered activation energy of $\mathrm{NiO}$ toward catalytic reaction.(124) The $\mathrm{C}_{2} \mathrm{H}_{5} \mathrm{OH}$ catalytic yield is reported at $49.1 \%$ and 92.2\%, respectively, for two $\mathrm{Pd}-\mathrm{CNT}$ nanohybrids $(\mathrm{Pd} / \mathrm{PdO}$ ratio $=90 / 10$ vs $60 / 40)$, depending on the architecture and dispersion status of Pd NPs that control electron transport and mass transfer processes.(125) During $\mathrm{CO}_{2}$ photoreduction, the optimal $23 \mathrm{wt} \% \mathrm{Ni}$ graphene reaches the maximum $\mathrm{CH}_{4}$-evolution rate $(642 \mu \mathrm{mol} / \mathrm{h} / \mathrm{g})$ and quantum yield (1.98\%) due to excellent charge separation at the C-Ni CMI.(126) The optimum MLC is also present for other CNTs- (CNTs-Pd(125) and CNTs-Ni-Zr(127)), GFNs-CMNHs (graphene- $\mathrm{MoS}_{2}-\mathrm{TiO}_{2}(128)$ and RGO-Pt-TiO 2 (129)) and CDs-CMNHs $\left(\mathrm{CDs}-\mathrm{TiO}_{2}(121)\right.$ and CDs- $\mathrm{ZnO}(123))$. Consequently, more research in this area is essential to maximizing the catalytic performance of CMNHs by optimizing MLC.

The multifunctionality of CMNHs in energy harvesting sector (both $\mathrm{H}_{2} \mathrm{O}$ splitting and $\mathrm{CO}_{2}$ conversion) is demonstrated by concurrent $\mathrm{H}_{2} \mathrm{O}$ splitting and $\mathrm{CO}_{2}$ conversion by $\mathrm{g}_{-} \mathrm{C}_{3} \mathrm{~N}_{4}-$ $\mathrm{Au}-\mathrm{TiO}_{2},(130) \mathrm{H}_{2} \mathrm{O}$ and $\mathrm{CO}_{2}$ photoreduction by RGO-BiWO $6^{-}-\mathrm{C}_{3} \mathrm{~N}_{4},(19) \mathrm{CO}$ and $\mathrm{CH}_{4}$ production by graphene- $\mathrm{TiO}_{2}$, (131) $\mathrm{CO}_{2}$ reduction in generating syngas $\left(\mathrm{CO}\right.$ and $\mathrm{H}_{2}$ ) by CDs- $\mathrm{Co}_{3} \mathrm{O}_{4}-\mathrm{C}_{3} \mathrm{~N}_{4}(132)$ and $\mathrm{g}-\mathrm{C}_{3} \mathrm{~N}_{4}-\mathrm{Ag}$,(133) and many others shown in SI Tables S1-S4. Additionally, the multifunctional $\mathrm{CMNHs}$ also show great potentials in other energy-related applications including electrocatalytic reactions (e.g., oxygen reduction reaction, electrocatalytic oxidation of alcohols, electrochemical reduction of $\mathrm{CO}_{2}$ and $\mathrm{H}_{2} \mathrm{O}_{2}$, methane reforming, and others; see SI Tables S1-S4). Interested readers can find more detailed information regarding CMNHs applications in electrocatalytic reactions in the literature. (134-138)

\subsection{Water Treatment}

3.2.1. Contaminant Removal and Microbial Inactivation-Simultaneous, fast, and effective removal of multiple inorganic/organic pollutants and inactivation of microbes have 
been at the forefront for developing water treatment technologies. Benefiting from the uniqueness and multifunctionality, the CMNHs have already shown outstanding ability for contaminant removal (adsorption and photocatalytic/redox degradation). CMNHs can quickly (minutes to several hours) and effectively remove a range of contaminants (generally $>90 \%$ degradation), including organic contaminants such as dyes, phenols, and persistent organic pollutants (e.g., polycyclic aromatic hydrocarbons and polychlorinated biphenyls), emerging contaminants (pharmaceuticals and personal care products, PPCPs; endocrine disrupting compounds, EDCs; and perfluorochemicals), and inorganic toxins such as heavy metals (As, $\mathrm{Cd}, \mathrm{Cr}, \mathrm{Hg}$, and $\mathrm{Pb}$ ) and radionuclides (Am, Eu, La, and U) (SI Tables S1-S4). Inactivation of microbes is also achieved effectively by the CMNHs (SI Tables S1-S4). Selected examples and associated mechanisms for contaminant removal are briefly presented here (detailed mechanisms particularly those for microbial inactivation are given in SI Tables S1-S4).

CNTs- $\mathrm{TiO}_{2}$ is used for photocatalytic degradation of a mixture of 22 PPCPs and EDCs in wastewater effluents at low concentrations $(\mu \mathrm{g} / \mathrm{L})$ under $\mathrm{UV}$ and simulated solar irradiation. (139) The $\mathrm{CNTs}-\mathrm{TiO}_{2}$ performs better (9-96\% vs 9-87\% degradation efficiency, and $0.05-$ 0.43 vs $0.05-0.17 \mathrm{~min}^{-1}$ degradation rate constant) compared to conventional photocatalysts (Degussa $\mathrm{P} 25 \mathrm{TiO}_{2}$ ). Mechanisms responsible for such performance are likely enhanced dispersion of $\mathrm{TiO}_{2}$, preconcentration of contaminants on the surfaces of both CNTs and $\mathrm{TiO}_{2} \mathrm{NMs}$, rich surface-active sites of both, and rapid separation of photoinduced electronhole pairs. These findings underscore that $\mathrm{CNTs}-\mathrm{TiO}_{2}$ has promise in removing emerging organic pollutants from wastewater.(139) Furthermore, complete and fast (minutes to several hours) removal (adsorption, catalysis, and redox) of a diverse set of contaminants including heavy metals, radionuclides, dyes, phenols, PPCPs, EDCs, and polychlorinated biphenyls, as well as inactivation of pathogens from water and wastewater have been frequently reported for GFNs-CMNHs like GO-Ag, (140) GO-Ag ${ }_{3} \mathrm{PO}_{4},(141) \mathrm{RGO}-\mathrm{PdAg},(142) \mathrm{RGO}-\mathrm{Ag}-$ $\mathrm{Fe}_{3} \mathrm{O}_{4},(143)$ and $\mathrm{GO}-\mathrm{MnFe}_{2} \mathrm{O}_{4}$ (e.g., maximum adsorption capacities for $\mathrm{La}$ and $\mathrm{Ce}$ are as high as 1001 and $982 \mathrm{mg} / \mathrm{g}$ ).(144) Also, coremoval of ciprofloxacin (88\%), rhodamine B $(97 \%)$, tetracycline $(67 \%)$, and bisphenol A (60\%) is also observed for CDs-BiOBr within 1-3.5 h under visible-light irradiation due to enhanced light absorption and excellent active centers for charge-carriers separation at the CMIs.(145) Fabricated with a biogenic green and cost-effective approach, the $\mathrm{g}-\mathrm{C}_{3} \mathrm{~N}_{4}-\mathrm{Ag}$ composite shows a high dye degradation efficiency ( $\sim 100 \%$ and $\sim 89 \%$ degradation of methylene blue and rhodamine B within $4 \mathrm{~h}$ ) and a strong performance toward inactivation of pathogens (Escherichia coli, Staphylococcus aureus, and Pseudomonas aeruginosa) under visible-light illumination.(146) Enhanced AgNP dispersion, larger SSA, prolonged visible-light absorption due to LSPR, suppressed charge recombination, and greater production of reactive oxygen species (ROS) such as ${ }^{\circ} \mathrm{O}_{2}{ }^{-}$and ${ }^{\bullet} \mathrm{OH}$ and release of $\mathrm{Ag}^{+}$ions collectively contribute to the greater photocatalytic performance and reactivity of $\mathrm{g}_{-} \mathrm{C}_{3} \mathrm{~N}_{4}-\mathrm{Ag}$ than the parent NMs.(147) For CMNHs that include antimicrobial MNPs $\left(\mathrm{Ag}, \mathrm{Au}, \mathrm{CuO}, \mathrm{TiO}_{2}\right.$, and $\left.\mathrm{ZnO}\right)$, their antimicrobial performance is always higher than the parent MNPs. The greater antimicrobial activity of the MNPs in the nanoheterostructures is likely caused by enhanced particle dispersion, larger SSA, enhanced direct-interaction between MNPs and microbes, and additional antimicrobial activity from the CNMs(148) (SI Tables S1-S4). Inactivation of $P$. 
aeruginosa has been successfully achieved by harnessing microwave radiation and generating ROS with CNT- $\mathrm{Er}_{2} \mathrm{O}_{3}$ nanohybrids.(149) For MNPs with magnetic properties like $\mathrm{Fe}, \mathrm{Ni}, \mathrm{Co}, \mathrm{Fe}_{x} \mathrm{O}_{y}$, and $\mathrm{MFe}_{2} \mathrm{O}_{4}$ (M denotes metal), $(150,151)$ the magnetically separable CMNHs can be easily recycled using an external magnetic field, suppressing the likelihood of generating a secondary waste from the release of the nanoscale treatment agents. Moreover, the nanohybrids exhibit high stability, selectivity, and reusability with no appreciable deterioration in reactivity after several consecutive cycles of use $(n \geq 6),(152$ $155)$ due to the strong mechanical strength of the carbon scaffolds. These advantages can greatly minimize operational cost, while enhancing the removal efficiency of multiple contaminants from water and wastewater.

Recently, CMNHs-enabled single-atom catalyst(156) has attracted significant attention due to high catalytic activity (maximized atomically catalytic efficiency due to complete exposure of surface sites), stability, and selectivity. Using a facile confined-interface-directed route, the Pd atoms are anchored onto the interfaces of double-shelled hollow RGO (inner shell)-amorphous carbon (outer shell) nanospheres, as shown by DFT calculations.(157) The resulting RGO-amorphous carbon-Pd nanohybrids show a significantly higher turnover frequency $\left(602 \mathrm{~min}^{-1}\right)$ than that of RGO-Pd $\left(106 \mathrm{~min}^{-1}\right)$ and amorphous carbon-Pd (97 $\mathrm{min}^{-1}$ ) in 4-aminophenol reduction due to the ideally dispersed Pd atoms allowing for access to all catalytic surface sites. Furthermore, the nanohybrids exhibit high stability in 4aminophenol reduction (100\% conversion during five repeated cycles and $>95 \%$ conversion after the eighth repeated cycle).(157) These findings offer a new direction in maximizing the atomic efficiency, activity, and stability in metal-based heterogeneous catalysis for contaminant removal.

Through Raman, XPS, and EPR characterization, the dual-reaction-centered g- $\mathrm{C}_{3} \mathrm{~N}_{4}-$ $\mathrm{Al}_{2} \mathrm{O}_{3}-\mathrm{Cu}$ and $\mathrm{CDs}-\mathrm{Al}_{2} \mathrm{O}_{3}-\mathrm{Cu}$ nanohybrids (electron-rich $\mathrm{Cu}$ center and electron-deficient $\mathrm{Al}$ site) are reported to significantly facilitate electron transfer and ${ }^{\circ} \mathrm{OH}$ generation, showing remarkable promise in catalytic degradation of organic pollutants under mild Fentonreaction conditions.(158) A similar multiple-reaction-centered RGO-CoAl (layered double hydroxide; $\mathrm{LDH}$ ) $-g-\mathrm{C}_{3} \mathrm{~N}_{4}$ is recently reported to exhibit $\sim 100 \%$ photocatalytic removal and mineralization of congo red and tetracycline within $30 \mathrm{~min}$, which is $\sim 20$ - and $\sim 15$-times higher than that of $\mathrm{CoAl}$ and $\mathrm{g}_{-} \mathrm{C}_{3} \mathrm{~N}_{4}$, respectively (Figure 4).(159) This is due to the beneficial 2D stacking of RGO, CoAl, and g- $\mathrm{C}_{3} \mathrm{~N}_{4}$ that results in multiple intimate CMIs (RGO-CoAl and $\mathrm{g}-\mathrm{C}_{3} \mathrm{~N}_{4}-\mathrm{CoAl}$ ) and hinders direct recombination of electron-hole pairs, thereby accelerating interfacial charge transfer. Similar findings have also been reported for 2D-2D g- $\mathrm{C}_{3} \mathrm{~N}_{4}-\mathrm{MoS}_{2}$ and 2D-0D g- $\mathrm{C}_{3} \mathrm{~N}_{4}-\mathrm{Pt}$ in photocatalytic degradation.(160) These results highlight the significance of dimensionality in controlling photocatalytic reactivity of CMNHs, which also brings forward a new rationale for nanoscale engineering of multiplereaction-centered heterojunctions as high-performance photocatalysts for water treatment.

Besides the strong influence of particle size, shape, morphology, dimensionality, and MLC discussed earlier, the mode of material hybridization also impacts the performance of $\mathrm{CMNHs}$ for contaminant removal. The in situ synthesized CDs- $\mathrm{TiO}_{2}\left(\right.$ is-CDs-- $\mathrm{TiO}_{2}$ ) shows much higher photocatalytic activity for benzene, pesticides, and phenol over the 3 synthesized $\mathrm{CDs}-\mathrm{TiO}_{2}$, due to greater up-converted photoluminescence, enhanced particle 
dispersion, and faster transfer of photogenerated electron-hole pairs at the closer CMIs of isCDs- $\mathrm{TiO}_{2}$.(161) These results indirectly demonstrate the dominant role of CMIs, which control the catalytic performance of CMNHs (with intimately contacted CMIs within the nanoheterojunctions; Figure 1).

3.2.2. Membrane Technology-Membrane-based water treatment and desalination technologies are popular treatment options in many parts of the world.(162-164) CNMs (CNTs and GFNs) have been extensively used to modify membranes and impart mechanical strength, improve water permeability and flux (e.g., aligned CNTs), enable tunability of hydrophobicity, introduce selectivity and antifouling capability, and deliver flexibility toward functionalization.(4,165-167) Recently, CNTs- and GFNs-CMNHs have shown great potential in various membrane technologies including reverse osmosis $\left(\mathrm{CNTs}-\mathrm{TiO}_{2}\right.$, (168) GO-Ag,(169) and GO-Fe(170)), forward osmosis (CNTs-SiO 2 -polyvinylidene fluoride(171) and GO-Ag(172)), ultrafiltration (CNTs-Al(173) and GO-TiO ${ }_{2}(174)$ ), nanofiltration (CNTs-Al(175) and RGO-UiO-66(176)), microfiltration $\left(\mathrm{GO}-\mathrm{Al}_{2} \mathrm{O}_{3}(177)\right)$, capacitive deionization $\left(\mathrm{CNTs}-\mathrm{MnO}_{X}(178)\right.$ and $\left.\mathrm{GO}-\mathrm{Ag}-\mathrm{Cu}(179)\right)$, electrochemical deionization ( $\mathrm{RGO}-\mathrm{FePO}_{4}(180)$ ), membrane distillation ( $\mathrm{RGO}-\mathrm{Bi}_{2} \mathrm{WO}_{6}(181)$ ), and organic solvent nanofiltration (GO-ZIF-8(182)). For example, the $\mathrm{RGO} @ \mathrm{Fe}_{3} \mathrm{O}_{4}$ nanofiltration membranes present high water permeance $\left(\sim 300 \mathrm{~L} / \mathrm{m}^{2} / \mathrm{h} / \mathrm{bar}\right.$ ) and dye (Rhodamine $\mathrm{B}$ and bisphenol A) and ion $\left(\mathrm{CuSO}_{4}, \mathrm{CdSO}_{4}, \mathrm{MnSO}_{4}\right.$, and $\left.\mathrm{CoSO}_{4}\right)$ rejection by utilizing the expanded interlayer spacings and nanochannels between the ordered laminar RGO layers due to uniform loading of $\mathrm{Fe}_{3} \mathrm{O}_{4}$ NPs (Figure 5).(183) The $\mathrm{RGO} @ \mathrm{Fe}_{3} \mathrm{O}_{4}$ nanofiltration membrane system can be easily scaled up for wastewater treatment, and its sufficient mechanistic strength and stability under high-pressure and cross-flow operations will enable these applications (Figure 5).(183)

g- $\mathrm{C}_{3} \mathrm{~N}_{4}$ (tris-triazine) is an ideal material for membrane technologies because of its geometry and the triangular nanopores $(\sim 3.11 \AA)(184)$ that exist on the 2D nanosheets, which allow for easy passage of water molecules with kinetic diameter of 2.6 $\AA$.(185) The g$\mathrm{C}_{3} \mathrm{~N}_{4}-\mathrm{Ag}_{3} \mathrm{PO}_{4}$-polyvinylidene fluoride, (186) g- $\mathrm{C}_{3} \mathrm{~N}_{4}-\mathrm{Fe}(\mathrm{OH})_{3}-\mathrm{Al}_{2} \mathrm{O}_{3},(187)$ and $\mathrm{g}_{-} \mathrm{C}_{3} \mathrm{~N}_{4}-$ CNTs-GO- $\mathrm{TiO}_{2}$ (188) nanofiltration membranes, g- $\mathrm{C}_{3} \mathrm{~N}_{4}-\mathrm{Ag}_{3} \mathrm{PO}_{4}$-poly(ether sulfone) microfiltration membranes,(189) and g- $\mathrm{C}_{3} \mathrm{~N}_{4}-\mathrm{Ag}-$ nafion ultrafiltration membranes(190) exhibit improved fouling resistance, photocatalytic degradation efficiency, antibacterial activity, stability, reusability, and water flux. For example, the g- $\mathrm{C}_{3} \mathrm{~N}_{4}-\mathrm{CNTs}-\mathrm{GO}-\mathrm{TiO}_{2}$ nanofiltration membranes exhibit enhanced water flux $\left(\sim 16 \mathrm{~L} / \mathrm{m}^{2} / \mathrm{h} / \mathrm{bar}\right)$ while maintaining an increased dye ( $\sim 100 \%$ for methyl orange) and salt ( $67 \%$ for $\left.\mathrm{Na}_{2} \mathrm{SO}_{4}\right)$ rejection efficiency. CNTs are known to expand the interlayer spacing between neighboring graphene nanosheets and thus enhance the stability and strength of the membrane, while the $\mathrm{g}-\mathrm{C}_{3} \mathrm{~N}_{4}$ and $\mathrm{TiO}_{2}$ NPs deliver the desired catalytic-activity.(188) The $\mathrm{g}_{-} \mathrm{C}_{3} \mathrm{~N}_{4}-\mathrm{CNT}-\mathrm{GO}-\mathrm{TiO}_{2}$ membranes also display multifunctionalities in photocatalytic coremoval of ammonia (50\%), sulfamethoxazole (80\%), and bisphenol A (82\%) in wastewater from aquaculture.(188) Integrating membrane filtration with photocatalysis (incorporating g- $\mathrm{C}_{3} \mathrm{~N}_{4}-\mathrm{CMNHs}$ ) opens doors for fabricating the next-generation antifouling membranes in water treatment and desalination applications. 
In addition to g- $\mathrm{C}_{3} \mathrm{~N}_{4}$, the facile production and appealing physicochemical attributes (small size, good biocompatibility, tunable hydrophilicity, rich surface functional groups, and antifouling properties) of CDs enable these materials to modify desalination and water treatment membranes.(191) CDs-CMNHs can be readily integrated with various membrane materials (thin film nanocomposites and polymers) in reverse osmosis, nanofiltration, and pressure retarded osmosis applications.(191) The CDs-CMNHs-modified membranes (CDs$\left.\mathrm{TiO}_{2}-\mathrm{SiO}_{2}\right)(192)$ have shown to outperform unmodified membranes in terms of treatment performance (salt rejection and contaminant degradation time and efficiency), stability, and reusability. The enhancement in hydrophilicity, permeability, and antifouling property results in biofilm reduction (medicated by electrostatic repulsion between negatively charged CDs and bacteria, physical interaction, and enhanced oxidative stress).(148) Because the CDsCMNHs are nonselective toward bacteria, the membranes functionalized with these materials present a proof-of-concept which can be used for developing novel antibacterial membranes in the future.

\subsection{Environmental Sensing and Remediation}

3.3.1. Environmental Sensing-CMNHs have shown advantages in sensing of multifarious environmental species such as pollutants (heavy metals, antibiotics, pesticides, phenolics, and microcystins) and biomacromolecules (enzymes, proteins, RNA, and DNA) (SI Tables S1-S4). Appealing attributes in effective electron and electrochemical charge transfer (Section 2.1 and Figure 1), abundant surface functional groups, high sensitivity, strong photostability, and favorable biocompatibility can enhance the sensing performance. (50,193-195) The dual-emission CDs-CdSe-ZnS@ $\mathrm{SiO}_{2}$ fluorescent probe is developed for in vivo imaging of $\mathrm{Cu}^{2+}(0.2-1 \mu \mathrm{M}$ linear detection range) in living cells with high degrees of specificity and sensitivity.(196) A graphene-Bi framework is assembled for in situ detection of multiple heavy metal ions (1-120 $\mu \mathrm{g} / \mathrm{L}$ of $\mathrm{Pb}(\mathrm{II})$ and $\mathrm{Cd}(\mathrm{II}), 40-300 \mu \mathrm{g} / \mathrm{L}$ of $\mathrm{Zn}(\mathrm{II})$, and with a detection limit of $0.02-4 \mu \mathrm{g} / \mathrm{L}$ ). The controllable nanoarchitecture, large SSA, and fast mass and electron transfer are unique attributes of the nanohybrids.(197) Based on blue photoluminescence and excitation-wavelength-dependent emission, the CDsEu sensor can selectively detect tetracycline (with a linear range of $0.5-200 \mu \mathrm{M}$ and a detection limit of $0.3 \mu \mathrm{M}$ ) for lake water samples.(198) Despite interferences from methyl parathion, pentachlorophenol, and carbaryl, the $\mathrm{RGO}-\mathrm{BiPO}_{4}\left(\mathrm{RGO} / \mathrm{BiPO}_{4}\right.$ optimal mass ratio $=0.03$ ) photoelectrochemical sensor can selectively detect chlorpyrifos within $0.05-80$ $\mathrm{ng} / \mathrm{mL}$ with a low detection limit of $0.02 \mathrm{ng} / \mathrm{mL}$ (mediated by reduced particle agglomeration).(199) The highly selective $\mathrm{CNTs}-\mathrm{TiO}_{2}$ photoelectrochemical sensor shows ultrasensitive detection range (1.0 pM-3.0 nM) for microcystin-LR.(200) These findings manifest the robustness of CMNHs in sensing environmental pollutants at ultratrace levels with high degrees of selectivity and stability.

In addition to environmental pollutants, CDs-Au-poly(amidoamine) immunosensor can identify an important cancer biomarker (alpha-fetoprotein) with a wide linear detection range of $100 \mathrm{fg} / \mathrm{mL}-100 \mathrm{ng} / \mathrm{mL}$ and a low detection limit of $0.025 \mathrm{pg} / \mathrm{mL}$ for serum samples.(201) An innovative dual-channel CDs-Au biosensing system is recently fabricated to concurrently monitor multiple nucleotide sequences (breast cancer and thymidine kinase RNA/DNA) with a linear range of 4-120 nM and a detection limit of 1.5-4.5 nM (Figure 6). 
(202) Excellent visible-light response and fluorescence resonance energy transfer, novel hairpin structure, and strong interactions between AuNPs and DNA account for the ultrahigh selectivity, sensitivity, specificity, and multifunctionality of the biosensors toward RNA/DNA (Figure 6).(202) The CDs-Au-based biosensing model presents a prototype for nanoengineering similar or more sophisticated CMNHs-based monitoring systems to analyze any possible gene sequence or aptamer-substrate complex in environmental matrices.

The $\mathrm{g}-\mathrm{C}_{3} \mathrm{~N}_{4}-\mathrm{CMNHs}$ also show promising advantages in environmental sensing of biomacromolecules due to fast response and high detection sensitivity arising from their unique electrical and optical attributes (Section 2.1 and Figure 1) and abundant surface functional groups.(52,203-205) The suppressed charge recombination and improved photocurrent conversion efficiency make the $\mathrm{g}-\mathrm{C}_{3} \mathrm{~N}_{4}-\mathrm{TiO}_{2}$-graphene PEC biosensors highly sensitive to pcDNA3-HBV in the linear range of $0.01 \mathrm{fM}-20 \mathrm{nM}$ with a $0.005 \mathrm{fM}$ detection limit.(206) Such a biosensor also exhibits a high degree of selectivity (no obvious interferences with presence of pcDNA3, pcDNA3-His, pCMV5, pCMV-N-HA, and pCMVC-HA), stability (for 14 days), and reproducibility (relative standard deviation $=2.3-4.5 \%$ ). (206) Owing to the novel exciton-plasmon interactions in the $p-n$ heterojunction, enhanced resonance energy transfer and photocurrent, and tunable signal change modulation, the $\mathrm{g}$ $\mathrm{C}_{3} \mathrm{~N}_{4}-\mathrm{CdS} @ \mathrm{Au}-\mathrm{Ag}$ photoelectrochemical biosensor can trace sub-fM level (0.05 fM) microRNA-21 in complex biological samples with good specificity, reproducibility, and stability.(207) A similar g- $\mathrm{C}_{3} \mathrm{~N}_{4}-\mathrm{CdS}$ photoelectrochemical immunosensor is also reported to exhibit a wide linear detection range $(0.01-10 \mathrm{nM})$ and a low detection limit (3.53 $\mathrm{pM})$ for $\mathrm{N}^{6}$-methyladenosine ( $\mathrm{m}^{6} \mathrm{~A}$; methylated RNA) for the blood serum from breast cancer patients (SI Figure S2).(208) The dynamic monitoring of the $\mathrm{m}^{6} \mathrm{~A}$ methylated RNA expression in vivo provides the $\mathrm{g}-\mathrm{C}_{3} \mathrm{~N}_{4}-\mathrm{CdS}$-based biosensors with the capability of early cancer detection abilities.

3.3.2. In Situ Nanoremediation-Restoration of contaminated sites remains to be challenging due to inefficiency in contaminant removal alongside with high cost of conventional remediation technologies, for example, the U.S. Environmental Protection Agency estimates that approximately US\$209 billion is needed to clean up 294000 US contaminated sites from 2004-2033.(209) Currently, nanoscale zerovalent iron (NZVI) is the only nanomaterial that has been used in pilot- and field-scale demonstrations for in situ nanoremediation purposes.(210) However, the high aggregation propensity of NZVI (generally $\unlhd \mathrm{m}$ transport distance from injection point) and its lack of selectivity toward contaminants greatly limit its remedial performance for contaminated site remediation.(210) Because CMNHs may provide improved stability, potentially longer travel distances, and an ability to remove multiple contaminants effectively and simultaneously (Section 3.2 and SI Tables S1-S4), the next-generation CMNHs hold a potential for in situ nanoremediation. (211) Compared to the large volume of literature on CMNHs' applications in energy harvesting and water treatment fields discussed earlier, no research has been reported to explore the promising applications of CMNHs for contaminated site remediation. Because aggregation and transport propensities of NMs (e.g., NZVI) dictate their performance in contaminated site remediation, this section focuses on the aggregation and transport of 
CMNHs in aquatic environments to direct the development of next-generation multifunctional CMNHs for in situ nanoremediation.

3.3.2.1. Aggregation of CMNHs: Hua et al.(212) first examined aggregation of graphene$\mathrm{TiO}_{2}$ in water under environmentally relevant $\mathrm{pH}(4-10)$ and salt type $(0-200 \mathrm{mM} \mathrm{NaCl}$ and 0-8 $\mathrm{mM} \mathrm{CaCl}_{2}$ ). The nanohybrids display Derjaguin-Landau-Verwey-Overbeek (DLVO)and Schulze-Hardy-type aggregation, for example, greater aggregation occurs at lower $\mathrm{pH}$, higher ionic strengths, or with presence of $\mathrm{Ca}^{2+}\left(\mathrm{vs} \mathrm{Na}^{+}\right)$. Our recent findings also demonstrate that DLVO theory and Schulze-Hardy rule well predict the aggregation behaviors of RGO-Ag, $\mathrm{RGO}-\mathrm{Fe}_{3} \mathrm{O}_{4}$, and $\mathrm{RGO}-\mathrm{Ag}-\mathrm{Fe}_{3} \mathrm{O}_{4}$ nanohybrids in $\mathrm{NaCl}$ and $\mathrm{CaCl}_{2}$. (213) Das et al.(214) probed the "part-whole" question of nanohybrid aggregation using $\mathrm{CNT}-\mathrm{TiO}_{2}$, which is a function of MLC (C/Ti molar ratio $=1: 0.1,1: 0.05$, and 1:0.033). The aggregation of $\mathrm{CNTs}-\mathrm{TiO}_{2}$ increases with increasing MLC (aggregation order: 1:0.033 < 1:0.05 1:0.1), which is inconsistent with DLVO theory's prediction because the negative zeta-potential of $\mathrm{CNT}-\mathrm{TiO}_{2}$ follows the order of: 1:0.033 < 1:0.05 $<$ 1:0.1 (electrostatic repulsion is the greatest for 1:0.1).(214) The authors explained that MLC-dominated properties such as fractal dimension and asphericity, charge heterogeneity, and surface roughness likely result in aggregation behavior of nanohybrids that cannot be captured by that of its parts.(214) These findings highlight the significance of $\mathrm{pH}$ and MLC in dominating CMNHs' aggregation in aqueous solutions.

$\mathrm{pH}$ controls electrostatic double layer interactions, and thus NMs' aggregation. NMs and $\mathrm{CMNHs}$ are expected to be stable when solution $\mathrm{pH}$ is far away from their $\mathrm{pH}_{\mathrm{PZC}}(\mathrm{pH}$ of point of zero charge); but tend to aggregate at their $\mathrm{pH}_{\mathrm{PZC}}$ where net surface charge approaches zero. The $\mathrm{pH}_{\mathrm{PZC}}$ of CNTs, GFNs, CDs, and g- $\mathrm{C}_{3} \mathrm{~N}_{4}$ is reported at 3-4,(215,216) $2.5-3,(72,217-219) 2.0-2.5,(220)$ and 4-5,(221,222) respectively (Figure 7). Compared to CNMs, MNPs have higher $\mathrm{pH}_{\mathrm{PZC}}$, for example, $\mathrm{Al}_{2} \mathrm{O}_{3}\left(\mathrm{pH}_{\mathrm{PZC}} 8-10\right), \mathrm{Fe}_{x} \mathrm{O}_{y}\left(\mathrm{pH}_{\mathrm{PZC}} 7-9.5\right)$, $\mathrm{TiO}_{2}$ ( $\mathrm{pH}_{\mathrm{PZC}} 6-7.8$ ), and $\mathrm{ZnO}$ (pH $\mathrm{pZC}_{7.5-10.2)}$ (Figure 7).(223) Hybridizing less negatively charged MNPs with CNMs causes a shift of CNMs' $\mathrm{pH}_{\mathrm{PZC}}$ toward a higher $\mathrm{pH}$ (Figure 7); for example, the $\mathrm{pH}_{\mathrm{PZC}}$ of $\mathrm{GO}-\mathrm{MnFe}_{2} \mathrm{O}_{4}$ nanohybrids $\left(\mathrm{pH}_{\mathrm{PZC}} 4.85\right)(224)$ is higher than that of $\mathrm{GO}$ ( $\mathrm{pH}_{\mathrm{PZC}}$ 2.5-3).(219) Moreover, the $\mathrm{pH}_{\mathrm{PZC}}$ of CMNHs shifts toward a higher $\mathrm{pH}$ with increasing MLCs. For example, $\mathrm{pH}_{\mathrm{PZC}}$ of $\mathrm{GO}_{-} \mathrm{TiO}_{2}$ follows the order: $4.1>$ $4.0>3.5>3.2>3.0$ for 1.0, 1.4, 2.9, 3.3, and $6.0 \mathrm{wt} \%$ GO-loaded nanohybrids, respectively.(225) Therefore, $\mathrm{pH}$ and MLC codetermine CMNHs' aggregation via controlling their surface charges in aqueous suspensions.

Besides MLC, other newly emerging attributes of CMNHs (Section 2) also impact their aggregation. The separation distance between $2 \mathrm{D} \mathrm{g}-\mathrm{C}_{3} \mathrm{~N}_{4}$ nanosheets is enhanced upon surface-anchoring of MNPs, which increases physical separation (also for RGO- $\mathrm{Fe}_{3} \mathrm{O}_{4}$; Figure 5). Increased separation distance weakens the van der Waals (vdW) attractions between $\mathrm{g}_{-} \mathrm{C}_{3} \mathrm{~N}_{4}$-metal nanohybrids (vs individual $\mathrm{g}-\mathrm{C}_{3} \mathrm{~N}_{4}$ ), as demonstrated by higher dispersion of $\mathrm{g}-\mathrm{C}_{3} \mathrm{~N}_{4}$ and $\mathrm{TiO}_{2}$ in the $\mathrm{g}-\mathrm{C}_{3} \mathrm{~N}_{4}-\mathrm{TiO}_{2}$ suspension.(226) However, the localized $\mathrm{vdW}$ interaction at the CMIs is likely strengthened, due to the coupling of new built-in electric field and local electromagnetic field (Figure 1a). The coupling becomes more pronounced when magnetic MNPs $\left(\mathrm{Fe}_{X} \mathrm{O}_{y}\right)$ are introduced, since magnetism synergistically intensifies the coupling and yields large $\mathrm{CMNHs}$ aggregates. For example, even at a high 
dispersant concentration ( $2 \mathrm{wt} \%$ carboxymethylcellulose), the hydrodynamic diameter $\left(D_{\mathrm{H}}\right)$ is much larger for the magnetic CNTs-Fe ${ }_{3} \mathrm{O}_{4}$ vs CNTs $\left(3264 \mathrm{~nm}\right.$ vs $3052 \mathrm{~nm} ; \Delta D_{\mathrm{H}}=212$ $\mathrm{nm}$ ), given that the anchored $\mathrm{Fe}_{3} \mathrm{O}_{4}$ is only $20-30 \mathrm{~nm}$.(211) Therefore, the overall and localized vdW interactions collectively determine the aggregation of CMNHs in aqueous solution. Surface roughness,(214) charge heterogeneity,(214) dimensionality, and anisotropy are also likely to influence CMNHs aggregation. Diffusion- or reaction-limited cluster aggregation (DLCA or RLCA)(227) occurs, depending on the aggregation state (fast or slow) and dimensionality of particles. The aggregates are observed to be monodispersed in the DLCA regime, but become more compact in the RLCA regime.(227) Higher dimensional CMNHs call in the DLCA regime of aggregation, forming more compacted clusters and thus minimizing overall system entropy.(228-230) Surface defects including oxyanion functional groups introduced during CMNHs synthesis (e.g., chemical oxidation and ultrasonication) also influence CMNHs aggregation in aqueous suspension via altering electrostatic double layer (EDL) repulsive interactions. $(23,231)$

3.3.2.2. Transport of CMNHs: Transport capability of NMs determines their efficacy in remediating contaminated sites.(211) The transport of $\mathrm{CNTs}-\mathrm{Fe}_{3} \mathrm{O}_{4}$ in laboratory-scale sand columns is recently reported.(211) The as-synthesized CNTs- $-\mathrm{Fe}_{3} \mathrm{O}_{4}$ nanohybrids are highly aggregated due to strong hydrophobic, localized vdW, and magnetic attractions, but 2 wt \% carboxymethylcellulose can effectively disperse $\mathrm{CNTs}-\mathrm{Fe}_{3} \mathrm{O}_{4}$ particles by electrosteric repulsions. A novel transport feature was characterized by an initial lower effluent peak, followed by a sharp, higher effluent peak, probably due to the interplay between the variability of fluid viscosity (water and viscous carboxymethylcellulose) and size-selective retention(232) of CNTs- $\mathrm{Fe}_{3} \mathrm{O}_{4}$. The predicted maximum transport distance of CNTs- $\mathrm{Fe}_{3} \mathrm{O}_{4}$ using the Tufenkji-Elimelech model(233) ranges between 0.38-46 m, supporting the feasibility of applying the magnetically recyclable $\mathrm{CNTs}-\mathrm{Fe}_{3} \mathrm{O}_{4}$ for in situ nanoremediation. (211) Our recent modeling efforts(234) reveal that conventional colloid transport model can capture the transport and retention of $\mathrm{RGO}-\mathrm{Fe}_{3} \mathrm{O}_{4}, \mathrm{RGO}-\mathrm{TiO}_{2}$, and $\mathrm{RGO}-\mathrm{ZnO}$ nanohybrids under a range of $\mathrm{NaCl}, \mathrm{CaCl}_{2}$, and $\mathrm{NOM}$ concentrations. Possible transport scenarios of the RGO-metal nanohybrids are forecasted via inverse fitting under environmentally relevant physicochemical conditions (flow velocity, porosity, and collector size) using Hydrus-1D software.(235)

The altered and newly emerging attributes affecting CMNHs' aggregation (described above) also influence their transport in porous media. Other attributes that may alter CMNHs transport are discussed below. The small $(\sim 5.5 \mathrm{~nm})$ negatively charged CDs $(-21.2$ to -38.2 $\mathrm{mV}$ in $1 \mathrm{mM} \mathrm{NaCl}$ at $\mathrm{pH} 6-9$ ) show high mobility in sand columns even at very high ionic strengths (>50\% breakthrough in $700 \mathrm{mM} \mathrm{NaCl}$ at $\mathrm{pH}$ 6).(236) Thus, the highly mobile CDs will enhance the mobility of CDs-CMNHs, when CDs are anchored onto MNPs surfaces (SI Figure $\mathrm{S} 1 \mathrm{e}, \mathrm{f})$. In terms of potential retention mechanisms in porous media, straining likely dominates CNTs- and RGO-CMNHs retention as large CNTs- $\mathrm{Fe}_{3} \mathrm{O}_{4}, \mathrm{RGO}-\mathrm{Fe}_{3} \mathrm{O}_{4}$, RGO$\mathrm{ZnO}$, and RGO-NZVI ( $\geq 1 \mu \mathrm{m}$ ) aggregates are frequently found at environmentally relevant conditions. $(211,234)$ Straining has a dynamic role during the transport of CMNHs in porous media, since it progressively narrows down the pore-throat, and thus enhances subsequent particle retention, particularly near the column inlet, as has been demonstrated by the 
hyperexponential retention profiles in the transport studies of parent NMs and CMNHs. $(211,234)$ More systematic studies are necessary to understand aggregation and transport of CMNHs (particularly g- $\mathrm{C}_{3} \mathrm{~N}_{4}$ and $\mathrm{CDs}-\mathrm{CMNHs}$ ) in aquatic environments for their effective use as in situ nanoremediation agents.

\section{Challenges and Perspectives}

The advantages of $\mathrm{CMNHs}$ in harnessing solar energy for $\mathrm{H}_{2}$ and $\mathrm{O}_{2}$ evolution and $\mathrm{CO}_{2}$ conversion stem from their appealing light harvesting capability, photocatalytic activity, stability, and selectivity, which are dependent on material type, composition (MLC), structure, crystallinity, morphology, dimensionality, and size that tailor electronic, optical, and band structure, and ultimately the charge transfer properties of the nanoheterostructures. However, fundamental knowledge on photoinduced electron-hole pairs, electron separation, and charge transfer dynamics at CMIs in the nanoheterostructures remains largely unexplored. This is particularly true for more complicated Z-scheme and MOFs-based CMNHs that exhibit high photocatalytic reactivity. Another key issue associated with Zscheme and MOFs systems relates to the substantial energy loss and thus the low quantum yield during electron transfer processes.(237) State-of-the-art in situ characterizations like atom probe tomography, ion scattering, EPR and photoluminescence spectroscopy, and Xray absorption spectroscopy (XAS) measurements combined with theoretical simulations (electronic structure modeling and first-principles DFT) are vital for unravelling electronhole pair transfer pathways and charge cascading processes at molecular and atomic levels. This knowledge will enable designing more efficient, targeted, and economically feasible CMNHs with higher quantum efficiency by optimizing utilization of full-spectrum sunlight. To this end, prioritizing the development of $\mathrm{g}-\mathrm{C}_{3} \mathrm{~N}_{4}-\mathrm{CDs}-\mathrm{MNPs}$ is necessitated owing to the excellent full-use of sunlight by CDs and their abundant reactive sites toward hybridization with other materials.

Single-atom catalysis-based, dual-/multiple-reaction-centered, and double Z-scheme CMNHs have attracted significant interests due to their ultrahigh photocatalytic activity and stability that can be harnessed for energy harvesting, particularly for degrading recalcitrant contaminants (perfluorochemicals). Taking single-atom catalysts as an example: 2D GFNs and $\mathrm{g}_{-} \mathrm{C}_{3} \mathrm{~N}_{4}$ offer ample supporting sites for accommodating single-atom metals with prefect dispersion.(238) Nonetheless, key thermodynamic parameters affecting the photocatalytic activity and quantum yield including charge-carrier mobility time, diffusion length, and lifetime are currently unknown. Coupling in situ microscopic (subangstrom-resolution aberration-corrected high-angle annular dark-field scanning transmission microscope), spectroscopic (X-ray absorption fine structure), and advanced modeling (DFT) measurements can be valuable for probing the oxidation state, bonding structure, and coordination environment of single-atom in the nanoheterojunctions. This information will direct the development of next-generation CMNHs-based photocatalysts with maximized metal-catalytic reactivity toward recalcitrant contaminant degradation. MLC should be considered for fabricating CMNHs to achieve optimum performances.

While CNTs- and GFNs-CMNHs underperform in $\mathrm{H}_{2} \mathrm{O}$ splitting and $\mathrm{CO}_{2}$ conversion compared to $\mathrm{g}_{-} \mathrm{C}_{3} \mathrm{~N}_{4}$ - and CDs-CMNHs, the large SSA, rich surface-reactive sites and 
defects, and remarkable electron transfer properties render them as powerful candidates for contaminant removal via adsorption and catalysis due (partly) to accelerated electron-hole pair separation for MNPs.(67) Additionally, CNTs and GFNs (e.g., RGO) acting as "electron-transport-bridge"(239) can facilitate the construction of Z-scheme g- $\mathrm{C}_{3} \mathrm{~N}_{4}$-RGOMNPs, resulting in well-contacted CMIs, short charge-transfer distance, and superior photocatalytic performances. Introduction order of parent materials, synthetic conditions, and nanoscale assembly can tune CMNHs' properties (morphology, band alignment, layer arrangement, defect density, vacancy, and porosity) that affect the light utilization and photocatalytic efficiencies. Designing rational nanoheterojunctions by orderly assembling g$\mathrm{C}_{3} \mathrm{~N}_{4}$, GFNs/CNTs, and MNPs with well-matched energy levels warrants further exploration toward more efficient $\mathrm{H}_{2} \mathrm{O}$ splitting, $\mathrm{CO}_{2}$ conversion, contaminant removal, and microbial disinfection.

Tremendous progress has been made in advancing CMNHs-modified membranes for water treatment and desalination using reverse osmosis, forward osmosis, microfiltration, ultrafiltration, and nanofiltration technologies. The physicochemical properties of CMNHs along with their loading amount, assembling strategy, dispersion state, and orientation into the composite membrane modulate the mechanical stability, contaminant removal efficiency, solute rejection and antifouling ability, selectivity, and reusability of the membrane. Understanding the structure-property relationships of CMNHs in the composite membranes is pivotal for optimizing their performances, but how these parameters (e.g., loading amount and assembling strategy) tailor membrane structures, properties, and functions remains poorly understood. Systematic studies are essential to understanding the structure-property relationships for developing next-generation advanced membranes. Furthermore, pilot- or field-scale testings must be conducted to evaluate the reliability of long-term use of CMNHs-modified membranes for future industrial applications.

CMNHs (particularly CDs- and g- $\mathrm{C}_{3} \mathrm{~N}_{4}-\mathrm{CMNHs}$ ) show the benefits to sensitively and selectively monitor multifarious environmental contaminants and biomacromolecules (RNA/ DNA) at ultratrace (pM-fM) levels due to their unique fluorescence and luminescence attributes. However, explanations on fluorometric and luminometric mechanisms for CMNHs-based sensors are rather empirical and far from clear because size, structure, crystallinity, morphology, surface states and defects, MLC, and hybridization mode all likely impact the absorbance and excitation/emission processes involving fluorescence/ luminescence. New techniques like XPS, EPR, electrochemical impedance, and surfaceenhanced Raman spectroscopy, two-photon fluorescence imaging, and up-converted fluorescence imaging coupled with theoretical modeling can facilitate a deeper understanding of the fluorometric and luminometric mechanisms toward designing the nextgeneration (bio)sensors for a broader and more effective environmental and biological applications (e.g., cancer diagnosis).

While DLVO theory and Schulze-Hardy rule can be used to qualitatively or semiquantitatively describe the overall aggregation behaviors of certain CMNHs (e.g., CNT$\mathrm{TiO}_{2}$, (214) RGO-Ag,(213) RGO-Ag-Fe $\mathrm{O}_{4},(213)$ and $\mathrm{RGO}--\mathrm{TiO}_{2}(212)$ ), challenges still remain for quantitative description of the aggregation kinetics and morphology/structure evolution of CMNHs aggregates, particularly when taking into account the newly emerging 
attributes of CMNHs (e.g., shape, dimensionality, MLC, and anisotropy). State-of-the-art in situ real-time identifications may enable more accurate and direct observations of CMNHs aggregation (e.g., growth kinetics and morphology/structure evolution). For example, using direct-imaging cryogenic transmission and scanning electron microscopy (cryo-TEM/SEM) with a nanoscale resolution, Kleinerman et al.(240) observed various stages of liquid crystalline phase evolution and domain morphology development of CNTs in aqueous suspensions, which is controlled by the aspect ratio, diameter, and purity degree of CNTs. Similarly, polarized light microscopy (PLM) allows direct imaging of CNTs(241) and GFNs(242) at the micrometer scale. Particularly, in situ real-time imaging with atomic force microscopy (AFM)(243) has the power to directly observe anisotropic aggregation kinetics of CMNHs. Small-angle scattering (SAS) technique can provide particle size distribution, dispersity (mono- and poly dispersity), and structural information on dimensionality of NPs in aqueous suspensions. Consequently, combining cryo-TEM/SEM, PLM, real-time AFM and SAS techniques along with DLVO theory calculations using surface element integration (SEI) technique(244-246) (SI Text S1) can advance a mechanistic understanding of CMNHs aggregation (growth kinetics and morphology/structure evolution) in aqueous systems.

The aforementioned future research directions can facilitate accurate descriptions of CMNHs aggregation. This can pave the way for more reliable description and prediction of CMNHs transport in environmental media. Nonetheless, natural soil and sediment matrices are highly complex and heterogeneous in terms of compositions, structures, properties, and functions. For example, physical and hydrodynamic properties of porous media such as pore structure, particle size distribution, porosity, preferential flow/pathway, geometry, connectivity, and tortuosity can strongly affect the transport of NPs (e.g., CMNHs).(247) New approaches of coupling mass transport measurements of CMNHs at the mesoscopic scale with direct measurements of physical and hydrodynamic proeprties of the porous media (e.g., by using a 3D X-ray computed tomography (CT) technique)(247,248) are needed to unravel the pore-scale processes.(249) Particularly, the nondestructive 3D X-ray CT technique can enable accurate characterization of pore network structure with regard to particle size distribution, porosity, and tortuosity of the porous media, all of which can influence CMNHs transport and retention in environmental media.

Mathematical modeling is also necessary to simulate and predict the transport and retention of CMNHs in environmental media. This is particularly important when the hydrodynamic size of CMNHs aproaches the pore size/throat of porous media in which straining and ripening effects on colloid retention become significant.(232) The modified MODFLOW-, (250) continuum-,(251) and artificial neutral network-based models(252) are good candidates, since these model formulas mechanistically account for colloid retention mechanisms including particle aggregation, straining, ripening, site-blocking, and sizeexclusion. Alternatively, physically based mechanistic models like two-region, two-domain, and dual-permeability models can explicitly account for preferential flow and local/bulk transport in porous media at different scales (e.g., pore, representative elementary volume, and field scales).(247) To better correlate CMNHs' retention mechanisms with their newly emerging attributes (e.g., morphology, dimensionality, and MLC), porous media properties (e.g., physical and hydrodynamic properties), and environmental conditions (e.g., water content, water chemistry, and pore-water velocity), machine learning technique (i.e., 
decision tree) can be advantageous for identifying factors influencing CMNHs transport and retention in porous media. $(253,254)$ This may facilitate the development of quantitative relationships between CMNHs mobility in porous media and their physicochemical properties using X-ray CT techniques, mathematical modeling, and machine learning techniques.

Optimizing the transport capability of $\mathrm{CMNHs}$ for in situ nanoremediation remains challenging, as these CMNHs (e.g., $\mathrm{CNTs}-\mathrm{Fe}_{3} \mathrm{O}_{4}$ ) are likely highly aggregated even at low ionic strengths.(211) Stabilizers like surfactants, polymers, biomacromolecules, or their combinations should be examined for identifying their contributions in enhancing CMNHs transport in soil and groundwater. Unlike conventional colloid transport studies that neglects fluid viscosity variability, fluid viscosity should be monitored continuously, especially with presence of high concentrations of stabilizers whose viscosity could be several-orders of magnitude higher than that of water.(211) Monitoring fluid viscosity helps unravelling CMNHs transport mechanisms which, in turn, enables more accurate estimation of operational time and remediation efficiency for in situ nanoremediation.

Practical application of noble MNPs can be impeded by the high price and low abundance. Fortunately, inexpensive synthesis of CNMs and noble-metal-free MNPs has been scaled-up to kilogram scale. $(255,256)$ Moreover, most highly efficient CMNHs are obtained via in situ strategy in which affordable metal salts are used as precursors. One can thus prepare largescale CMNHs at reasonable price for real-world applications such as wastewater treatment and in situ nanoremediation. Benefiting from the versatility of CNMs, inexpensive magnetic MNPs $\left(\mathrm{Fe}_{x} \mathrm{O}_{y}\right)$ can be facilely and strongly anchored onto CMNHs to render recyclable and reusable benefits, which lowers down the usage cost and minimizes potential environmental risks of CMNHs (e.g., toxicity from MNPs like AgNPs). While research, development, and application of CMNHs are still in the infancy, the invigorating properties/ multifunctionalities of the new type of material can afford fascinating new opportunities for scientists and engineers to devote more research activities into this rapidly growing field. Particular focus should be devoted to developing next-generation environmental benign CMNHs. We are most optimiztic that more revolutionary applications of CMNHs along with the advancements of both fundamental physics and chemistry and practical techniques will expand the horizon and open new doors for simultaneously achieving better human life, cleaner energy, and environmental sustainability.

\section{Supplementary Material}

Refer to Web version on PubMed Central for supplementary material.

\section{Acknowledgments}

This research was funded by the United States Environmental Protection Agency. The viewpoints associated with this article are those of the authors, and do not necessarily reflect the views or policies of USEPA.

\section{Abbreviations}

CNTs

carbon nanotubes 
GFNs

CDs

g- $\mathrm{C}_{3} \mathrm{~N}_{4}$

CMNHs

EWE

CNMs

MNPs

CB

CMI

DFT

EDCs

EPR

GO

HRTEM

LDH

LSPR

MLC

MOF

PPCPs

PRET

RGO

ROS

SSA

UV-vis-NIR

VB

XAS

XPS graphene family nanomaterials

carbon dots

graphitic carbon nitride

carbon-metal nanohybrids

energy-water-environment

carbonaceous nanomaterials

metal nanoparticles

conduction band

carbon-metal interface

density functional theory

endocrine disrupting compounds

electron paramagnetic resonance

graphene oxide

high-resolution transmission electron microscope

layered double hydroxide

localized surface plasmon resonance

metal loading capacity

metal organic framework

pharmaceuticals and personal care products

plasmon resonance energy transfer

reduced graphene oxide

reactive oxygen species

specific surface area

ultraviolet-visible-near-infrared

valence band

X-ray absorption spectroscopy

X-ray photoelectron microscopy 


\section{References}

1. Catley-Carlson M The non-stop waste of water. Nature 2019, 565, 426-427, DOI: 10.1038/ d41586-019-00214-w

2. Alvarez PJJ; Chan CK; Elimelech M; halas NJ; Villagran D Emerging opportunities for nanotechnology to enhance water security. Nat. Nanotechnol 2018, 13 (8), 634-641, DOI: 10.1038/ s41565-018-0203-2 [PubMed: 30082804]

3. Yousefi N; Liu X; Elimelech M; Tufenkji N Environmental performance of graphene-based 3D macrostructures. Nat. Nanotechnol 2019, 14, 107-119, DOI: 10.1038/s41565-018-0325-6 [PubMed: 30617310]

4. Mauter MS; Zucker I; Perreault F; Werber JR; Kim JH; Elimelech M The role of nanotechnology in tackling global water challenges. Nat. Sustain 2018, 1, 166-175, DOI: 10.1038/s41893-018-0046-8

5. Ong WJ; Tan LL; Ng YH; Yong ST; Chai SP Graphitic carbon nitride (g-C3N4)-based photocatalysts for artificial photosynthesis and environmental remediation: Are we a step closer to achieving sustainability?. Chem. Rev 2016, 116 (12), 7159-7329, DOI: 10.1021/ acs.chemrev.6b00075 [PubMed: 27199146]

6. Teixeira IF; Barbosa ECM; Tsang SCE; Camargo PHC Carbon nitrides and metal nanoparticles: From controlled synthesis to design principles for improved photocatalysis. Chem. Soc. Rev 2018, 47 (20), 7783-7817, DOI: 10.1039/C8CS00479J [PubMed: 30234202]

7. Falinski MM; Plata DL; Chopra SS; Theis TL; Gilbertson LM; Zimmerman JB A framework for sustainable nanomaterial selection and design based on performance, hazard, and economic considerations. Nat. Nanotechnol 2018, 13 (8), 708-714, DOI: 10.1038/s41565-018-0120-4 [PubMed: 29713076]

8. Iijima S Helical microtubules of graphitic carbon. Nature 1991, 354, 56-58, DOI: $10.1038 / 354056 \mathrm{a} 0$

9. Geim AK Graphene: Status and prospects. Science 2009, 324 (5934), 1530-1534, DOI: 10.1126/ science.1158877 [PubMed: 19541989]

10. Xu X; Ray R; Gu Y; Ploehn HJ; Gearheart L; Raker K; Scrivens WA Electrophoretic analysis and purification of fluorescent single-walled carbon nanotube fragments. J. Am. Chem. Soc 2004, 126 (40), 12736-12737, DOI: 10.1021/ja040082h [PubMed: 15469243]

11. Kumaravel V; Mathew S; Bartlett J; Pillai SC Photocatalytic hydrogen production using metal doped $\mathrm{TiO}_{2}$ : A review of recent advances. Appl. Catal., B 2019, 244, 1021-1064, DOI: 10.1016/ j.apcatb.2018.11.080

12. Sang L; Zhao Y; Burda $\mathrm{C} \mathrm{TiO}_{2}$ nanoparticles as functional building blocks. Chem. Rev 2014, 114 (19), 9283-9318, DOI: 10.1021/cr400629p [PubMed: 25294395]

13. Clavero C Plasmon-induced hot-electron generation at nanoparticle/metal-oxide interfaces for photovoltaic and photocatalytic devices. Nat. Photonics 2014, 8, 95-103, DOI: 10.1038/ nphoton.2013.238

14. Eigler S; Hirsch A Chemistry with graphene and graphene oxide-Challenges for synthetic chemists. Angew. Chem., Int. Ed 2014, 53 (30), 7720-7738, DOI: 10.1002/anie.201402780

15. Huang D; Li Z; Zeng G; Zhou C; Xue W; Gong X; Yan X; Chen S; Wang W; Cheng M Megamerger in photocatalytic field: $2 \mathrm{D} \mathrm{g}-\mathrm{C}_{3} \mathrm{~N}_{4}$ nanosheets serve as support of $0 \mathrm{D}$ nanomaterials for improving photocatalytic performance. Appl. Catal., B 2019, 240, 153-173, DOI: 10.1016/ j.apcatb.2018.08.071

16. Huang X; Qi X; Boey F; Zhang H Graphene-based composites. Chem. Soc. Rev 2012, 41 (2), 666686, DOI: 10.1039/C1CS15078B [PubMed: 21796314]

17. Shearer CJ; Cherevan A; Eder D Application and future challenges of functional nanocarbon hybrids. Adv. Mater 2014, 26 (15), 2295-2318, DOI: 10.1002/adma.201305254 [PubMed: 24677386]

18. Das B; Plazas-Tuttle J; Sabaraya IV; Jain SS; Sabo-Attwood T; Saleh NB An elegant method for large scale synthesis of metal oxide-carbon nanotube nanohybrids for nano-environmental application and implication studies. Environ. Sci.: Nano 2017, 4 (1), 60-68, DOI: 10.1039/ C6EN00294C 
19. Jo WK; Kumar S; Eslava S; Tonda S Construction of $\mathrm{Bi}_{2} \mathrm{WO}_{6} / \mathrm{RGO} / \mathrm{g}-\mathrm{C}_{3} \mathrm{~N}_{4} 2 \mathrm{D} / 2 \mathrm{D} / 2 \mathrm{D}$ hybrid Zscheme heterojunctions with large interfacial contact area for efficient charge separation and highperformance photoreduction of $\mathrm{CO}_{2}$ and $\mathrm{H}_{2} \mathrm{O}$ into solar fuels. Appl. Catal., B 2018, 239, 586-598, DOI: 10.1016/j.apcatb.2018.08.056

20. Li XH; Antonietti M Metal nanoparticles at mesoporous N-doped carbons and carbon nitrides: Functional Mott-Schottky heterojunctions for catalysis. Chem. Soc. Rev 2013, 42 (16), 65936604, DOI: 10.1039/c3cs60067j [PubMed: 23765224]

21. Wang C; Astruc D Recent developments of metallic nanoparticle-graphene nanocatalysts. Prog. Mater. Sci 2018, 94, 306-383, DOI: 10.1016/j.pmatsci.2018.01.003

22. Zhao MQ; Zhang Q; Huang JQ; Wei F Hierarchical nanocomposites derived from nanocarbons and layered double hydroxides-properties, synthesis, and applications. Adv. Funct. Mater 2012, 22 (4), 675-694, DOI: 10.1002/adfm.201102222

23. Aich N; Plazas-Tuttle J; Lead JR; Saleh NB A critical review of nanohybrids: Synthesis, applications and environmental implications. Environ. Chem 2014, 11 (6), 609-623, DOI: 10.1071/EN14127

24. Khan M; Tahir MN; Adil SF; Khan HU; Siddiqui MRH; Al-warthan AA; Tremel W Graphene based metal and metal oxide nanocomposites: Synthesis, properties and their applications. J. Mater. Chem. A 2015, 3 (37), 18753-18808, DOI: 10.1039/C5TA02240A

25. Anwer H; Park JW Synthesis and characterization of a heterojunction $\mathrm{rGO} / \mathrm{ZrO}_{2} / \mathrm{Ag}_{3} \mathrm{PO}_{4}$ nanocomposite for degradation of organic contaminants. J. Hazard. Mater 2018, 358, 416-426, DOI: 10.1016/j.jhazmat.2018.07.019 [PubMed: 30007252]

26. Hua S; Qu D; An L; Jiang W; Wen Y; Wang X; Wang X; Sun Z Highly efficient p-type $\mathrm{Cu}_{3} \mathrm{P} / \mathrm{n}$ type $\mathrm{g}_{-} \mathrm{C}_{3} \mathrm{~N}_{4}$ photocatalyst through Z-scheme charge transfer route. Appl. Catal., B 2018, 240, 253-261

27. Huang Y; Wang P; Wang Z; Rao Y; Cao JJ; Pu S; Ho W; Lee SC Protonated g- $\mathrm{C}_{3} \mathrm{~N}_{4} / \mathrm{Ti}^{3+}$ selfdoped $\mathrm{TiO}_{2}$ nanocomposite films: Room-temperature preparation, hydrophilicity, and application for photocatalytic $\mathrm{NO}_{\mathrm{x}}$ removal. Appl. Catal., B 2019, 240, 122-131, DOI: 10.1016/ j.apcatb.2018.08.078

28. Gao J; Zhu M; Huang H; Liu Y; Kang Z Advances, challenges and promises of carbon dots. Inorg. Chem. Front 2017, 4 (12), 1963- 1986, DOI: 10.1039/C7QI00614D

29. Duo F; Wang Y; Fan CL; Zhang X; Wang Y Enhanced visible light photocatalytic activity and stability of CQDs/BiOBr composites: The upconversion effect of CQDs. J. Alloys Compd 2016, 685, 34-41, DOI: 10.1016/j.jallcom.2016.05.259

30. Chen J; Che H; Huang K; Liu C; Shi W Fabrication of a ternary plasmonic photocatalyst $\mathrm{CQDs} / \mathrm{Ag} / \mathrm{Ag}_{2} \mathrm{O}$ to harness charge flow for photocatalytic elimination of pollutants. Appl. Catal., B 2016, 192, 134-144, DOI: 10.1016/j.apcatb.2016.03.056

31. Li N; Tian Y; Zhao J; Zhang J; Zuo W; Kong L; Cui H Z-scheme 2D/3D g-C ${ }_{3} \mathrm{~N}_{4} @ Z$ ZnO with enhanced photocatalytic activity for cephalexin oxidation under solar light. Chem. Eng. J 2018, 352, 412-422, DOI: 10.1016/j.cej.2018.07.038

32. Xiong C; Jiang S; Song S; Wu X; Li J; Le ZG Solid-solution-like o- $\mathrm{C}_{3} \mathrm{~N}_{4} / \mathrm{Ag}_{2} \mathrm{SO}_{4}$ nanocomposite as a direct Z-Scheme photocatalytic system for photosynthesis of active oxygen species. ACS Sustainable Chem. Eng 2018, 6 (8), 10905-10913, DOI: 10.1021/acssuschemeng.8b02241

33. Maiti UN; Lee WJ; Lee JM; Oh Y; Kim JY; Kim JE; Shim J; Han TH; Kim SO 25th anniversary article: Chemically modified/doped carbon nanotubes \& graphene for optimized nanostructures \& nanodevices. Adv. Mater 2014, 26 (1), 40-67, DOI: 10.1002/adma.201303265 [PubMed: 24123343]

34. Su DS; Perathoner S; Centi G Nanocarbons for the development of advanced catalysts. Chem. Rev 2013, 113 (8), 5782-5816, DOI: 10.1021/cr300367d [PubMed: 23721498]

35. Zhang H; Ji Z; Xia T; Meng H; Low-Kam C; Liu R; Pokhrel S; Lin S; Wang X; Liao YP; Wang M; Li L; Rallo R; Damoiseaux R; Telesca D; Madler L; Cohen Y; Zink JI; Nel AE Use of metal oxide nanoparticle band gap to develop a predictive paradigm for oxidative stress and acute pulmonary inflammation. ACS Nano 2012, 6 (5), 4349-4368, DOI: 10.1021/nn3010087 [PubMed: 22502734] 
36. Ma X; Hu J; He H; Dong S; Huang C; Chen X New understanding on enhanced photocatalytic activity of $\mathrm{g}-\mathrm{C}_{3} \mathrm{~N}_{4} / \mathrm{BiPO}_{4}$ heterojunctions by effective interfacial coupling. ACS Appl. Nano Mater 2018, 1 (10), 5507-5515, DOI: 10.1021/acsanm.8b01012

37. Dong F; Zhao Z; Sun Y; Zhang Y; Yan S; Wu Z An advanced semimetal-organic Bi spheres-g$\mathrm{C}_{3} \mathrm{~N}_{4}$ nanohybrid with SPR-enhanced visible-light photocatalytic performance for NO purification. Environ. Sci. Technol 2015, 49 (20), 12432-12440, DOI: 10.1021/acs.est.5b03758 [PubMed: 26375261]

38. Zou W; Deng B; Hu X; Zhou Y; Pu Y; Yu S; Ma K; Sun J; Wan H; Dong L Crystal-planedependent metal oxide-support interaction in $\mathrm{CeO}_{2} / \mathrm{g}-\mathrm{C}_{3} \mathrm{~N}_{4}$ for photocatalytic hydrogen evolution. Appl. Catal., B 2018, 238, 111-118, DOI: 10.1016/j.apcatb.2018.07.022

39. Cui W; Li J; Sun Y; Wang H; Jiang G; Lee SC; Dong F Enhancing ROS generation and suppressing toxic intermediate production in photocatalytic $\mathrm{NO}$ oxidation on $\mathrm{O} / \mathrm{Ba}$ cofunctionalized amorphous carbon nitride. Appl. Catal., B 2018, 237, 938-946, DOI: 10.1016/ j.apcatb.2018.06.071

40. Liang C; Niu CG; Zhang L; Wen XJ; Yang SF; Guo H; Zeng GM Construction of 2D heterojunction system with enhanced photocatalytic performance: Plasmonic Bi and reduced graphene oxide co-modified $\mathrm{Bi}_{5} \mathrm{O}_{7} \mathrm{I}$ with high-speed charge transfer channels. J. Hazard. Mater 2019, 361, 245-258, DOI: 10.1016/j.jhazmat.2018.08.099 [PubMed: 30199824]

41. Wang Z; Zhang T; Ding M; Dong B; Li Y; Chen M; Li X; Huang J; Wang H; Zhao X; Li Y; Li D; Jia C; Sun L; Guo H; Ye Y; Sun D; Chen Y; Yang T; Zhang J; Ono S; Han Z; Zhang Z Electricfield control of magnetism in a few-layered van der Waals ferromagnetic semiconductor. Nat. Nanotechnol 2018, 13 (7), 554-559, DOI: 10.1038/s41565-018-0186-z [PubMed: 29967458]

42. Warren SC; Thimsen E Plasmonic solar water splitting. Energy Environ. Sci 2012, 5 (1), 5133 5146, DOI: 10.1039/C1EE02875H

43. Wang X; Long R; Liu D; Yang D; Wang C; Xiong Y Enhanced full-spectrum water splitting by confining plasmonic Au nanoparticles in $\mathrm{N}$-doped $\mathrm{TiO}_{2}$ bowl nanoarrays. Nano Energy 2016, 24 , 87-93, DOI: 10.1016/j.nanoen.2016.04.013

44. Hutton GAM; Martindale BCM; Reisner E Carbon dots as photosensitisers for solar-driven catalysis. Chem. Soc. Rev 2017, 46 (20), 6111-6123, DOI: 10.1039/C7CS00235A [PubMed: 28664961]

45. Choi Y; Choi Y; Kwon OH; Kim BS Carbon dots: Bottom-up syntheses, properties, and lightharvesting applications. Chem. - Asian J 2018, 13 (6), 586-598, DOI: 10.1002/asia.201701736 [PubMed: 29316309]

46. De B; Karak N Recent progress on carbon dot-metal based nanohybrids for photochemical and electrochemical applications. J. Mater. Chem. A 2017, 5 (5), 1826-1859, DOI: 10.1039/ C6TA10220D

47. Lim SY; Shen W; Gao Z Carbon quantum dots and their applications. Chem. Soc. Rev 2015, 44 (1), 362-381, DOI: 10.1039/C4CS00269E [PubMed: 25316556]

48. Wang R; Lu KQ; Tang ZR; Xu YJ Recent progress in carbon quantum dots: Synthesis, properties and applications in photocatalysis. J. Mater. Chem. A 2017, 5 (8), 3717-3734, DOI: 10.1039/ C6TA08660H

49. Karimzadeh A; Hasanzadeh M; Shadjou N; de la Guardia M Optical bio(sensing) using nitrogen doped graphene quantum dots: Recent advances and future challenges. TrAC, Trends Anal. Chem 2018, 108, 110-121, DOI: 10.1016/j.trac.2018.08.012

50. Shi L; Yin Y; Zhang LC; Wang S; Sillanpaa M; Sun H Design and engineering heterojunctions for the photoelectrochemical monitoring of environmental pollutants: A review. Appl. Catal., B 2019, 248, 405-422, DOI: 10.1016/j.apcatb.2019.02.044

51. Zang Y; Fan J; Ju Y; Xue H; Pang H Current advances in semiconductor nanomaterial-based photoelectrochemical biosensing. Chem. - Eur. J 2018, 24 (53), 14010-14027, DOI: 10.1002/ chem.201801358 [PubMed: 29687506]

52. Huang D; Yan X; Yan M; Zeng G; Zhou C; Wan J; Cheng M; Xue W Graphitic carbon nitride based heterojunction photoactive nanocomposites: Applications and mechanism insight. ACS Appl. Mater. Interfaces 2018, 10 (25), 21035-21055, DOI: 10.1021/acsami.8b03620 [PubMed: 29856204] 
53. Eder D; Windle AH Morphology control of $\mathrm{CNT}^{-\mathrm{TiO}_{2}}$ hybrid materials and rutile nanotubes. J. Mater. Chem 2008, 18 (17), 2036-2043, DOI: 10.1039/b800499d

54. Zheng D; Zhang G; Wang X Integrating CdS quantum dots on hollow graphitic carbon nitride nanospheres for hydrogen evolution photocatalysis. Appl. Catal., B 2015, 179, 479-488, DOI: 10.1016/j.apcatb.2015.05.060

55. Henych J; Stengl V; Mattsson A; Tolasz J; Osterlund L Civil warfare agent simulant DMMP reactive adsorption on $\mathrm{TiO}_{2}$ /graphene oxide composites prepared via titanium peroxo-complex or urea precipitation. J. Hazard. Mater 2018, 359, 482-490, DOI: 10.1016/j.jhazmat.2018.07.095 [PubMed: 30075367]

56. Essner JB; Laber CH; Baker GA Carbon dot reduced bimetallic nanoparticles: Size and surface plasmon resonance tunability for enhanced catalytic applications. J. Mater. Chem. A 2015, 3 (31), 16354-16360, DOI: 10.1039/C5TA02949J

57. Li Y; Wang J; Yang Y; Zhang Y; He D; An Q; Cao G Seed-induced growing various $\mathrm{TiO}_{2}$ nanostructures on $\mathrm{g}-\mathrm{C}_{3} \mathrm{~N}_{4}$ nanosheets with much enhanced photocatalytic activity under visible light. J. Hazard. Mater 2015, 292, 79-89, DOI: 10.1016/j.jhazmat.2015.03.006 [PubMed: 25797926]

58. Ma Y; Li X; Yang Z; Xu S; Zhang W; Su Y; Hu N; Lu W; Feng J; Zhang Y Morphology control and photocatalysis enhancement by in situ hybridization of cuprous oxide with nitrogen-doped carbon quantum dots. Langmuir 2016, 32 (27), 9418-9427, DOI: 10.1021/acs.langmuir.6b02011 [PubMed: 27571475]

59. Bai S; Wang X; Hu C; Xie M; Jiang J; Xiong Y Two-dimensional g- $\mathrm{C}_{3} \mathrm{~N}_{4}$ : An ideal platform for examining facet selectivity of metal co-catalysts in photocatalysis. Chem. Commun 2014, 50 (46), 6094-6097, DOI: 10.1039/C4CC00745J

60. Gu L; Wang J; Zou Z; Han X Graphitic- $\mathrm{C}_{3} \mathrm{~N}_{4}$-hybridized $\mathrm{TiO}_{2}$ nanosheets with reactive $\{001\}$ facets to enhance the UV- and visible-light photocatalytic activity. J. Hazard. Mater 2014, 268, 216-223, DOI: 10.1016/j.jhazmat.2014.01.021 [PubMed: 24509092]

61. Lei Y; Yang C; Hou J; Wang F; Min S; Ma X; Jin Z; Xu J; Lu G; Huang KW Strongly coupled $\mathrm{CdS} / g r a p h e n e$ quantum dots nanohybrids for highly efficient photocatalytic hydrogen evolution: Unraveling the essential roles of graphene quantum dots. Appl. Catal., B 2017, 216, 59-69, DOI: 10.1016/j.apcatb.2017.05.063

62. Li H; Liu R; Liu Y; Huang H; Yu H; Ming H; Lian S; Lee ST; Kang Z Carbon quantum dots/Cu $2 \mathrm{O}$ composites with protruding nanostructures and their highly efficient (near) infrared photocatalytic behavior. J. Mater. Chem 2012, 22 (34), 17470-17475, DOI: 10.1039/c2jm32827e

63. Tian J; Leng Y; Zhao Z; Xia Y; Sang Y; Hao P; Zhan J; Li M; Liu H Carbon quantum dots/ hydrogenated $\mathrm{TiO}_{2}$ nanobelt heterostructures and their broad spectrum photocatalytic properties under UV, visible, and near-infrared irradiation. Nano Energy 2015, 11, 419-427, DOI: 10.1016/ j.nanoen.2014.10.025

64. Zhang J; Liu X; Wang X; Mu L; Yuan M; Liu B; Shi H Carbon dots-decorated $\mathrm{Na}_{2} \mathrm{~W}_{4} \mathrm{O}_{13}$ composite with $\mathrm{WO}_{3}$ for highly efficient photocatalytic antibacterial activity. J. Hazard. Mater 2018, 359, 1-8, DOI: 10.1016/j.jhazmat.2018.06.072 [PubMed: 30007199]

65. Choi H; Ko SJ; Choi Y; Joo P; Kim T; Lee BR; Jung JW; Choi HJ; Cha M; Jeong JR; Hwang IW; Song MH; Kim BS; Kim JY Versatile surface plasmon resonance of carbon-dot-supported silver nanoparticles in polymer optoelectronic devices. Nat. Photonics 2013, 7, 732-738, DOI: 10.1038/ nphoton.2013.181

66. Dey D; Bhattacharya T; Majumdar B; Mandani S; Sharwati B; Sarma TK Carbon dot reduced palladium nanoparticles as active catalysts for carbon-carbon bond formation. Dalton Trans 2013, 42 (38), 13821-13825, DOI: 10.1039/c3dt51234g [PubMed: 23958940]

67. Hasani A; Tekalgne M; Le QV; Jang HW; Kim SY Two-dimensional materials as catalysts for solar fuels: Hydrogen evolution reaction and $\mathrm{CO}_{2}$ reduction. J. Mater. Chem. A 2019, 7 (2), 430 454, DOI: $10.1039 / \mathrm{C} 8 \mathrm{TA} 09496 \mathrm{~A}$

68. Aich N; Masud A; Sabo-Attwood T; Plazas-Tuttle J; Saleh NB Dimensional variations in nanohybrids: Property alterations, applications, and considerations for toxicological implications In Anisotropic and Shape-Selective Nanomaterials. Nanostructure Science and Technology; Hunyadi Murph S, Larsen G, Coopersmith K, Eds.; Springer: Cham, Switzerland, 2017; pp 271291. 
69. Georgiou T; Jalil R; Belle BD; Britnell L; Gorbachev RV; Morozov SV; Kim YJ; Gholinia A; Haigh SJ; Makarovsky O; Eaves L; Ponomarenko LA; Geim AK; Novoselov KS; Mishchenko A Vertical field-effect transistor based on graphene- $\mathrm{WS}_{2}$ heterostructures for flexible and transparent electronics. Nat. Nanotechnol 2013, 8 (2), 100-103, DOI: 10.1038/nnano.2012.224 [PubMed: 23263726]

70. Yu WJ; Liu Y; Zhou H; Yin A; Li Z; Huang Y; Duan X Highly efficient gate-tunable photocurrent generation in vertical heterostructures of layered materials. Nat. Nanotechnol 2013, 8 (12), 952958, DOI: 10.1038/nnano.2013.219 [PubMed: 24162001]

71. Lonkar SP; Pillai VV; Alhassan SM Three-dimensional NiS-MoS2/graphene heterostructured nanohybrids as high-performance hydrodesulfurization catalysts. ACS Appl. Nano Mater 2018, 1 (7), 3114-3123, DOI: 10.1021/acsanm.8b00287

72. Yang K; Wang J; Chen X; Zhao Q; Ghaffar A; Chen B Application of graphene-based materials in water purification: From the nanoscale to specific devices. Environ. Sci.: Nano 2018, 5 (6), 1264 1297, DOI: 10.1039/C8EN00194D

73. Fu J; Chang B; Tian Y; Xi F; Dong X Novel $\mathrm{C}_{3} \mathrm{~N}_{4}-\mathrm{CdS}$ composite photocatalysts with organicinorganic heterojunctions: In situ synthesis, exceptional activity, high stability and photocatalytic mechanism. J. Mater. Chem. A 2013, 1 (9), 3083-3090, DOI: 10.1039/c2ta00672c

74. Bian J; Huang C; Wang L; Hung TF; Daoud WA; Zhang R Carbon dot loading and $\mathrm{TiO}_{2}$ nanorod length dependence of photoelectrochemical properties in carbon dot $/ \mathrm{TiO}_{2}$ nanorod array nanocomposites. ACS Appl. Mater. Interfaces 2014, 6 (7), 4883-4890, DOI: 10.1021/am4059183 [PubMed: 24601482]

75. Jiang T; Zhang L; Ji M; Wang Q; Zhao Q; Fu X; Yin H Carbon nanotubes/ $/ \mathrm{TiO}_{2}$ nanotubes composite photocatalysts for efficient degradation of methyl orange dye. Particuology 2013, 11 (6), 737-742, DOI: 10.1016/j.partic.2012.07.008

76. Liu G; Han K; Zhou Y; Ye H; Zhang X; Hu J; Li X Facile synthesis of highly dispersed Ag doped graphene oxide/titanate nanotubes as a visible light photocatalytic membrane for water treatment. ACS Sustainable Chem. Eng 2018, 6 (5), 6256-6263, DOI: 10.1021/acssuschemeng.8b00029

77. Hu X; Deng F; Huang W; Zeng G; Luo X; Dionysiou DD The band structure control of visiblelight-driven $\mathrm{rGO} / \mathrm{ZnS}-\mathrm{MoS}_{2}$ for excellent photocatalytic degradation performance and long-term stability. Chem. Eng. J 2018, 350, 248-256, DOI: 10.1016/j.cej.2018.05.182

78. Eder D Carbon nanotube-inorganic hybrids. Chem. Rev 2010, 110 (3), 1348-1385, DOI: 10.1021/ cr800433k [PubMed: 20108978]

79. Eder D Carbon nanotube-inorganic hybrids. Chem. Rev 2010, 110 (3), 1348-1385, DOI: 10.1021/ cr800433k [PubMed: 20108978]

80. Awfa D; Ateia M; Fujii M; Johnson MS; Yoshimura C Photodegradation of pharmaceuticals and personal care products in water treatment using carbonaceous- $\mathrm{TiO}_{2}$ composites: A critical review of recent literature. Water Res. 2018, 142, 26-45, DOI: 10.1016/j.watres.2018.05.036 [PubMed: 29859390]

81. Gangu KK; Maddila S; Jonnalagadda SB A review on novel composites of MWCNTs mediated semiconducting materials as photocatalysts in water treatment. Sci. Total Environ 2019, 646, 1398-1412, DOI: 10.1016/j.scitotenv.2018.07.375 [PubMed: 30235625]

82. Yi H; Huang D; Qin L; Zeng G; Lai C; Cheng M; Ye S; Song B; Ren X; Guo X Selective prepared carbon nanomaterials for advanced photocatalytic application in environmental pollutant treatment and hydrogen production. Appl. Catal., B 2018, 239, 408-424, DOI: 10.1016/j.apcatb.2018.07.068

83. Kim S; Park CM; Jang M; Son A; Her N; Yu M; Snyder S; Kim DH; Yoon Y Aqueous removal of inorganic and organic contaminants by graphene-based nanoadsorbents: A review. Chemosphere 2018, 212, 1104-1124, DOI: 10.1016/j.chemosphere.2018.09.033 [PubMed: 30286540]

84. Upadhyay RKSN; Roy SS Role of graphene/metal oxide composites as photocatalysts, adsorbents and disinfectants in water treatment: A review. RSC Adv. 2018, 4 (5), 3823-3851, DOI: 10.1039/ C3RA45013A

85. Fu J; Yu J; Jiang C; Cheng B g- $\mathrm{C}_{3} \mathrm{~N}_{4}$-based heterostructured photocatalysts. Adv. Energy Mater 2018, 8 (3), 1701503, DOI: 10.1002/aenm.201701503 
86. Jiang L; Yuan X; Zeng G; Liang J; Wu Z; Wang H Construction of an all-solid-state Z-scheme photocatalyst based on graphite carbon nitride and its enhancement to catalytic activity. Environ. Sci.: Nano 2018, 5 (3), 599-615, DOI: 10.1039/C7EN01031A

87. Xie G; Zhang K; Guo B; Liu Q; Fang L; Gong JR Graphene-based materials for hydrogen generation from light-driven water splitting. Adv. Mater 2013, 25 (28), 3820-3839, DOI: 10.1002/ adma.201301207 [PubMed: 23813606]

88. Wang X; Maeda K; Thomas A; Takanabe K; Xin G; Carlsson JM; Domen K; Antonietti M A metal-free polymeric photocatalyst for hydrogen production from water under visible light. Nat. Mater 2009, 8 (1), 76-80, DOI: 10.1038/nmat2317 [PubMed: 18997776]

89. Luo Y; Deng B; Pu Y; Liu A; Wang J; Ma K; Gao F; Gao B; Zou W; Dong L Interfacial coupling effects in $\mathrm{g}-\mathrm{C}_{3} \mathrm{~N}_{4} / \mathrm{SrTiO}_{3}$ nanocomposites with enhanced $\mathrm{H}_{2}$ evolution under visible light irradiation. Appl. Catal., B 2019, 247, 1-9, DOI: 10.1016/j.apcatb.2019.01.089

90. Zhou Z; Zhang Y; Shen Y; Liu S; Zhang Y Molecular engineering of polymeric carbon nitride: Advancing applications from photocatalysis to biosensing and more. Chem. Soc. Rev 2018, 47 (7), 2298-2321, DOI: 10.1039/C7CS00840F [PubMed: 29517786]

91. She X; Wu J; Xu H; Zhong J; Wang Y; Song Y; Nie K; Liu Y; Yang Y; Rodrigues MTF; Vajtal R; Lou J; Du D; Li H; Ajayan PM High efficiency photocatalytic water splitting using 2D a$\mathrm{Fe}_{2} \mathrm{O}_{3} / g-\mathrm{C}_{3} \mathrm{~N}_{4} \mathrm{Z}$-scheme catalysts. Adv. Energy Mater 2017, 7 (17), 1700025, DOI: $10.1002 /$ aenm.201700025

92. Samanta S; Martha S; Parida K Facile synthesis of $\mathrm{Au} / \mathrm{g}-\mathrm{C}_{3} \mathrm{~N}_{4}$ nanocomposites: An inorganic/ organic hybrid plasmonic photocatalyst with enhanced hydrogen gas evolution under visible-light irradiation. ChemCatChem 2014, 6 (5), 1453-1462, DOI: 10.1002/cctc.201300949

93. Linic S; Christopher P; Ingram DB Plasmonic-metal nanostructures for efficient conversion of solar to chemical energy. Nat. Mater 2011, 10 (12), 911-921, DOI: 10.1038/nmat3151 [PubMed: 22109608]

94. Chen J; Dong CL; Du Y; Zhao D; Shen S Nanogap engineered plasmon-enhancement in photocatalytic solar hydrogen conversion. Adv. Mater. Interfaces 2015, 2 (14), 1500280, DOI: 10.1002/admi.201500280

95. Zou Y; Shi JW; Ma D; Fan Z; Niu C; Wang L Fabrication of g- $\mathrm{C}_{3} \mathrm{~N}_{4} / \mathrm{Au} / \mathrm{C}-\mathrm{TiO}_{2}$ hollow structures as visible-light-driven $\mathrm{Z}$-scheme photocatalysts with enhanced photocatalytic $\mathrm{H}_{2}$ evolution. ChemCatChem 2017, 9 (19), 3752-3761, DOI: 10.1002/cctc.201700542

96. Li W; Feng C; Dai S; Yue J; Hua F; Hou H Fabrication of sulfur-doped g- $\mathrm{C}_{3} \mathrm{~N}_{4} / \mathrm{Au} / \mathrm{CdS} \mathrm{Z}$-scheme photocatalyst to improve the photocatalytic performance under visible light. Appl. Catal., B 2015, 168-169, 465-471, DOI: 10.1016/j.apcatb.2015.01.012

97. Ding X; Li Y; Zhao J; Zhu Y; Li Y; Deng W; Wang C Enhanced photocatalytic H2 evolution over $\mathrm{CdS} / \mathrm{Au} / \mathrm{g}-\mathrm{C}_{3} \mathrm{~N}_{4}$ composite photocatalyst under visible-light irradiation. APL Mater. 2015, 3, 104410, DOI: 10.1063/1.4926935

98. Liu W; Shen J; Yang X; Liu Q; Tang H Dual Z-scheme g- $\mathrm{C}_{3} \mathrm{~N}_{4} / \mathrm{Ag}_{3} \mathrm{PO}_{4} / \mathrm{Ag}_{2} \mathrm{MoO}_{4}$ ternary composite photocatalyst for solar oxygen evolution from water splitting. Appl. Surf. Sci 2018, 456, 369-378, DOI: 10.1016/j.apsusc.2018.06.156

99. Li Y; Lv K; Ho W; Dong F; Wu X; Xia Y Hybridization of rutile $\mathrm{TiO}_{2}\left(\mathrm{rTiO}_{2}\right)$ with $\mathrm{g}_{-} \mathrm{C}_{3} \mathrm{~N}_{4}$ quantum dots (CN QDs): An efficient visible-light-driven Z-scheme hybridized photocatalyst. Appl. Catal., B 2017, 202, 611-619, DOI: 10.1016/j.apcatb.2016.09.055

100. Kim SR; Jo WK Application of a photostable silver-assisted Z-scheme $\mathrm{NiTiO}_{3}$ nanorod/g- $\mathrm{C}_{3} \mathrm{~N}_{4}$ nanocomposite for efficient hydrogen generation. Int. J. Hydrogen Energy 2019, 44 (2), 801-808, DOI: 10.1016/j.ijhydene.2018.11.014

101. Wang CC; Yi XH; Wang P Powerful combination of MOFs and $\mathrm{C}_{3} \mathrm{~N}_{4}$ for enhanced photocatalytic performance. Appl. Catal., B 2019, 247, 24-48, DOI: 10.1016/j.apcatb.2019.01.091

102. Tian L; Yang X; Liu Q; Qu F; Tang H Anchoring metal-organic framework nanoparticles on graphitic carbon nitrides for solar-driven photocatalytic hydrogen evolution. Appl. Surf. Sci 2018, 455, 403-409, DOI: 10.1016/j.apsusc.2018.06.014

103. Wang R; Gu L; Zhou J; Liu X; Teng F; Li C; Shen Y; Yuan Y Quasi-polymeric metal-organic framework UiO-66/g- $\mathrm{C}_{3} \mathrm{~N}_{4}$ heterojunctions for enhanced photocatalytic hydrogen evolution 
under visible light irradiation. Adv. Mater. Interfaces 2015, 2 (10), 1500037, DOI: 10.1002/ admi.201500037

104. Bai C; Bi J; Wu J; Meng H; Xu Y; Han Y; Zhang X Fabrication of noble-metal-free g- $\mathrm{C}_{3} \mathrm{~N}_{4}-$ MIL-53(Fe) composite for enhanced photocatalytic $\mathrm{H}_{2}$-generation performance. Appl. Organomet. Chem 2018, 32 (12), e4597, DOI: 10.1002/aoc.4597

105. Han C; Lu Y; Zhang J; Ge L; Li Y; Chen C; Xin Y; Wu L; Fang S Novel PtCo alloy nanoparticle decorated $2 \mathrm{D} \mathrm{g}-\mathrm{C}_{3} \mathrm{~N}_{4}$ nanosheets with enhanced photocatalytic activity for $\mathrm{H}_{2}$ evolution under visible light irradiation. J. Mater. Chem. A 2015, 3 (46), 23274-23282, DOI: 10.1039/ C5TA05370F

106. Han C; Wu L; Ge L; Li Y; Zhao Z AuPd bimetallic nanoparticles decorated graphitic carbon nitride for highly efficient reduction of water to $\mathrm{H}_{2}$ under visible light irradiation. Carbon 2015, 92, 31-40, DOI: 10.1016/j.carbon.2015.02.070

107. Zhang G; Lan ZA; Lin L; Lin S; Wang X Overall water splitting by Pt/g- $\mathrm{C}_{3} \mathrm{~N}_{4}$ photocatalysts without using sacrificial agents. Chem. Sci 2016, 7 (5), 3062-3066, DOI: 10.1039/C5SC04572J [PubMed: 29997797]

108. Jiao Y; Huang Q; Wang J; He Z; Li Z A novel $\mathrm{MoS}_{2}$ quantum dots (QDs) decorated Z-scheme g$\mathrm{C}_{3} \mathrm{~N}_{4}$ nanosheet/N-doped carbon dots heterostructure photocatalyst for photocatalytic hydrogen evolution. Appl. Catal., B 2019, 247, 124-132, DOI: 10.1016/j.apcatb.2019.01.073

109. Zhang X; Dong H; Sun XJ; Yang DD; Sheng JL; Tang HL; Meng XB; Zhang FM Step-by-step improving photocatalytic hydrogen evolution activity of $\mathrm{NH}_{2}-\mathrm{UiO}-66$ by constructing heterojunction and encapsulating carbon nanodots. ACS Sustainable Chem. Eng 2018, 6 (9), 11563-11569, DOI: 10.1021/acssuschemeng.8b01740

110. Han M; Zhu S; Lu S; Song Y; Feng T; Tao S; Liu J; Yang B Recent progress on the photocatalysis of carbon dots: Classification, mechanism and applications. Nano Today 2018, 19, 201-208, DOI: 10.1016/j.nantod.2018.02.008

111. Wang WH; Himeda Y; Muckerman JT; Manbeck GF; Fujita $\mathrm{E} \mathrm{CO}_{2}$ hydrogenation to formate and methanol as an alternative to photo- and electrochemical $\mathrm{CO}_{2}$ reduction. Chem. Rev 2015, 115 (23), 12936-12973, DOI: 10.1021/acs.chemrev.5b00197 [PubMed: 26335851]

112. Chang $\mathrm{X}$; Wang $\mathrm{T}$; Gong $\mathrm{J} \mathrm{CO}_{2}$ photo-reduction: Insights into $\mathrm{CO}_{2}$ activation and reaction on surfaces of photocatalysts. Energy Environ. Sci 2016, 9 (7), 2177-2196, DOI: 10.1039/ C6EE00383D

113. Zhou J; Chen W; Sun C; Han L; Qin C; Chen M; Wang X; Wang E; Su Z Oxidative polyoxometalates modified graphitic carbon nitride for visible-light $\mathrm{CO}_{2}$ reduction. ACS Appl. Mater. Interfaces 2017, 9 (13), 11689-11695, DOI: 10.1021/acsami.7b01721 [PubMed: 28339181]

114. He Y; Zhang L; Fan M; Wang X; Walbridge ML; Nong Q; Wu Y; Zhao L Z-scheme $\mathrm{SnO}_{2-\mathrm{x}} / \mathrm{g}$ $\mathrm{C}_{3} \mathrm{~N}_{4}$ composite as an efficient photocatalyst for dyedegradation and photocatalytic $\mathrm{CO}_{2}$ reduction. Sol. Energy Mater. Sol. Cells 2015, 137, 175-184, DOI: 10.1016/j.solmat.2015.01.037

115. He Y; Zhang L; Teng B; Fan M New application of Z-scheme $\mathrm{Ag}_{3} \mathrm{PO}_{4} / g-\mathrm{C}_{3} \mathrm{~N}_{4}$ composite in converting $\mathrm{CO}_{2}$ to fuel. Environ. Sci. Technol 2015, 49 (1), 649-656, DOI: 10.1021/es5046309 [PubMed: 25485763]

116. Li H; Gao Y; Wu X; Lee PH; Shih K Fabrication of heterostructured g- $\mathrm{C}_{3} \mathrm{~N}_{4} / \mathrm{Ag}-\mathrm{TiO}_{2}$ hybrid photocatalyst with enhanced performance in photocatalytic conversion of $\mathrm{CO}_{2}$ under simulated sunlight irradiation. Appl. Surf. Sci 2017, 402, 198-207, DOI: 10.1016/j.apsusc.2017.01.041

117. Bai Y; Chen T; Wang P; Wang L; Ye L; Shi X; Bai W Size-dependent role of gold in $\mathrm{g}_{-} \mathrm{C}_{3} \mathrm{~N}_{4} /$ $\mathrm{BiOBr} / \mathrm{Au}$ system for photocatalytic $\mathrm{CO}_{2}$ reduction and dye degradation. Sol. Energy Mater. Sol. Cells 2016, 157, 406-414, DOI: 10.1016/j.solmat.2016.07.001

118. Cao S; Li Y; Zhu B; Jaroniec M; Yu J Facet effect of Pd cocatalyst on photocatalytic $\mathrm{CO}_{2}$ reduction over g- $\mathrm{C}_{3} \mathrm{~N}_{4}$. J. Catal 2017, 349, 208-217, DOI: 10.1016/j.jcat.2017.02.005

119. Li H; Zhang X; MacFarlane DR Carbon quantum dots/ $\mathrm{Cu}_{2} \mathrm{O}$ heterostructures for solar-lightdriven conversion of $\mathrm{CO}_{2}$ to methanol. Adv. Energy Mater 2015, 5 (5), 1401077, DOI: 10.1002/ aenm.201401077 
120. Kong XY; Tan WL; Ng BJ; Chai SP; Mohamed AW Harnessing Vis-NIR broad spectrum for photocatalytic $\mathrm{CO}_{2}$ reduction over carbon quantum dots-decorated ultrathin Bi2WO6 nanosheets. Nano Res. 2017, 10 (5), 1720-1731, DOI: 10.1007/s12274-017-1435-4

121. Li M; Wang M; Zhu L; Li Y; Yan Z; Shen Z; Cao X Facile microwave assisted synthesis of N-rich carbon quantum dots/dual-phase $\mathrm{TiO}_{2}$ heterostructured nanocomposites with high activity in $\mathrm{CO}_{2}$ photoreduction. Appl. Catal., B 2018, 231, 269-276, DOI: 10.1016/j.apcatb.2018.03.027

122. Zhu C; Liu C; Fu Y; Gao J; Huang H; Liu Y; Kang Z Construction of CDs/CdS photocatalysts for stable and efficient hydrogen production in water and seawater. Appl. Catal., B 2019, 242, 178 185, DOI: 10.1016/j.apcatb.2018.09.096

123. Lin LY; Kavadiya S; Karakocak BB; Nie Y; Raliya R; Wang ST; Berezin MY; Biswas P ZnO Zn $_{1}$ I carbon dots composite hollow spheres: Facile aerosol synthesis and superior $\mathrm{CO}_{2}$ photoreduction under UV, visible and near-infrared irradiation. Appl. Catal., B 2018, 230, 36-48, DOI: 10.1016/ j.apcatb.2018.02.018

124. Lv Y; Li J; Feng B; Liu P; Hao F; Xiong W; Luo H Multi-walled carbon nanotubes supported nickel nanoparticles doped with magnesia and copper for adiponitrile hydrogenation with high activity and chemoselectivity under mild conditions. Chem. Eng. J 2018, 346, 203-216, DOI: 10.1016/j.cej.2018.04.031

125. Lv Y; Li J; Feng B; Liu P; Hao F; Xiong W; Luo H Multi-walled carbon nanotubes supported nickel nanoparticles doped with magnesia and copper for adiponitrile hydrogenation with high activity and chemoselectivity under mild conditions. Chem. Eng. J 2018, 346, 203-216, DOI: 10.1016/j.cej.2018.04.031

126. Mateo D; Albero J; Garcia H Graphene supported NiO/Ni nanoparticles as efficient photocatalyst for gas phase $\mathrm{CO}_{2}$ reduction with hydrogen. Appl. Catal., B 2018, 224, 563-571, DOI: 10.1016/ j.apcatb.2017.10.071

127. Romero-Sáez M; Dongil AB; Benito N; Espinoza-González R; Escalona N; Gracia $\mathrm{F} \mathrm{CO}_{2}$ methanation over nickel- $\mathrm{ZrO}_{2}$ catalyst supported on carbon nanotubes: A comparison between two impregnation strategies. Appl. Catal., B 2018, 237, 817-825, DOI: 10.1016/ j.apcatb.2018.06.045

128. Jung H; Cho KM; Kim KH; Yoo HW; Saggaf AA; Gereige I; Jung HT Highly efficient and stable $\mathrm{CO}_{2}$ reduction photocatalyst with a hierarchical structure of mesoporous $\mathrm{TiO}_{2}$ on $3 \mathrm{D}$ graphene with few-layered $\mathrm{MoS}_{2}$. ACS Sustainable Chem. Eng 2018, 6 (5), 5718-5724, DOI: 10.1021/ acssuschemeng.8b00002

129. Zhao Y; Wei Y; Wu X; Zheng H; Zhao Z; Liu J; Li J Graphene-wrapped Pt/TiO 2 photocatalysts with enhanced photogenerated charges separation and reactant adsorption for high selective photoreduction of $\mathrm{CO}_{2}$ to $\mathrm{CH}_{4}$. Appl. Catal., B 2018, 226, 360-372, DOI: 10.1016/ j.apcatb.2017.12.071

130. Raziq F; Humayun M; Ali A; Wang T; Khan A; Fu Q; Wei L; Zeng H; Zheng Z; Khan B; Shen H; $\mathrm{Zu} \mathrm{X;} \mathrm{Li} \mathrm{S;} \mathrm{Qiao} \mathrm{L} \mathrm{Synthesis} \mathrm{of} \mathrm{S-doped} \mathrm{porous} \mathrm{g}-\mathrm{C}_{3} \mathrm{~N}_{4}$ by using ionic liquids and subsequently coupled with $\mathrm{Au}-\mathrm{TiO}_{2}$ for exceptional cocatalyst-free visible-light catalytic activities. Appl. Catal., B 2018, 237, 1082-1090, DOI: 10.1016/j.apcatb.2018.06.009

131. Yang J; Wen Z; Shen X; Dai J; Li Y; Li Y A comparative study on the photocatalytic behavior of graphene- $\mathrm{TiO}_{2}$ nanostructures: Effect of $\mathrm{TiO}_{2}$ dimensionality on interfacial charge transfer. Chem. Eng. J 2018, 334, 907-921, DOI: 10.1016/j.cej.2017.10.088

132. Guo S; Zhao S; Wu X; Li H; Zhou Y; Zhu C; Yang N; Jiang X; Gao J; Bai L; Liu Y; Lifshitz Y; Lee ST; Kang $\mathrm{Z} \mathrm{A} \mathrm{Co} 3 \mathrm{O}_{4}$-CDots- $\mathrm{C}_{3} \mathrm{~N}_{4}$ three component electrocatalyst design concept for efficient and tunable $\mathrm{CO}_{2}$ reduction to syngas. Nat. Commun 2017, 8, 1828, DOI: 10.1038/ s41467-017-01893-7 [PubMed: 29184053]

133. Sastre F; Munoz-Batista MJ; Kubacka A; Fernandez-Garcia M; Smith WA; Kapteijin M; Gascon J Efficient electrochemical production of syngas from $\mathrm{CO}_{2}$ and $\mathrm{H}_{2} \mathrm{O}$ by using a nanostructured $\mathrm{Ag} / \mathrm{g}-\mathrm{C}_{3} \mathrm{~N}_{4}$ catalyst. ChemElectroChem 2016, 3 (9), 1497-1502, DOI: 10.1002/celc.201600392

134. Chen D; Tang L; Li J Graphene-based materials in electrochemistry. Chem. Soc. Rev 2010, 39 (8), 3157-3180, DOI: 10.1039/b923596e [PubMed: 20589275]

135. Sun M; Liu H; Liu Y; Qu J; Li J Graphene-based transition metal oxide nanocomposites for the oxygen reduction reaction. Nanoscale 2015, 7 (4), 1250-1269, DOI: 10.1039/C4NR05838K [PubMed: 25502117] 
136. Zheng Y; Jiao Y; Qiao SZ Engineering of carbon-based electrocatalysts for emerging energy conversion: From fundamentality to functionality. Adv. Mater 2015, 27 (36), 5372-5378, DOI: 10.1002/adma.201500821 [PubMed: 26174510]

137. Jin H; Guo C; Liu X; Liu J; Vasileff A; Jiao Y; Zheng Y; Qiao SZ Emerging two-dimensional nanomaterials for electrocatalysis. Chem. Rev 2018, 118 (13), 6337-6408, DOI: 10.1021/ acs.chemrev.7b00689 [PubMed: 29552883]

138. Xia BY; Yan Y; Li N; Wu HB; Lou XW; Wang X A metal-organic framework-derived bifunctional oxygen electrocatalyst. Nat. Energy 2016, 1, 15006, DOI: 10.1038/nenergy.2015.6

139. Murgolo S; Petronella F; Ciannarella R; Comparelli R; Agostiano A; Curri ML; Mascolo G UV and solar-based photocatalytic degradation of organic pollutants by nano-sized $\mathrm{TiO}_{2}$ grown on carbon nanotubes. Catal. Today 2015, 240, 114-124, DOI: 10.1016/j.cattod.2014.04.021

140. Kim MJ; Ko D; Ko K; Kim D; Lee JY; Woo SM; Kim W; Chung H Effects of silver-graphene oxide nanocomposites on soil microbial communities. J. Hazard. Mater 2018, 346, 93-102, DOI: 10.1016/j.jhazmat.2017.11.032 [PubMed: 29248800]

141. Yang X; Cai H; Bao M; Yu J; Lu J; Li Y Insight into the highly efficient degradation of PAHs in water over graphene oxide/ $\mathrm{Ag}_{3} \mathrm{PO}_{4}$ composites under visible light irradiation. Chem. Eng. $\mathrm{J}$ 2018, 334, 355- 376, DOI: 10.1016/j.cej.2017.09.104

142. Bhat SA; Rashid N; Rather MA; Pandit SA; Rather GM; Ingole PP; Bhat MA PdAg bimetallic nanoalloy-decorated graphene: A nanohybrid with unprecedented electrocatalytic, catalytic, and sensing activities. ACS Appl. Mater. Interfaces 2018, 10 (19), 16376-16389, DOI: 10.1021/ acsami.8b00510 [PubMed: 29658695]

143. Park CM; Heo J; Wang D; Su C; Yoon Y Heterogeneous activation of persulfate by reduced graphene oxide-elemental silver/magnetite nanohybrids for the oxidative degradation of pharmaceuticals and endocrine disrupting compounds in water. Appl. Catal., B 2018, 225, 91-99, DOI: 10.1016/j.apcatb.2017.11.058 [PubMed: 32704206]

144. Ghobadi M; Gharabaghi M; Abdollahi H; Boroumand Z; Moradian $\mathrm{M} \mathrm{MnFe}_{2} \mathrm{O}_{4}$-graphene oxide magnetic nanoparticles as a high-performance adsorbent for rare earth elements: Synthesis, isotherms, kinetics, thermodynamics and desorption. J. Hazard. Mater 2018, 351, 308-316, DOI: 10.1016/j.jhazmat.2018.03.011 [PubMed: 29554528]

145. Di J; Xia J; Ji M; Wang B; Li X; Zhang Q; Chen Z; Li H Nitrogen-doped carbon quantum dots/ BiOBr ultrathin nanosheets: In situ strong coupling and improved molecular oxygen activation ability under visible light irradiation. ACS Sustainable Chem. Eng 2016, 4 (1), 136-146, DOI: 10.1021/acssuschemeng.5b00862

146. Khan ME; Han TH; Khan MM; Karim MR; Cho MH Environmentally sustainable fabrication of $\mathrm{Ag} @ \mathrm{~g}-\mathrm{C}_{3} \mathrm{~N}_{4}$ nanostructures and their multifunctional efficacy as antibacterial agents and photocatalysts. ACS Appl. Nano Mater 2018, 1 (6), 2912-2922, DOI: 10.1021/acsanm.8b00548

147. Zhang C; Li Y; Shuai D; Shen Y; Xiong W; Wang L Graphitic carbon nitride $\left(\mathrm{g}_{-} \mathrm{C}_{3} \mathrm{~N}_{4}\right)$-based photocatalysts for water disinfection and microbial control: A review. Chemosphere 2019, 214, 462-479, DOI: 10.1016/j.chemosphere.2018.09.137 [PubMed: 30273880]

148. Anand A; Unnikrishnan B; Wei SC; Chou CP; Zhang LZ; Huang CC Graphene oxide and carbon dots as broad-spectrum antimicrobial agents - A minireview. Nanoscale Horiz 2019, 4 (1), 117 137, DOI: 10.1039/C8NH00174J [PubMed: 32254148]

149. Plazas-Tuttle J; Das D; Sabaraya IV; Saleh NB Harnessing the power of microwaves for inactivating Pseudomonas aeruginosa with nanohybrids. Environ. Sci.: Nano 2018, 5 (1), 72-82, DOI: $10.1039 / \mathrm{C} 7 \mathrm{EN} 00702 \mathrm{G}$

150. Gomez-Pastora J; Dominguez S; Bringas E; Rivero MJ; Ortiz I; Dionysiou DD Review and perspectives on the use of magnetic nanophotocatalysts (MNPCs) in water treatment. Chem. Eng. J 2017, 310, 407-427, DOI: 10.1016/j.cej.2016.04.140

151. Mousavi M; Habibi-Yangjeh A; Pouran SR Review on magnetically separable graphitic carbon nitride-based nanocomposites as promising visible-light-driven photocatalysts. J. Mater. Sci.: Mater. Electron 2018, 29 (3), 1719-1747, DOI: 10.1007/s10854-017-8166-x

152. Gamshadzehi E; Nassiri M; Ershadifar H One-pot synthesis of microporous $\mathrm{Fe}_{2} \mathrm{O}_{3} / g-\mathrm{C}_{3} \mathrm{~N}_{4}$ and its application for efficient removal of phosphate from sewage and polluted seawater. Colloids Surf., A 2019, 567, 7-15, DOI: 10.1016/j.colsurfa.2019.01.029 
153. Mady AH; Baynosa ML; Tuma D; Shim JJ Heterogeneous activation of peroxymonosulfate by a novel magnetic 3D $\gamma-\mathrm{MnO}_{2} @ \mathrm{ZnFe}_{2} \mathrm{O}_{4} / \mathrm{rGO}$ nanohybrid as a robust catalyst for phenol degradation. Appl. Catal., B 2019, 244, 946-956, DOI: 10.1016/j.apcatb.2018.11.086

154. Wang F; Yu X; Ge M; Wu S; Guan J; Tang J; Wu X; Ritchie RO Facile self-assembly synthesis of $\gamma-\mathrm{Fe}_{2} \mathrm{O}_{3}$ /graphene oxide for enhanced photo-Fenton reaction. Environ. Pollut 2019, 248, $229-$ 237, DOI: 10.1016/j.envpol.2019.01.018 [PubMed: 30798024]

155. Xin X; Li SH; Zhang N; Tang ZR; Xu YJ 3D graphene/AgBr/Ag cascade aerogel for efficient photocatalytic disinfection. Appl. Catal., B 2019, 245, 343-350, DOI: 10.1016/ j.apcatb.2018.12.066

156. Qiao B; Wang A; Yang X; Allard LF; Jiang Z; Cui Y; Liu J; Li J; Zhang T Single-atom catalysis of CO oxidation using Pt1/FeOx. Nat. Chem 2011, 3, 634-641, DOI: 10.1038/nchem.1095 [PubMed: 21778984]

157. Xi J; Sun H; Wang D; Zhang Z; Duan X; Xiao J; Xiao F; Liu L; Wang S Confined-interfacedirected synthesis of Palladium single-atom catalysts on graphene/amorphous carbon. Appl. Catal., B 2018, 225, 291-297, DOI: 10.1016/j.apcatb.2017.11.057

158. Xu S; Zhu H; Cao W; Wen Z; Wang J; François-Xavier CP; Wintgens $\mathrm{T} \mathrm{Cu}-\mathrm{Al}_{2} \mathrm{O}_{3}-\mathrm{g}_{-} \mathrm{C}_{3} \mathrm{~N}_{4}$ and $\mathrm{Cu}-\mathrm{Al}_{2} \mathrm{O}_{3}$-C-dots with dual-reaction centres for simultaneous enhancement of Fenton-like catalytic activity and selective $\mathrm{H}_{2} \mathrm{O}_{2}$ conversion to hydroxyl radicals. Appl. Catal., B 2018, 234, 223-233, DOI: 10.1016/j.apcatb.2018.04.029

159. Jo WK; Tonda S Novel CoAl-LDH/g- $\mathrm{C}_{3} \mathrm{~N}_{4} / \mathrm{RGO}$ ternary heterojunction with notable $2 \mathrm{D} / 2 \mathrm{D} / 2 \mathrm{D}$ configuration for highly efficient visible-light-induced photocatalytic elimination of dye and antibiotic pollutants. J. Hazard. Mater 2019, 368, 778-787, DOI: 10.1016/j.jhazmat.2019.01.114 [PubMed: 30739031]

160. Yuan YJ; Shen Z; Wu S; Su Y; Pei L; Ji Z; Ding M; Bai W; Chen Y; Yu ZT; Zou Z Liquid exfoliation of $g-\mathrm{C}_{3} \mathrm{~N}_{4}$ nanosheets to construct $2 \mathrm{D}-2 \mathrm{D} \mathrm{MoS}_{2} / \mathrm{g}-\mathrm{C}_{3} \mathrm{~N}_{4}$ photocatalyst for enhanced photocatalytic $\mathrm{H}_{2}$ production activity. Appl. Catal., B 2019, 246, 120-128, DOI: 10.1016/ j.apcatb.2019.01.043

161. Hazarika D; Karak N Photocatalytic degradation of organic contaminants under solar light using carbon dot/titanium dioxide nanohybrid, obtained through a facile approach. Appl. Surf. Sci 2016, 376, 276-285, DOI: 10.1016/j.apsusc.2016.03.165

162. Elimelech M; Phillip WA The future of seawater desalination: Energy, technology, and the environment. Science 2011, 333 (6043), 712-717, DOI: 10.1126/science.1200488 [PubMed: 21817042]

163. Logan BE; Elimelech M Membrane-based processes for sustainable power generation using water. Nature 2012, 488 (7411), 313-319, DOI: 10.1038/nature11477 [PubMed: 22895336]

164. Werber JR; Osuji CO; Elimelech M Materials for next-generation desalination and water purification membranes. Nat. Rev. Mater 2016, 1, 16018, DOI: 10.1038/natrevmats.2016.18

165. Ali S; Rehman SA; Luan HY; Farid MU; Huang H Challenges and opportunities in functional carbon nanotubes for membrane-based water treatment and desalination. Sci. Total Environ 2019, 646, 1126-1139, DOI: 10.1016/j.scitotenv.2018.07.348 [PubMed: 30235599]

166. Song N; Gao X; Ma Z; Wang X; Wei Y; Gao G A review of graphene-based separation membrane: Materials, characteristics, preparation and applications. Desalination 2018, 437, 5972, DOI: 10.1016/j.desal.2018.02.024

167. Wang X; Zhao Y; Tian E; Li J; Ren Y Graphene oxide-based polymeric membranes for water treatment. Adv. Mater. Interfaces 2018, 5 (15), 1701427, DOI: 10.1002/admi.201701427

168. Shaban M; Ashraf AM; AbdAllah H; Abd El-Salam HM Titanium dioxide nanoribbons/multiwalled carbon nanotube nanocomposite blended polyethersulfone membrane for brackish water desalination. Desalination 2018, 444, 129-141, DOI: 10.1016/j.desal.2018.07.006

169. Yu L; Zhou W; Li Y; Zhou Q; Xu H; Gao B; Wang Z Antibacterial thin film nanocomposite membranes incorporated with graphene oxide quantum dot mediated silver nanoparticle for reverse osmosis application. ACS Sustainable Chem. Eng 2019, 7 (9), 8724-8734, DOI: 10.1021/ acssuschemeng.9b00598 
170. Armendariz-Ontiveros MM; Garcia AG; de los Santos Villalobo S; Weihs GAF. Biofouling performance of RO membranes coated with Iron NPs on graphene oxide. Desalination 2019, 451, 45-58, DOI: 10.1016/j.desal.2018.07.005

171. Zhang X; Shen L; Guan CY; Liu CX; Lang WZ; Wang Y Construction of $\mathrm{SiO}_{2} @ \mathrm{MWNTs}$ incorporated PVDF substrate for reducing internal concentration polarization in forward osmosis. J. Membr. Sci 2018, 564, 328-341, DOI: 10.1016/j.memsci.2018.07.043

172. Firouzjaei MD; Shamsabadi AA; Aktij SA; Seyedpour SF; Gh MS; Rahimpour A; Esfahani MR; Ulbricht M; Soroush M Exploiting synergetic effects of graphene oxide and a silver-based metalorganic framework to enhance antifouling and anti-biofouling properties of thin-film nanocomposite membranes. ACS Appl. Mater. Interfaces 2018, 10 (49), 42967-42978, DOI: 10.1021/acsami.8b12714 [PubMed: 30411881]

173. Mao H; Qiu M; Chen X; Verweij H; Fan Y Fabrication and in-situ fouling mitigation of a supported carbon nanotube/gamma-alumina ultrafiltration membrane. J. Membr. Sci 2018, 550, 26-35, DOI: 10.1016/j.memsci.2017.12.050

174. Xu H; Ding M; Chen W; Li Y; Wang K Nitrogen-doped GO/TiO 2 nanocomposite ultrafiltration membranes for improved photocatalytic performance. Sep. Purif. Technol 2018, 195, 70-82, DOI: 10.1016/j.seppur.2017.12.003

175. In JB; Cho KR; Tran TX; Kim SM; Wang YM; Grigoropoulos CP; Noy A; Fornasiero F Effect of enhanced thermal stability of alumina support layer on growth of vertically aligned single-walled carbon nanotubes and their application in nanofiltration membranes. Nanoscale Res. Lett 2018, 13, 173, DOI: 10.1186/s11671-018-2585-3 [PubMed: 29882075]

176. Guan K; Zhao D; Zheng M; Shen J; Zhou G; Liu G; Jin W 3D nanoporous crystals enabled 2D channels in graphene membrane with enhanced water purification performance. J. Membr. Sci 2017, 542, 41-51, DOI: 10.1016/j.memsci.2017.07.055

177. Hu X; Yu Y; Zhou J; Wang Y; Liang J; Zhang X; Chang Q; Song L The improved oil/water separation performance of graphene oxide modified $\mathrm{Al}_{2} \mathrm{O}_{3}$ microfiltration membrane. J. Membr. Sci 2015, 476, 200-204, DOI: 10.1016/j.memsci.2014.11.043

178. Shi W; Zhou X; Li J; Meshot ER; Taylor AD; Hu S; Kim JH; Elimelech M; Plata DL Highperformance capacitive deionization via manganese oxide-coated, vertically aligned carbon nanotube. Environ. Sci. Technol. Lett 2018, 5 (11), 692-700, DOI: 10.1021/acs.estlett.8b00397

179. Vengatesan MR; Darawsheh IFF; Govindan B; Alhseinat E; Banat F Ag-Cu bimetallic nanoparticle decorated graphene nanocomposite as an effective anode material for hybrid capacitive deionization (HCDI) system. Electrochim. Acta 2019, 297, 1052-1062, DOI: 10.1016/ j.electacta.2018.12.004

180. Guo L; Huang Y; Ding M; Leong ZY; Vafakhah S; Yang HY A high performance electrochemical deionization method to desalinate brackish water with an $\mathrm{FePO}_{4} / \mathrm{RGO}$ nanocomposite. J. Mater. Chem. A 2018, 6 (19), 8901-8908, DOI: 10.1039/C8TA01361F

181. Li Y; Zhu L Evaluation of the antifouling and photocatalytic properties of novel poly(vinylidene fluoride) membranes with a reduced graphene oxide-Bi2WO6 active layer. J. Appl. Polym. Sci 2017, 134 (42), 45426, DOI: 10.1002/app.45426

182. Yang H; Wang N; Wang L; Liu HX; An QF; Ji S Vacuum-assisted assembly of ZIF-8@GO composite membranes on ceramic tube with enhanced organic solvent nanofiltration performance. J. Membr. Sci 2018, 545, 158-166, DOI: 10.1016/j.memsci.2017.09.074

183. Zhang M; Guan K; Shen J; Liu G; Fan Y; Jin W Nanoparticles@ rGO membrane enabling highly enhanced water permeability and structural stability with preserved selectivity. AIChE J. 2017, 63 (11), 5054-5063, DOI: 10.1002/aic.15939

184. Jurgens B; Irran E; Senker J; Kroll P; Muller H; Schnick W Melem (2,5,8-Triamino-tri-striazine), an important intermediate during condensation of melamine rings to graphitic carbon nitride: Synthesis, structure determination by X-ray powder diffractometry, solid-state NMR, and theoretical studies. J. Am. Chem. Soc 2003, 125 (34), 10288-10300, DOI: 10.1021/ja0357689 [PubMed: 12926953]

185. Wu H; Gong Q; Olson DH; Li J Commensurate adsorption of hydrocarbons and alcohols in microporous metal organic frameworks. Chem. Rev 2012, 112 (2), 836-868, DOI: 10.1021/ cr200216x [PubMed: 22257090] 
186. Cui H; Yang L; Meng M; Zhang Q; Li B; Wu Y; Zhang Y; Lang J; Li C Facile preparation of antifouling $\mathrm{g}-\mathrm{C}_{3} \mathrm{~N}_{4} / \mathrm{Ag}_{3} \mathrm{PO}_{4}$ nanocomposite photocatalytic polyvinylidene fluoride membranes for effective removal of rhodamine B. Korean J. Chem. Eng 2019, 36 (2), 236-247, DOI: 10.1007/s11814-018-0207-5

187. Wang Y; Liu L; Hong J; Gao J; Deng C A novel Fe(OH) $3 / \mathrm{g}_{-} \mathrm{C}_{3} \mathrm{~N}_{4}$ composite membrane for high efficiency water purification. J. Membr. Sci 2018, 564, 372-381, DOI: 10.1016/ j.memsci.2018.07.027

188. Zhang Q; Chen S; Fan X; Zhang H; Yu H; Quan X A multifunctional graphene-based nanofiltration membrane under photo-assistance for enhanced water treatment based on layer-bylayer sieving. Appl. Catal., B 2018, 224, 204-213, DOI: 10.1016/j.apcatb.2017.10.016

189. Ghalamchi L; Aber S; Vatanpour V; Kian M A novel antibacterial mixed matrixed PES membrane fabricated from embedding aminated $\mathrm{Ag}_{3} \mathrm{PO}_{4} / \mathrm{g}-\mathrm{C}_{3} \mathrm{~N}_{4}$ nanocomposite for use in the membrane bioreactor. J. Ind. Eng. Chem 2019, 70, 412-426, DOI: 10.1016/j.jiec.2018.11.004

190. Zhang H; Cao J; Kang P; Tang Q; Sun Q; Ma M Ag nanocrystals decorated g- $\mathrm{C}_{3} \mathrm{~N}_{4} / \mathrm{Nafion}$ hybrid membranes: One-step synthesis and photocatalytic performance. Mater. Lett 2018, 213, 218-221, DOI: 10.1016/j.matlet.2017.11.068

191. Zhao DL; Chung TS Applications of carbon quantum dots (CQDs) in membrane technologies: A review. Water Res. 2018, 147, 43-49, DOI: 10.1016/j.watres.2018.09.040 [PubMed: 30296608]

192. Xie C; Fan T; Wang A; Chen SL Enhanced visible-light photocatalytic activity of a $\mathrm{TiO}_{2}$ membrane-asisted with $\mathrm{N}$-doped carbon quantum dots and $\mathrm{SiO}_{2}$ opal photonic crystal. Ind. Eng. Chem. Res 2019, 58 (1), 120-127, DOI: 10.1021/acs.iecr.8b05101

193. Wang Y; Xia Y Optical, electrochemical and catalytic methods for in-vitro diagnosis using carbonaceous nanoparticles: A review. Microchim. Acta 2019, 186, 50, DOI: 10.1007/ s00604-018-3110-1

194. Yang C; Denno ME; Pyakurel P; Venton BJ Recent trends in carbon nanomaterial-based electrochemical sensors for biomolecules: A review. Anal. Chim. Acta 2015, 887, 17-37, DOI: 10.1016/j.aca.2015.05.049 [PubMed: 26320782]

195. Wang DM; Lin KL; Huang CZ Carbon dots-involved chemiluminescence: Recent advances and developments. Luminescence 2019, 34, 4- 22, DOI: 10.1002/bio.3570 [PubMed: 30421859]

196. Zhu A; Qu Q; Shao X; Kong B; Tian Y Carbon-dot-based dual-emission nanohybrid produces a ratiometric fluorescent sensor for in vivo imaging of cellular copper ions. Angew. Chem., Int. Ed 2012, 51 (29), 7185-7189, DOI: 10.1002/anie.201109089

197. Shi L; Li Y; Rong X; Wang Y; Ding S Facile fabrication of a novel 3D graphene framework/Bi nanoparticle film for ultrasensitive electrochemical assays of heavy metal ions. Anal. Chim. Acta 2017, 968, 21-29, DOI: 10.1016/j.aca.2017.03.013 [PubMed: 28395771]

198. Liu ML; Chen BB; Yang T; Wang J; Liu XD; Huang CZ One-pot carbonization synthesis of europium-doped carbon quantum dots for highly selective detection of tetracycline. Methods Appl. Fluoresc 2017, 5 (1), 015003, DOI: 10.1088/2050-6120/aa5e2b [PubMed: 28248640]

199. Qian J; Yang Z; Wang C; Wang K; Liu Q; Jiang D; Yan Y; Wang K One-pot synthesis of BiPO4 functionalized reduced graphene oxide with enhanced photoelectrochemical performance for selective and sensitive detection of chlorpyrifos. J. Mater. Chem. A 2015, 3 (26), 13671-13678, DOI: 10.1039/C5TA02629F

200. Liu M; Ding X; Yang W; Wang Y; Zhao G; Yang N A pM leveled photoelectrochemical sensor for microcystin-LR based on surface molecularly imprinted $\mathrm{TiO}_{2} @ \mathrm{CNTs}$ nanostructure. J. Hazard. Mater 2017, 331, 309-320, DOI: 10.1016/j.jhazmat.2017.02.031 [PubMed: 28273581]

201. Gao Q; Han J; Ma Z Polyamidoamine dendrimers-capped carbon dots/Au nanocrystal nanocomposites and its application for electrochemical immunosensor. Biosens. Bioelectron 2013, 49, 323-328, DOI: 10.1016/j.bios.2013.05.048 [PubMed: 23792654]

202. Zhong D; Yang K; Wang Y; Yang X Dual-channel sensing strategy based on gold nanoparticles cooperating with carbon dots and hairpin structure for assaying RNA and DNA. Talanta 2017, 175, 217-223, DOI: 10.1016/j.talanta.2017.07.035 [PubMed: 28841982]

203. Wang L; Wang C; Hu X; Xue H; Pang H Metal/graphitic carbon nitride composites: Synthesis, structures, and applications. Chem. - Asian J 2016, 11, 3305-3328, DOI: 10.1002/ asia.201601178 [PubMed: 27717173] 
204. Dong Y; Wang Q; Wu H; Chen Y; Lu CH; Chi Y; Yang HH Graphitic carbon nitride materials: Sensing, imaging and therapy. Small 2016, 12 (39), 5376-5393, DOI: 10.1002/smll.201602056 [PubMed: 27611869]

205. Liu J; Wang H; Antonietti M Graphitic carbon nitride "reloaded": Emerging applications beyond (photo)catalysis. Chem. Soc. Rev 2016, 45 (8), 2308-2326, DOI: 10.1039/C5CS00767D [PubMed: 26864963]

206. Pang X; Bian H; Wang W; Liu C; Khan MS; Wang Q; Qi J; Wei Q; Du B A bio-chemical application of $\mathrm{N}-\mathrm{GQDs}$ and $\mathrm{g}-\mathrm{C}_{3} \mathrm{~N}_{4}$ QDs sensitized $\mathrm{TiO}_{2}$ nanopillars for the quantitative detection of pcDNA3-HBV. Biosens. Bioelectron 2017, 91, 456-464, DOI: 10.1016/ j.bios.2016.12.059 [PubMed: 28064131]

207. Dong YX; Cao JT; Wang B; Ma SH; Liu YM Exciton-plasmon Interactions between CdS@g$\mathrm{C}_{3} \mathrm{~N}_{4}$ heterojunction and $\mathrm{Au} @ \mathrm{Ag}$ nanoparticles coupled with DNAase-triggered signal amplification: Toward highly sensitive photoelectrochemical bioanalysis of MicroRNA. ACS Sustainable Chem. Eng 2017, 5 (11), 10840- 10848, DOI: 10.1021/acssuschemeng.7b02774

208. Wang H; Zhang Q; Yin H; Wang M; Jiang W; Ai S Photoelectrochemical immunosensor for methylated RNA detection based on $\mathrm{g}-\mathrm{C}_{3} \mathrm{~N}_{4} / \mathrm{CdS}$ quantum dots heterojunction and Phos-tagbiotin. Biosens. Bioelectron 2017, 95, 124-130, DOI: 10.1016/j.bios.2017.04.006 [PubMed: 28433859]

209. USEPA Cleaning Up the Nation's Waste Sites: Markets and Technology Trends, EPA 542-R-04015; Cincinnati, OH 9, 2004.

210. Phenrat T; Lowry GV Nanoscale Zerovalent Iron Particles for Environmental Restoration: From Fundamental Science to Field Scale Engineering Applications;Springer: Springer International Publishing: AG, Switzerland, 2019.

211. Wang D; Park CM; Masud A; Aich N; Su C Carboxymethylcellulose mediates the transport of carbon nanotube-magnetite nanohybrid aggregates in water-saturated porous media. Environ. Sci. Technol 2017, 51 (21), 12405-12415, DOI: 10.1021/acs.est.7b04037 [PubMed: 29037033]

212. Hua Z; Zhang J; Bai X; Ye Z; Tang Z; Liang L; Liu Y Aggregation of $\mathrm{TiO}_{2}$-graphene nanocomposites in aqueous environment: Influence of environmental factors and UV irradiation. Sci. Total Environ 2016, 539, 196-205, DOI: 10.1016/j.scitotenv.2015.08.143 [PubMed: 26360460]

213. Park CM; Wang D; Heo J; Her N; Su C Aggregation of reduced graphene oxide and its nanohybrids with magnetite and elemental silver under environmentally relevant conditions. J. Nanopart. Res 2018, 20, 93, DOI: 10.1007/s11051-018-4202-x [PubMed: 31595146]

214. Das D; Sabaraya IV; Zhu T; Sabo-Attwood T; Saleh NB Aggregation behavior of multiwalled carbon nanotube-titanium dioxide nanohybrids: Probing the part-whole question. Environ. Sci. Technol 2018, 52 (15), 8233-8241, DOI: 10.1021/acs.est.7b05826 [PubMed: 29944362]

215. Wei H; Deng S; Huang Q; Nie Y; Wang B; Huang J; Yu G Regenerable granular carbon nanotubes/alumina hybrid adsorbents for diclofenac sodium and carbamazepine removal from aqueous solution. Water Res. 2013, 47 (12), 4139-4147, DOI: 10.1016/j.watres.2012.11.062 [PubMed: 23579087]

216. Ma J; Ma Y; Yu F A novel one-pot route for large-scale synthesis of novel magnetic CNTs/Fe@C hybrids and their applications for binary dye removal. ACS Sustainable Chem. Eng 2018, 6 (7), 8178-8191, DOI: 10.1021/acssuschemeng.7b04668

217. Ren X; Li J; Chen C; Gao Y; Chen D; Su M; Alsaedi A; Hayat T Graphene analogues in aquatic environments and porous media: Dispersion, aggregation, deposition and transformation. Environ. Sci.: Nano 2018, 5 (6), 1298-1340, DOI: 10.1039/C7EN01258F

218. Lou Z; Cao Z; Xu J; Zhou X; Zhu J; Liu X; Baig SA; Zhou J; Xu X Enhanced removal of As(III)/(V) from water by simultaneously supported and stabilized Fe-Mn binary oxide nanohybrids. Chem. Eng. J 2017, 322, 710-721, DOI: 10.1016/j.cej.2017.04.079

219. Deng JH; Zhang XR; Zeng GM; Gong JL; Niu QY; Liang J Simultaneous removal of Cd(II) and ionic dyes from aqueous solution using magnetic graphene oxide nanocomposite as an adsorbent. Chem. Eng. J 2013, 226, 189-200, DOI: 10.1016/j.cej.2013.04.045

220. Wu ZL; Zhang P; Gao MX; Liu CF; Wang W; Leng F; Huang CZ One-pot hydrothermal synthesis of highly luminescent nitrogen-doped amphoteric carbon dots for bioimaging from 
Bombyx mori silk - natural proteins. J. Mater. Chem. B 2013, 1 (22), 2868-2873, DOI: 10.1039/ c3tb20418a [PubMed: 32260873]

221. Zhu B; Xia P; Ho W; Yu J Isoelectric point and adsorption activity of porous $\mathrm{g}_{-} \mathrm{C}_{3} \mathrm{~N}_{4}$. Appl. Surf. Sci 2015, 344, 188-195, DOI: 10.1016/j.apsusc.2015.03.086

222. Fronczak M; Demby K; Strachowski P; Strawski M; Bystrzejewski M Graphitic carbon nitride doped with the S-block metals: Adsorbent for the removal of methyl blue and copper (II) ions. Langmuir 2018, 34 (25), 7272-7283, DOI: 10.1021/acs.langmuir.8b01041 [PubMed: 29856628]

223. Kosmulski M The $\mathrm{pH}$ dependent surface charging and points of zero charge. VII. Update. Adv. Colloid Interface Sci 2018, 251, 115-138, DOI: 10.1016/j.cis.2017.10.005 [PubMed: 29153243]

224. Xu W; Song Y; Dai K; Sun S; Liu G; Yao J Novel ternary nanohybrids of tetraethylenepentamine and graphene oxide decorated with $\mathrm{MnFe}_{2} \mathrm{O}_{4}$ magnetic nanoparticles for the adsorption of $\mathrm{Pb}(\mathrm{II})$. J. Hazard. Mater 2018, 358, 337-345, DOI: 10.1016/j.jhazmat.2018.06.071 [PubMed: 30005245]

225. Morales-Torres S; Pastrana-Martínez LM; Figueiredo JL; Faria JL; Silva AMT Graphene oxideP25 photocatalysts for degradation of diphenhydramine pharmaceutical and methyl orange dye. Appl. Surf. Sci 2013, 275, 361-368, DOI: 10.1016/j.apsusc.2012.11.157

226. Zhao S; Chen S; Yu H; Quan X g- $\mathrm{C}_{3} \mathrm{~N}_{4} / \mathrm{TiO}_{2}$ hybrid photocatalyst with wide absorption wavelength range and effective photogenerated charge separation. Sep. Purif. Technol 2012, 99, 50-54, DOI: 10.1016/j.seppur.2012.08.024

227. Lin MY; Lindsay HM; Weitz DA; Ball RC; Klein R; Meakin P Universality in colloid aggregation. Nature 1989, 339, 360-362, DOI: 10.1038/339360a0

228. Ball RC; Witten TA Particle aggregation versus cluster aggregation in high dimensions. J. Stat. Phys 1984, 36 (5-6), 873-879, DOI: 10.1007/BF01012946

229. Mammen M; Shakhnovich EI; Deutch JM; Whitesides GM Estimating the entropic cost of selfassembly of multiparticle hydrogen-bonded aggregates based on the cyanuric acid melamine lattice. J. Org. Chem 1998, 63 (12), 3821-3830, DOI: 10.1021/jo970944f

230. Mammen M; Simanek EE; Whitesides GM Predicting the relative stabilities of multiparticle hydrogen-bonded aggregates based on the number of hydrogen bonds and the number of particles and measuring these stabilities with titrations using dimethyl sulfoxide. J. Am. Chem. Soc 1996, 118 (50), 12614-12623, DOI: 10.1021/ja962768i

231. Wang D; Sun W; Su C Environmental Applications and Implications of Carbon Nanotube-Metal Oxide Nanocomposites In Metal Oxide Nanocomposites: Synthesis and Applications; Raneesh B; Visakh PM, Eds.; John Wiley \& Sons, 2019.

232. Wang D; Jin Y; Jaisi DP Effect of size-selective retention on the cotransport of hydroxyapatite and goethite nanoparticles in saturated porous media. Environ. Sci. Technol 2015, 49 (14), 84618470, DOI: 10.1021/acs.est.5b01210 [PubMed: 26084013]

233. Tufenkji N; Elimelech M Correlation equation for predicting single-collector efficiency in physicochemical filtration in saturated porous media. Environ. Sci. Technol 2004, 38 (2), 529536, DOI: 10.1021/es034049r [PubMed: 14750730]

234. Wang D; Jin Y; Park CM; Heo J; Bai X; Aich N; Su C Modeling the transport of the "newhorizon" reduced graphene oxide-metal oxide nanohybrids in water-saturated porous media. Environ. Sci. Technol 2018, 52 (8), 4610-4622, DOI: 10.1021/acs.est.7b06488 [PubMed: 29582656]

235. Simunek J; van Genuchten MT; Sejna M Recent developments and applications of the HYDRUS computer software packages. Vadose Zone J.. 2016, 15, (7), 0 DOI: 10.2136/vzj2016.04.0033 .

236. Kamrani S; Rezaei M; Kord M; Baalousha M Transport and retention of carbon dots (CDs) in saturated and unsaturated porous media: Role of ionic strength, $\mathrm{pH}$, and collector grain size. Water Res. 2018, 133, 338-347, DOI: 10.1016/j.watres.2017.08.045 [PubMed: 28864305]

237. Rahman MZ; Davey K; Mullins CB Tuning the intrinsic properties of carbon nitride for high quantum yield photocatalytic hydrogen production. Adv. Sci 2018, 5, 1800820, DOI: 10.1002/ advs.201800820

238. Yang XF; Wang A; Qiao B; Li J; Liu J; Zhang T Single-atom catalysts: A New Frontier in heterogeneous catalysis. Acc. Chem. Res 2013, 46 (8), 1740-1748, DOI: 10.1021/ar300361m [PubMed: 23815772] 
239. Yang L; Wang P; Yin J; Wang C; Dong G; Wang Y; Ho W Engineering of incorporation the reduced graphene oxide on nanosheet-g- $\mathrm{C}_{3} \mathrm{~N}_{4}$ /perylene imide heterojunction for enhanced photocatalytic redox performance. Appl. Catal., B 2019, 250, 42-51, DOI: 10.1016/ j.apcatb.2019.02.076

240. Kleinerman O; Liberman L; Behabtu N; Pasquali M; Cohen Y; Talmon Y Direct imaging of carbon nanotube liquid-crystalline phase development in true solutions. Langmuir 2017, 33 (16), 4011-4018, DOI: 10.1021/acs.langmuir.7b00206 [PubMed: 28376617]

241. Parra-Vasquez ANG; Behabtu N; Green MJ; Pint CL; Young CC; Schmidt J; Kesselman E; Goyal A; Ajayan PM; Cohen Y; Talmon Y; Hauge RH; Pasquali M Spontaneous dissolution of ultralong single- and multiwalled carbon nanotubes. ACS Nano 2010, 4 (7), 3969-3978, DOI: 10.1021/ nn100864v [PubMed: 20593770]

242. Xu Z; Gao C Aqueous liquid crystals of graphene oxide. ACS Nano 2011, 5 (4), 2908-2915, DOI: $10.1021 / \mathrm{nn} 200069 \mathrm{w}$ [PubMed: 21375309]

243. Hovelmann J; Putnis CV In situ nanoscale imaging of struvite formation during the dissolution of natural brucite: Implications for Phosphorus Recovery from wastewaters. Environ. Sci. Technol 2016, 50 (23), 13032-13041, DOI: 10.1021/acs.est.6b04623 [PubMed: 27934285]

244. Bhattacharjee S; Chen JY; Elimelech M DLVO interaction energy between spheroidal particles and a flat surface. Colloids Surf., A 2000, 165 (1-3), 143-156, DOI: 10.1016/ S0927-7757(99)00448-3

245. Bhattacharjee S; Elimelech M Surface element integration: A novel technique for evaluation of DLVO interaction between a particle and a flat plate. J. Colloid Interface Sci 1997, 193 (2), 273 285, DOI: 10.1006/jcis.1997.5076 [PubMed: 9344528]

246. Bhattacharjee S; Ko CH; Elimelech M DLVO interaction between rough surfaces. Langmuir 1998, 14 (12), 3365-3375, DOI: 10.1021/la971360b

247. Kohne JM; Kohne S; Šimůnek J A review of model applications for structured soils: a) Water flow and tracer transport. J. Contam. Hydrol 2009, 104 (1-4), 4-35, DOI: 10.1016/ j.jconhyd.2008.10.002 [PubMed: 19012994]

248. Soto-Gomez D; Perez-Rodriguez P; Juiz LV; Lopez-Periago JE; Paradelo M A new method to trace colloid transport pathways in macroporous soils using X-ray computed tomography and fluorescence macrophotography. Eur. J. Soil Sci 2019, 70 (3), 431-442, DOI: 10.1111/ejss.12783

249. Hamamoto S; Moldrup P; Kawamoto K; Sakaki T; Nishimura T; Komatsu T Pore network structure linked by X-ray CT to particle characteristics and transport parameters. Soils Found 2016, 56 (4), 676-690, DOI: 10.1016/j.sandf.2016.07.008

250. Babakhani P; Fagerlund F; Shamsai A; Lowry GV; Phenrat T Modified MODFLOW-based model for simulating the agglomeration and transport of polymer-modified $\mathrm{Fe} 0$ nanoparticles in saturated porous media. Environ. Sci. Pollut. Res 2018, 25 (8), 7180-7199, DOI: 10.1007/ s11356-015-5193-0

251. Babakhani P; Bridge J; Doong RA; Phenrat T Continuum-based models and concepts for the transport of nanoparticles in saturated porous media: A state-of-the-science review. Adv. Colloid Interface Sci 2017, 246, 75-104, DOI: 10.1016/j.cis.2017.06.002 [PubMed: 28641812]

252. Babakhani P; Bridge J; Doong RA; Phenrat T Parameterization and prediction of nanoparticle transport in porous media: A reanalysis using artificial neural network. Water Resour. Res 2017, 53 (6), 4564-4585, DOI: 10.1002/2016WR020358

253. Goldberg E; McNew C; Scheringer M; Bucheli TD; Nelson P; Hungerbuhler K What factors determine the retention behavior of engineered nanomaterials in saturated porous media?. Environ. Sci. Technol 2017, 51 (5), 2729-2737, DOI: 10.1021/acs.est.6b05217 [PubMed: 28139914]

254. Goldberg E; Scheringer M; Bucheli TD; Hungerbuhler K Prediction of nanoparticle transport behavior from physicochemical properties: machine learning provides insights to guide the next generation of transport models. Environ. Sci.: Nano 2015, 2 (4), 352-360, DOI: 10.1039/ C5EN00050E

255. Dai Y; Li C; Shen Y; Lim T; Xu J; Li Y; Niemantsverdriet H; F B; Lock N; Su R. Light-tuned selective photosynthesis of azo- and azoxy-aromatics using graphitic C3N4. Nat. Commun 2018, 9, 60, DOI: 10.1038/s41467-017-02527-8 [PubMed: 29302040] 
256. Duan H; Wang D; Li Y Green chemistry for nanoparticle synthesis. Chem. Soc. Rev 2015, 44 (16), 5778-5792, DOI: 10.1039/C4CS00363B [PubMed: 25615873]

257. Shan D; Deng S; Jiang C; Chen Y; Wang B; Wang Y; Huang J; Yu G; Wiesner M Hydrophilic and strengthened 3D reduced graphene oxide/nano-Fe3O4 hybrid hydrogel for enhanced adsorption and catalytic oxidation of typical pharmaceuticals. Environ. Sci.: Nano 2018, 5 (7), 1650-1660, DOI: $10.1039 / C 8 E N 00422 F$

258. Kumar A; Kumar A; Sharma G; Al-Muhtaseb AH; Naushad M; Ghfar AA; Stadler FJ Quaternary magnetic $\mathrm{BiOCl} / \mathrm{g}-\mathrm{C}_{3} \mathrm{~N}_{4} / \mathrm{Cu}_{2} \mathrm{O} / \mathrm{Fe}_{3} \mathrm{O}_{4}$ nano-junction for visible light and solar powered degradation of sulfamethoxazole from aqueous environment. Chem. Eng. J 2018, 334, 462-478, DOI: $10.1016 /$ j.cej.2017.10.049

259. Guo R; Meng Q; Zhang H; Zhang X; Li B; Cheng Q; Cheng X Construction of $\mathrm{Fe}_{2} \mathrm{O}_{3} / \mathrm{Co}_{3} \mathrm{O}_{4} /$ exfoliated graphite composite and its high efficient treatment of landfill leachate by activation of potassium persulfate. Chem. Eng. J 2019, 355, 952-962, DOI: 10.1016/j.cej.2018.08.168

260. Hou J; Li H; Tang Y; Sun J; Fu H; Qu X; Xu Z; Yin D; Zheng S Supported N-doped carbon quantum dots as the highly effective peroxydisulfate catalysts for bisphenol $\mathrm{F}$ degradation. Appl. Catal., B 2018, 238, 225-235, DOI: 10.1016/j.apcatb.2018.07.032

261. Yu W; Zhan S; Shen Z; Zhou Q A newly synthesized Au/GO-Co ${ }_{3} \mathrm{O}_{4}$ composite effectively inhibits the replication of tetracycline resistance gene in water. Chem. Eng. J 2018, 345, 462470, DOI: 10.1016/j.cej.2018.03.108

262. Maji S; Ghosh A; Gupta K; Ghosh A; Ghorai U; Santra A; Sasikumar P; Ghosh UC Efficiency evaluation of arsenic(III) adsorption of novel graphene oxide@ iron-aluminium oxide composite for the contaminated water purification. Sep. Purif. Technol 2018, 197, 388-400, DOI: 10.1016/ j.seppur.2018.01.021

263. Zhu J; Zhu Z; Zhang H; Lu H; Zhang W; Qiu Y; Zhu L; Kuppers S Calcined layered double hydroxides/reduced graphene oxide composites with improved photocatalytic degradation of paracetamol and efficient oxidation-adsorption of As(III). Appl. Catal., B 2018, 225, 550-562, DOI: 10.1016/j.apcatb.2017.12.003 
a)

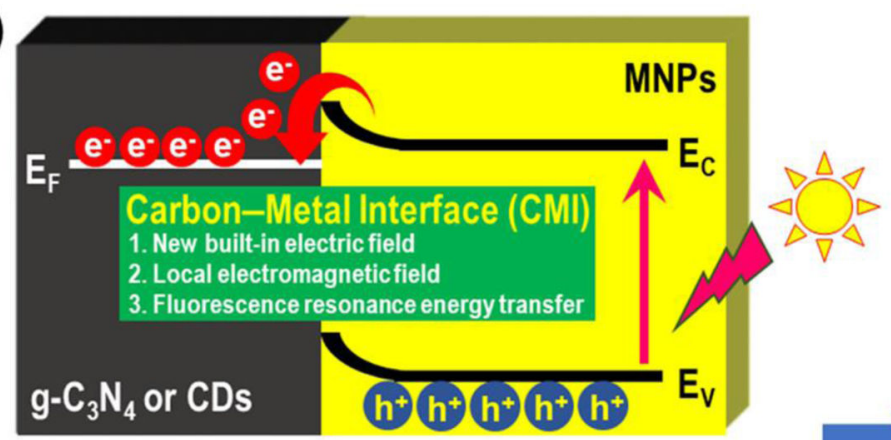

b)

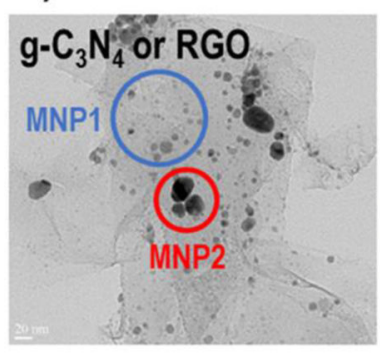

CMNHs Uniqueness/Multifunctionality: * CNMs: Photocatalyst, sensitizer, template * Reduced particle aggregation * Higher specific surface area * Abundant catalytically-active site * Localized surface plasmon resonance * Extended UV-Vis-NIR light absorption * Up-/down-converted photoluminescence * Promoted electron-charge transfer via CMl * Inhibited electron-hole pairs recombination * Lowered pollutant reaction potential, etc. c)

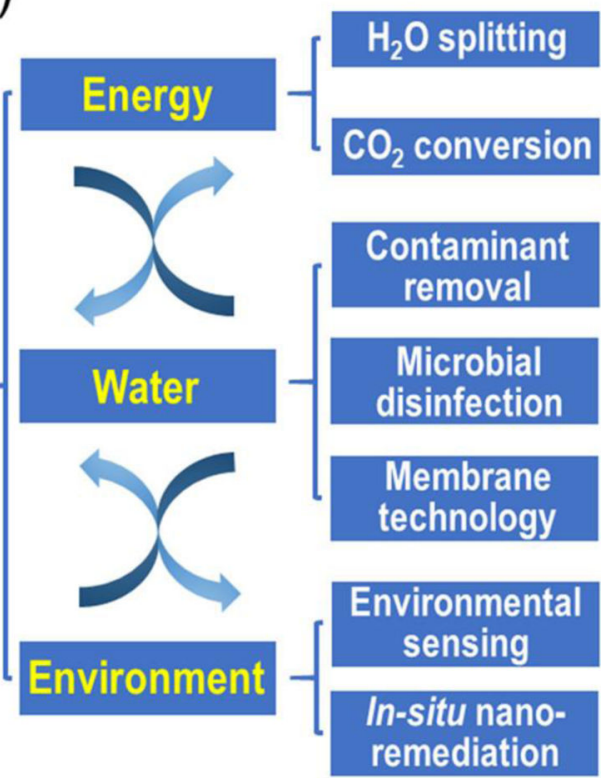

Figure 1.

Altered and emerging attributes of carbon-metal nanohybrids (CMNHs) make them the next-generation promising materials for addressing multiple issues and challenges at the important energy-water-environment (EWE) nexus. (a) Schematic diagram illustrates the electronic properties of CMNHs, highlighting the formation of the well-contacted, intimate carbon-metal interface (CMI). For metal nanoparticles (MNPs), the generation of photoexcited electron-hole pairs upon light irradiation is responsible for the photocatalytic/ redox degradation of contaminants. However, the rapid recombination of photogenerated electron-hole pairs significantly weakens their photocatalytic/redox performances. In comparison, for CMNHs, the photoexcited electrons can transfer from the conduction band $(\mathrm{CB})$ energy level $\left(\mathrm{E}_{\mathrm{C}}\right)$ of MNPs to the Fermi energy level $\left(\mathrm{E}_{\mathrm{F}}\right)$ of carbonaceous nanomaterials (CNMs; e.g., graphitic carbon nitride; $\mathrm{g}-\mathrm{C}_{3} \mathrm{~N}_{4}$ or carbon dots; $\mathrm{CDs}$ ), producing the unique attributes of new built-in electric field, local electromagnetic field, and fluorescence resonance energy transfer at the CMIs of the hybridized nanoheterojunctions. These newly emerging attributes at the CMIs can accelerate spatial separation and migration of photogenerated electron-hole pairs for enhanced photocatalytic/redox performances. $\mathrm{E}_{\mathrm{V}}$ refers to the valence band (VB) energy level of MNPs. Replotted from Li and Antonietti.(20) Copyright: 2013 Royal Society of Chemistry. (b) TEM image of CMNHs (e.g., g- $\mathrm{C}_{3} \mathrm{~N}_{4}$ - or RGO-MNP1-MNP2), and their uniqueness and multifunctionalities. GFNs denotes graphene family nanomaterials. MNP1 and MNP2 refer to two different MNPs. UV-vis-NIR denotes ultraviolet-visible-near-infrared. (c) The uniqueness and multifunctionalities of CMNHs render them exciting candidates for energy, water, and environmental applications including $\mathrm{H}_{2} \mathrm{O}$ splitting for $\mathrm{H}_{2}$ and $\mathrm{O}_{2}$ production, $\mathrm{CO}_{2}$ conversion for energy storage, contaminant removal, microbial disinfection, membrane technology, environmental sensing, and in situ nanoremediation. 


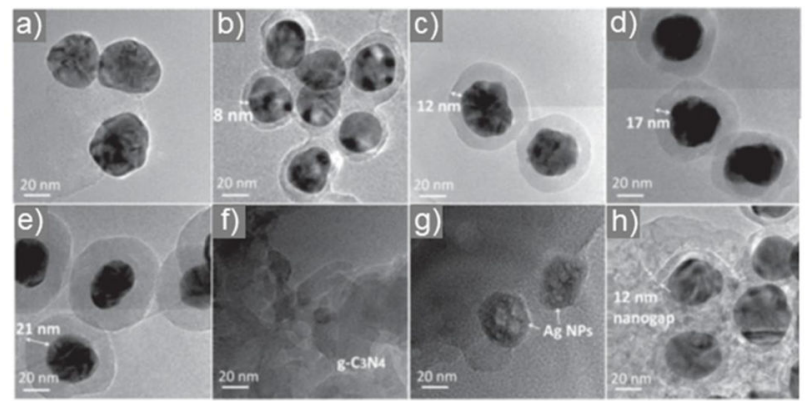

O)
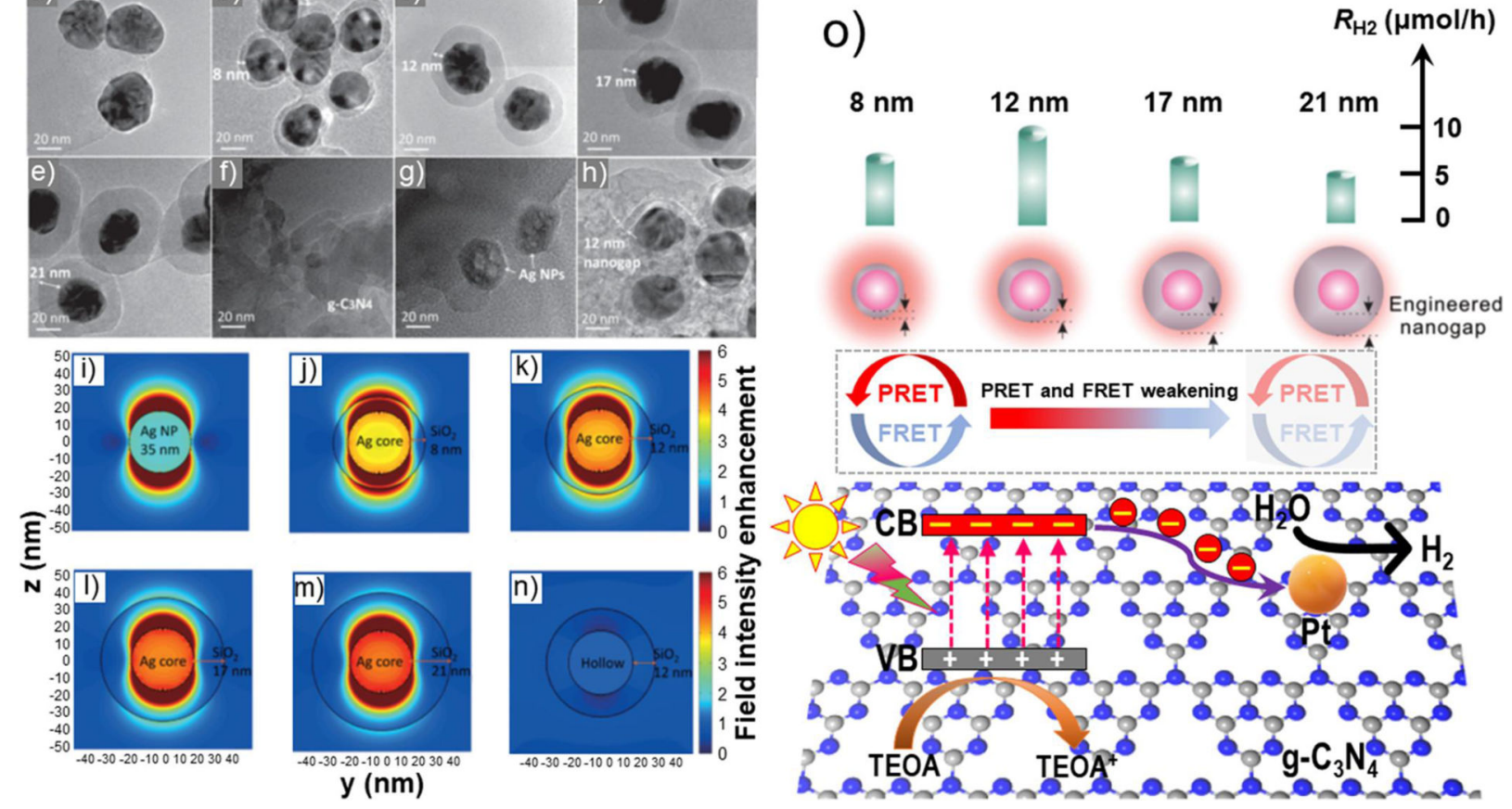

Figure 2.

(a-h) Transmission electron microscope (TEM) images of $\mathrm{Ag} @ \mathrm{SiO}_{2}$ (core@ shell) nanostructures in which the thickness of the $\mathrm{SiO}_{2}$ shell corresponds to 0 (a; no $\mathrm{SiO}_{2}$ capping), $8 \mathrm{~nm}$ (b), $12 \mathrm{~nm}$ (c and h; $12 \mathrm{~nm}$ nanogap), $17 \mathrm{~nm}$ (d), and $21 \mathrm{~nm}$ (e). (f-g) TEM images of pristine $\mathrm{g}-\mathrm{C}_{3} \mathrm{~N}_{4}$ and $\mathrm{Ag}$ core NPs, respectively. (i-n) Finite difference time domain (FDTD) simulations of the field enhancements for $\mathrm{AgNPs}$ (i), $\mathrm{Ag} @ \mathrm{SiO}_{2}-8 \mathrm{~nm}(\mathrm{j})$, $\mathrm{Ag} @ \mathrm{SiO}_{2}-12 \mathrm{~nm}(\mathrm{k}), \mathrm{Ag} @ \mathrm{SiO}_{2}-17$ nm (1), Ag@ $\mathrm{SiO}_{2}-21 \mathrm{~nm}(\mathrm{~m})$, and hollow $\mathrm{SiO}_{2}$ sphere with $12 \mathrm{~nm}$ shell thickness (n) using a 3D FDTD solver (openEMS). (o) Schematic diagram illustrates the photocatalytic $\mathrm{H}_{2}$ evolution by the $\mathrm{g}-\mathrm{C}_{3} \mathrm{~N}_{4}-\mathrm{Ag} @ \mathrm{SiO}_{2}$ heterojunction in which the plasmon resonance energy transfer (PRET) effect and Förster resonance energy transfer (FRET) effect gradually become weakened with the widening of the nanogap shown in (ae), as well as the photocatalytic $\mathrm{H}_{2}$ evolution rate for each $\mathrm{g}-\mathrm{C}_{3} \mathrm{~N}_{4}-\mathrm{Ag} @ \mathrm{SiO}_{2}$. The optimized photocatalytic $\mathrm{H}_{2}$ evolution rate $(11.4 \mu \mathrm{mol} / \mathrm{h})$ is achieved at the nanogap of 12 $\mathrm{nm}$ in which the PRET and the FRET are perfectly balanced. TEOA refers to triethanolamine. Replotted from Chen et al.(94) Copyright: 2015 Wiley. 

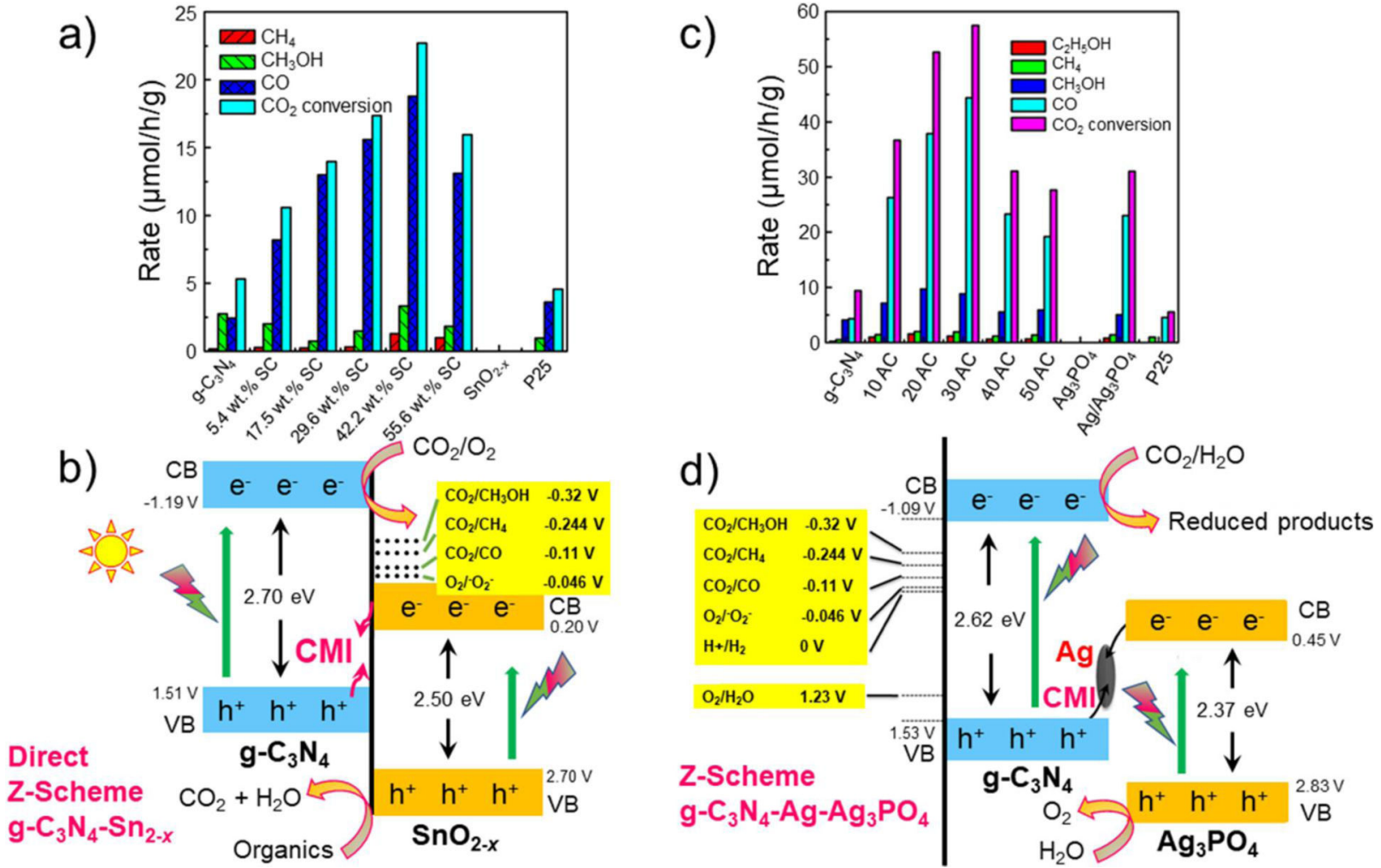

Figure 3.

(a) Formation rate of different products during photocatalytic $\mathrm{CO}_{2}$ reduction by the direct Zscheme $\mathrm{g}-\mathrm{C}_{3} \mathrm{~N}_{4}-\mathrm{SnO}_{2-X}$ composite under simulated sunlight irradiation. The $m$ wt $\% \mathrm{SC}$ refers to $\mathrm{g}_{-} \mathrm{C}_{3} \mathrm{~N}_{4}-\mathrm{SnO}_{2-X}$ with different $\mathrm{SnO}_{2-X}$ loading capacities. P25 refers to Degussa $\mathrm{TiO}_{2}$. (b) Reactions and mechanisms of photogenerated electron-hole pairs separation and transfer at the visible-light-driven $\mathrm{Z}$-scheme $\mathrm{g}-\mathrm{C}_{3} \mathrm{~N}_{4}-\mathrm{SnO}_{2-X} \mathrm{CMI}$. The photogenerated electrons in the $\mathrm{CB}$ of $\mathrm{SnO}_{2-X}$ are injected into the VB and annihilate the holes of $\mathrm{g}-\mathrm{C}_{3} \mathrm{~N}_{4}$ via $\mathrm{CMI}$, which facilitates the electron-hole pair separation and suppresses the charge recombination. Replotted from He et al.(114) Copyright: 2015 Elsevier. (c) Formation rate of different products during photocatalytic $\mathrm{CO}_{2}$ conversion by the Z-scheme $\mathrm{g}_{-} \mathrm{C}_{3} \mathrm{~N}_{4}-\mathrm{Ag}-$ $\mathrm{Ag}_{3} \mathrm{PO}_{4}$ heterojunction under simulated sunlight irradiation. The $m \mathrm{AC}$ refers to $\mathrm{g}_{-} \mathrm{C}_{3} \mathrm{~N}_{4}-$ $\mathrm{Ag}_{3} \mathrm{PO}_{4}$ with different molar ratios of $\mathrm{Ag}_{3} \mathrm{PO}_{4}$ vs $\mathrm{g}_{-} \mathrm{C}_{3} \mathrm{~N}_{4}$. The optimal $\mathrm{CO}_{2}$ conversion rate $(57.5 \mu \mathrm{mol} / \mathrm{h} / \mathrm{g})$ of the $\mathrm{g}-\mathrm{C}_{3} \mathrm{~N}_{4}-\mathrm{Ag}-\mathrm{Ag}_{3} \mathrm{PO}_{4}$ is 6.1 - and 10.4 -folds higher than that of $\mathrm{g}$ $\mathrm{C}_{3} \mathrm{~N}_{4}$ and Degussa P25 TiO 2 , respectively. (d) Reaction and mechanisms of photogenerated electron-hole pairs separation and transfer through the $\mathrm{Z}$-scheme $\mathrm{g}-\mathrm{C}_{3} \mathrm{~N}_{4}-\mathrm{Ag}-\mathrm{Ag}_{3} \mathrm{PO}_{4}$ heterojunction (e.g., CMIs). Because the $\mathrm{CB}$ edge of $\mathrm{Ag}_{3} \mathrm{PO}_{4}$ is more negative than the Fermi level of metallic $\mathrm{Ag}$, the photoinduced electrons of $\mathrm{Ag}_{3} \mathrm{PO}_{4} \mathrm{CB}$ flow to the metallic $\mathrm{Ag}$. The holes in the $\mathrm{VB}$ of $\mathrm{g}-\mathrm{C}_{3} \mathrm{~N}_{4}$ then shift to metallic $\mathrm{Ag}$ and combine with the electrons. One of the advantages of the Z-scheme photocatalytic system is that the Z-scheme electronhole pairs separation and transfer can retain the strong redox potential of $\mathrm{CMNHs}$ for $\mathrm{CO}_{2}$ photoreduction. Replotted from He et al.(115) Copyright: 2015 American Chemical Society. 
RGO-CoAl (LDH)-g- $\mathrm{C}_{3} \mathrm{~N}_{4}$

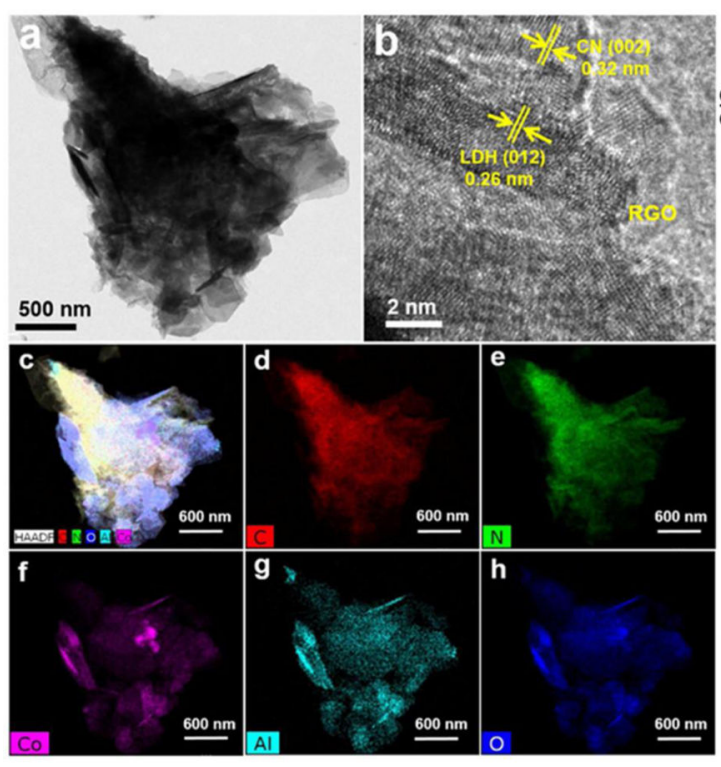

i)

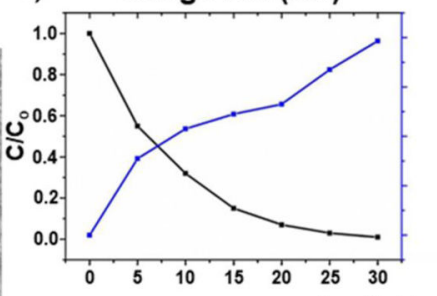

j) Tetracycline (TC)

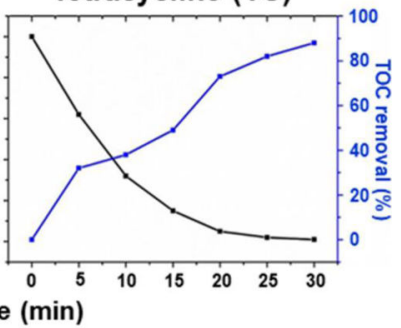

k)

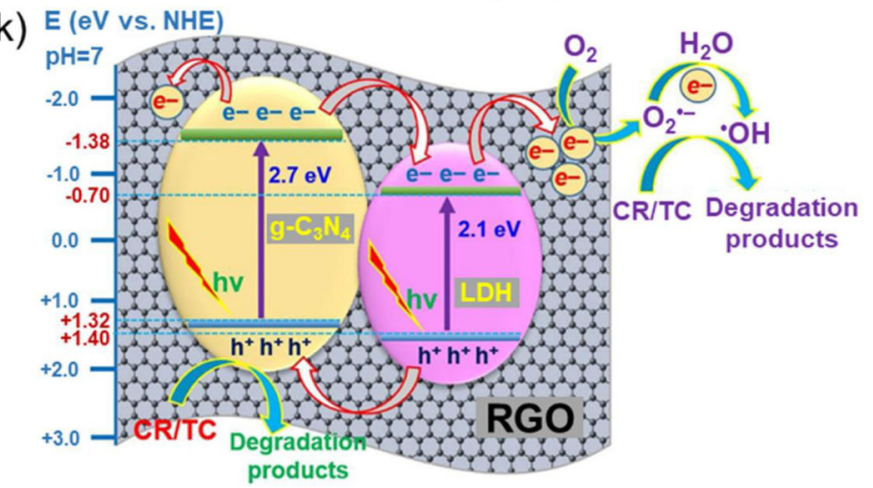

Figure 4.

(a-h) Transmission electron microscope (TEM) (a) and high-resolution TEM (b) images of the ternary 2D-2D-2D RGO-CoAl (LDH)- $g$ - $\mathrm{C}_{3} \mathrm{~N}_{4}$ composite photocatalyst, and energydispersive X-ray (EDX) mappings of component elements of total (c), C (d), N (e), Co (f), $\mathrm{Al}(\mathrm{g})$, and $\mathrm{O}(\mathrm{h})$, respectively. ( $\mathrm{i}-\mathrm{j})$ Photocatalytic degradation and total organic carbon (TOC) removal of congo red (CR; (i) and tetracycline (TC; j) by the ternary RGO-CoAl- $g$ $\mathrm{C}_{3} \mathrm{~N}_{4}$ photocatalyst under visible-light illumination. (k) Schematic diagram illustrates the photocatalytic mechanisms for CR and TC degradation by the ternary RGO-CoAl- $g-\mathrm{C}_{3} \mathrm{~N}_{4}$ nanoheterojunction. The appealing photocatalytic performance is mainly due to the large intimate interfacial contacts between 2D RGO, 2D CoAl, and 2D g- $\mathrm{C}_{3} \mathrm{~N}_{4}$, which accelerates the interfacial charge-transfer processes at the RGO-CoAl CMI, g- $\mathrm{C}_{3} \mathrm{~N}_{4}-\mathrm{CoAl} \mathrm{CMI}$, and RGO- $g-\mathrm{C}_{3} \mathrm{~N}_{4}$ interface. LDH refers to layered double hydroxide. Replotted from Jo and Tonda.(159) Copyright: 2019 Elsevier. 


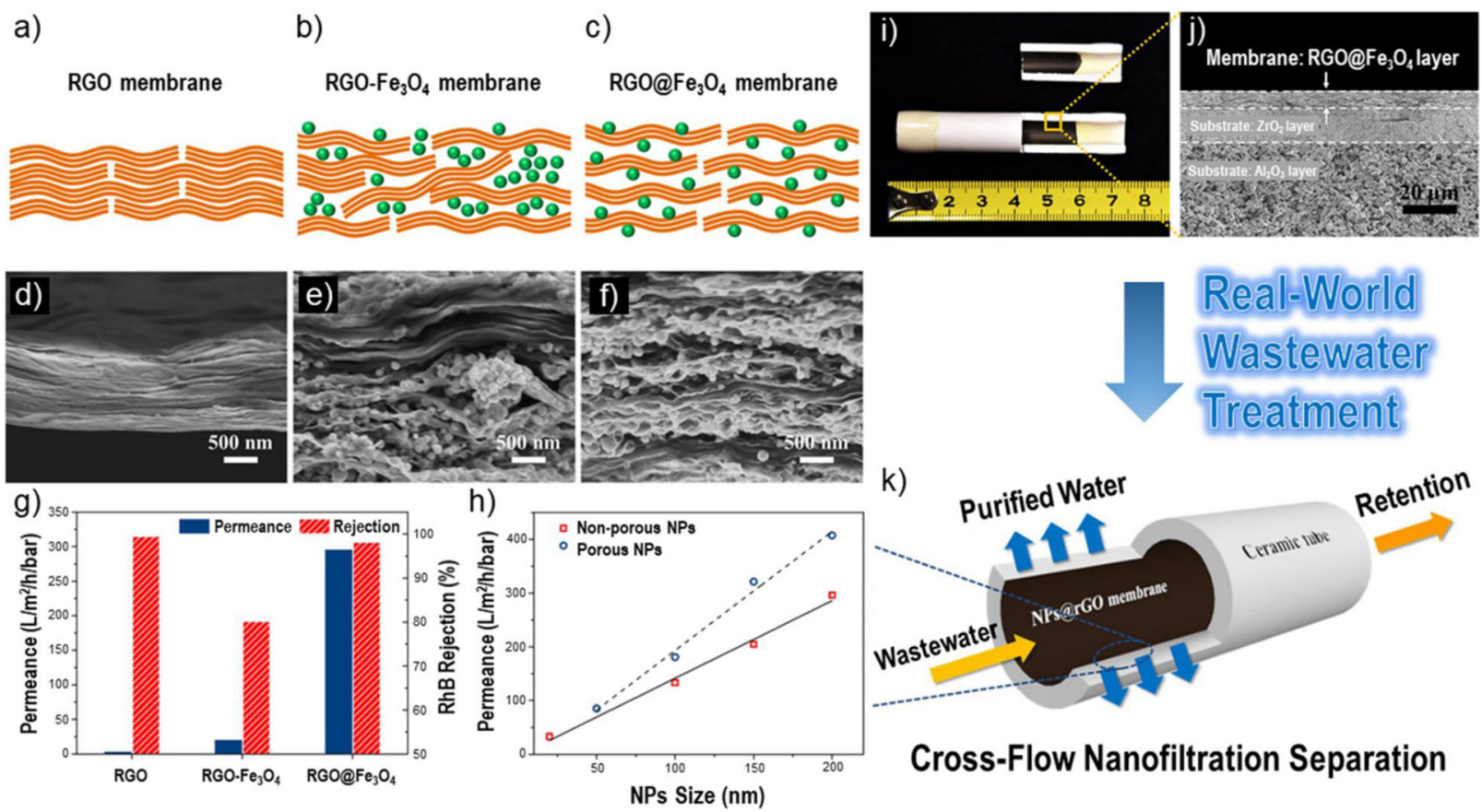

Figure 5.

(a-c) Schematic diagrams and (d-f) SEM images of cross-sectional morphology of (a and d) $\mathrm{RGO}$, (b and e) RGO-Fe $\mathrm{O}_{4}$, and (c and f) RGO@ $\mathrm{Fe}_{3} \mathrm{O}_{4}$ membranes. Note that the RGO$\mathrm{Fe}_{3} \mathrm{O}_{4}$ is obtained by simply mixing $\mathrm{Fe}_{3} \mathrm{O}_{4}$ NPs with RGO suspension using the intercalation method, in which the $\mathrm{Fe}_{3} \mathrm{O}_{4}$ NPs are disorderly and loosely attached onto RGO. In contrast, the $\mathrm{RGO} @ \mathrm{Fe}_{3} \mathrm{O}_{4}$ is synthesized via in situ solvothermal strategy, in which size- and density-controllable $\mathrm{Fe}_{3} \mathrm{O}_{4} \mathrm{NPs}$ are uniformly grown on the regularly stacked RGO nanosheets through precise coordination. (g) Water permeance and rejection of RGO, RGO$\mathrm{Fe}_{3} \mathrm{O}_{4}$, and RGO@ $\mathrm{Fe}_{3} \mathrm{O}_{4}$ membranes shown in (a-f). (h) Water permeance of RGO@NPs membranes using nonporous NPs $\left(\mathrm{Fe}_{3} \mathrm{O}_{4}\right.$ and $\left.\mathrm{TiO}_{2}\right)$ and porous NPs $(\mathrm{UiO}-66)$ having different particle sizes (Feed solution: $50 \mathrm{mg} / \mathrm{L}$ of rhodamine B and bisphenol A; $10 \mathrm{mM}$ of $\mathrm{CuSO}_{4}, \mathrm{CdSO}_{4}, \mathrm{MnSO}_{4}$, and $\mathrm{CoSO}_{4}$; Pressure: 2 bar; and Temperature: $25^{\circ} \mathrm{C}$ ). (i) photographs (black part of the inner surface is covered by sealing epoxy) and (j) SEM crosssectional image of the $\mathrm{RGO} @ \mathrm{Fe}_{3} \mathrm{O}_{4}$ membrane deposited on the inner surface of a ceramic tube $\left(\mathrm{ZrO}_{2}\right.$ and $\mathrm{Al}_{2} \mathrm{O}_{3}$ supporting layers). (k) The cross-flow nanofiltration system using the $\mathrm{RGO} @ \mathrm{Fe}_{3} \mathrm{O}_{4}$ membrane deposited on the inner surfaces of tubular ceramic tubes can be easily scaled up for effectively treating wastewater for real-world applications due to the stability for surviving the high pressure and cross-flow operations. Replotted from Zhang et al.(183) Copyright: 2017 Wiley. 


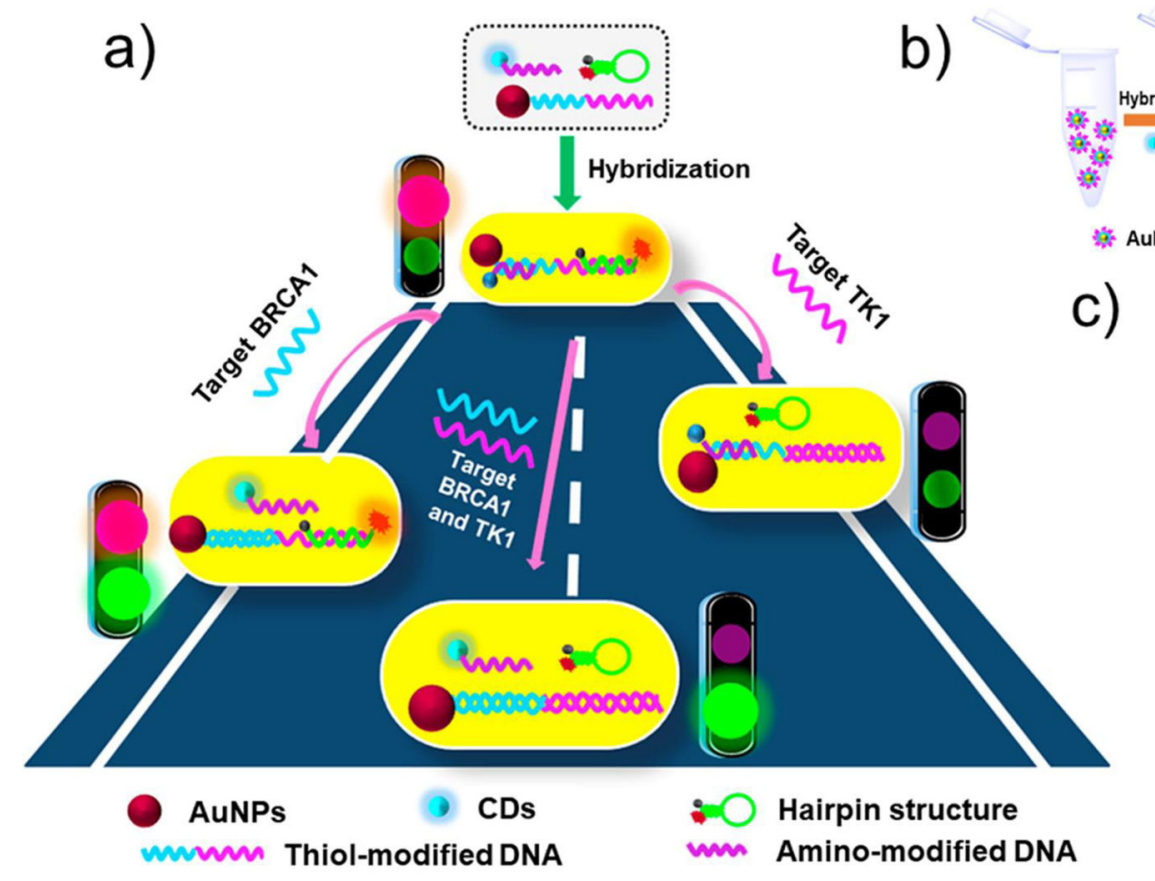

Figure 6.

A dual-channel CDs-Au biosensing system for assaying RNA and DNA due to the LSPR effect of AuNPs, strong interaction between AuNPs and ssDNAs, and appealing fluorescent attribute of CDs. (a) Schematic illustration of the dual-channel sensing model for assaying multiple nucleotide sequences including BRCA1 (breast cancer 1) and TK1 (thymidine kinase 1) RNA/DNA. (b) Schematic illustration for identifying the amount of hairpin structure hybridized with AuNPs-DNA. (c) Fluorescence spectra of the sensing model in the presence of different concentrations of BRCA1 RNA excited at $\lambda=345 \mathrm{~nm}(0-120 \mathrm{nM}$; c1), and in the presence of varied concentrations of TK1 RNA excited at $\lambda=535 \mathrm{~nm}(0-120 \mathrm{nM}$; c2). A good relationship $\left(R^{2}>0.99\right)$ occurs between the fluorescence intensity and the concentration of BRCA1/TK1 RNA. The CDs-Au biosystem can detect BRCA1 RNA/DNA in the linear range of $4-120 \mathrm{nM}$ with a detection limit of $1.5 \mathrm{nM}$ and $2.1 \mathrm{nM}$, respectively, for RNA and DNA. Also, it can detect 10-120 nM TK1 RNA/DNA with a detection limit of $3.6 \mathrm{nM}$ and $4.5 \mathrm{nM}$, respectively, for RNA and DNA. Replotted from Zhong et al.(202) Copyright: 2017 Elsevier. 


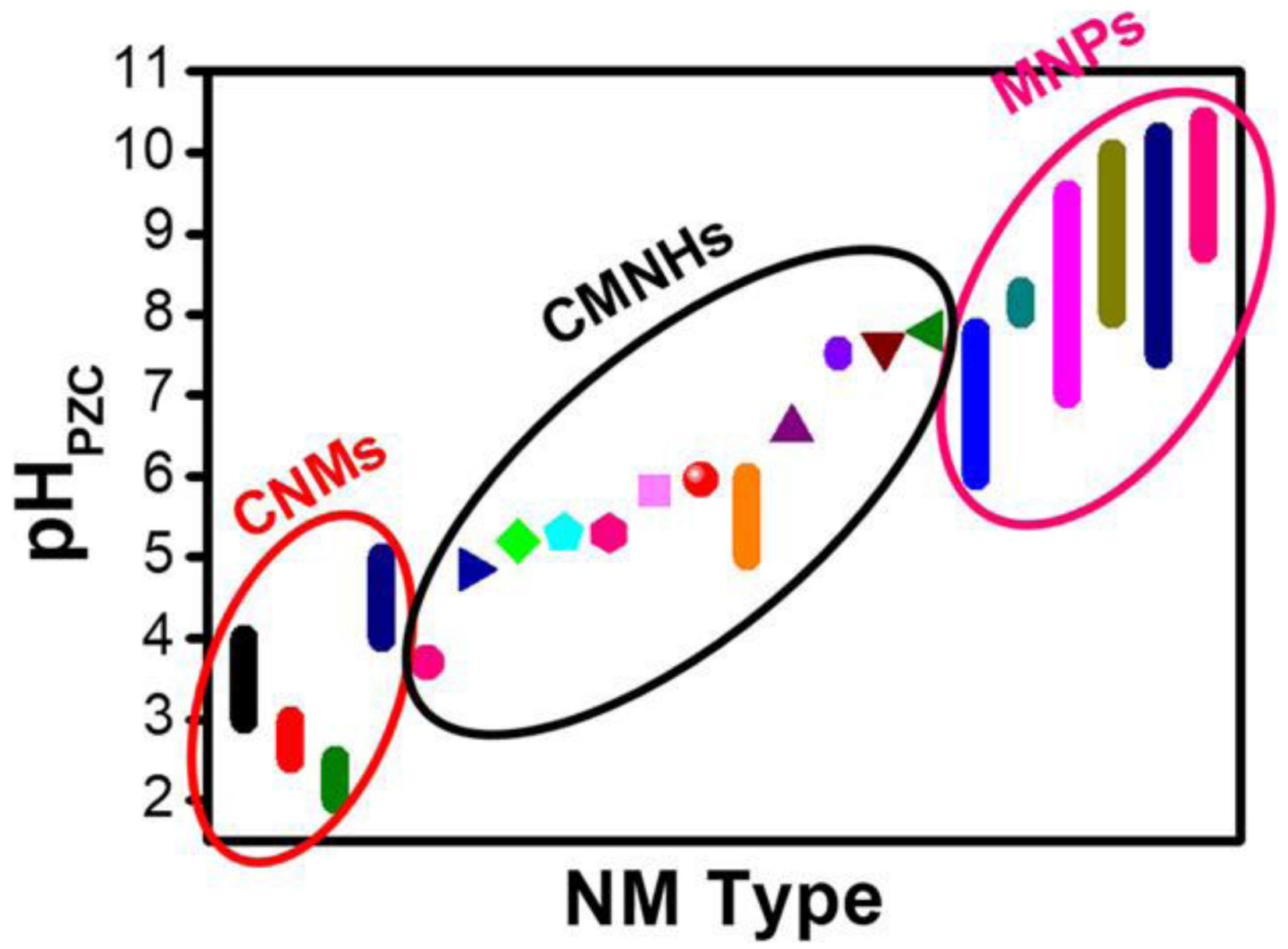

Figure 7.

Reported $\mathrm{pH}$ of point of zero charge $\left(\mathrm{pH}_{\mathrm{PZC}}\right.$ ) values of CNMs (marked within the red ellipse), CMNHs (marked within the black ellipse), and MNPs (marked within the pink ellipse). Starting from the left $x$-axis, the first four columns within the red ellipse denote: CNTs (3-4),(215,216) GFNs (2.5-3),(72,217-219) CDs (2-2.5),(220) and g- $\mathrm{C}_{3} \mathrm{~N}_{4}$ (4-5), $(221,222)$ respectively. The middle 12 dots/columns within the black ellipse denote: RGO$\mathrm{Fe}_{3} \mathrm{O}_{4}$ (3.7), (257) GO- $\mathrm{MnFe}_{2} \mathrm{O}_{4}$ (4.85),(224) RGO-TiO 2 (5.2),(212) g- $\mathrm{C}_{3} \mathrm{~N}_{4}-\mathrm{BiOCl}-$ $\mathrm{Cu}_{2} \mathrm{O}-\mathrm{Fe}_{3} \mathrm{O}_{4}$ (5.3),(258) graphene- $\mathrm{Co}_{3} \mathrm{O}_{4}-\mathrm{Fe}_{2} \mathrm{O}_{3}$ (5.3),(259) CDs-CeZrO 2 (5.8),(260) GO$\mathrm{Co}_{3} \mathrm{O}_{4}-\mathrm{Au}$ (5.95),(261) RGO-Fe $\mathrm{O}_{4}$ (5-6),(213) GO-Al-Fe (6.58),(262) RGO-Fe-Mn (7.47-7.56),(218) CDs- $\gamma-\mathrm{Al}_{2} \mathrm{O}_{3}$ (7.6),(260) and $\mathrm{RGO}-\mathrm{Zn}-\mathrm{Fe}$ (7.8)(263) nanohybrids, respectively. The last six columns within the pink ellipse denote: $\mathrm{TiO}_{2}(6-7.8), \mathrm{Cu}_{2} \mathrm{O}(8-$ 8.3), $\mathrm{Fe}_{x} \mathrm{O}_{y}$ (7-9.5), $\mathrm{Al}_{2} \mathrm{O}_{3}$ (8-10), $\mathrm{ZnO}$ (7.5-10.2), and $\mathrm{Zn}-\mathrm{Fe}$ oxides (8.8-10.4), respectively.(223) The numbers shown in the parentheses are the $\mathrm{pH}_{\mathrm{PZC}}$ values of the materials. 